\title{
Synthesis, Antitumor and Antiviral In Vitro Activities of New Benzotriazole-Dicarboxamide Derivatives
}

\author{
Roberta lbba ${ }^{1}$, Sandra Piras ${ }^{1 *}$, Paola Corona ${ }^{1}$, Federico Riu ${ }^{1}$, Roberta Loddo ${ }^{2 *}$, \\ Ilenia Delogu ${ }^{2}$, Gabriella Collu ${ }^{2}$, Giuseppina Sanna ${ }^{2}$, Paola Caria ${ }^{3}$, Tinuccia Dettori ${ }^{3}$ and \\ Antonio Carta ${ }^{1}$
}

${ }^{1}$ Department of Chemistry and Pharmacy, University of Sassari, Sassari, Italy, ${ }^{2}$ Department of Biomedical Sciences, Section of Microbiology and Virology, University of Cagliari, Cittadella Universitaria, Cagliari, Italy, ${ }^{3}$ Department of Biomedical Sciences, Section of Biochemistry, Biology and Genetics, University of Cagliari, Cittadella Universitaria, Cagliari, Italy

Cancer and viral infections continue to threaten humankind causing death worldwide. Hence, the discovery of new anticancer and antiviral agents still represents a major scientific goal. Heterocycles designed to mimic the chemical structure of natural pyrimidines and purines have been designed over the years, exerting their activity acting as false substrates on several different targets. We reported a series of bisbenzotriazole-dicarboxamide derivatives which inhibit viral helicase of poliovirus, and hence we planned structure modifications to obtain different series of new dicarboxamides. Here, the synthesis and characterization of 56 new compounds: 31 bis-benzotriazole dicarboxamides and 25 mono-substituted acidic derivatives are reported. The synthesized compounds were tested for their antiviral and antitumor activity. Mostly, compounds $\mathbf{4 a}, \mathbf{4 c}$ and $\mathbf{4 d}$ showed antiviral activity against tested Picornaviruses, Coxsackievirus B5 and Poliovirus-1. Likewise, four derivatives (3b, 3d, 4d, 9b) showed notable antiproliferative activity inhibiting cell growth in two distinct antitumor screenings. Compound $\mathbf{3} \mathbf{b}$ was selected as the antitumor lead compound for the wide range of activity and the potency proved. The lead compound was proved to induce apoptosis in SK-MES1 tumor cells, in a dose-dependent manner.

Keywords: antimetabolites, antiproliferative activity, antivirals, benzotriazole derivatives, dicarboxamides, coxsackievirus

\section{INTRODUCTION}

Among the various diseases that affect humankind, cancer and viral infections remain great threats to human health worldwide. Therefore, the identification of novel anticancer and antiviral agents remains one of the most pressing health problems and the most stimulating cue for research. Polycyclic benzo-fused azoles can mimic the chemical structure of natural pyrimidines and purines, exerting their biological activity acting as false substrates, resulting in antitumor, antibacterial or antiviral agents. Considering the similar mechanism of action of the latter, cross-activity has been highlighted for several molecules (Kaufman, 1980; Matsuda et al., 1999; Ramachandran et al., 2011; Brüning et al., 2012). Therefore, anticancer drugs have been proved active against viruses (Kaufman, 1980) and antiviral agents have shown antimetabolite activity (Bergman et al., 2002; De Clercq, 2004; 

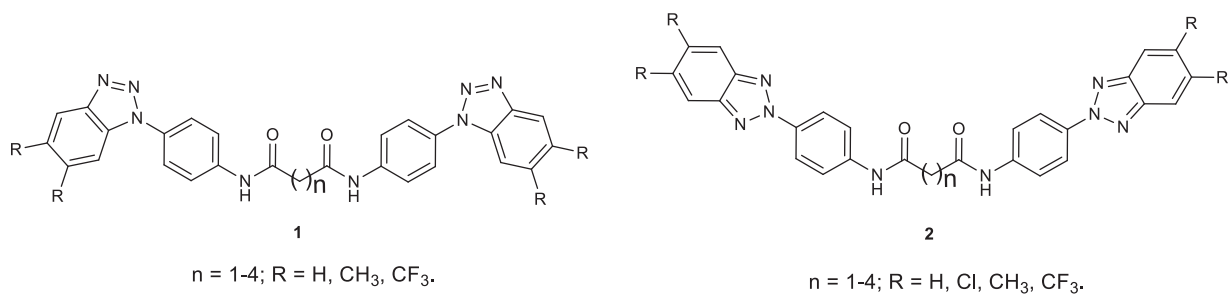

FIGURE 1 | Previously reported N,N'-bis-[4-(1H(2H)-benzo [d][1,2,3]triazol-1(2)-yl)phenyl]alkyl dicarboxamides 1 and 2.

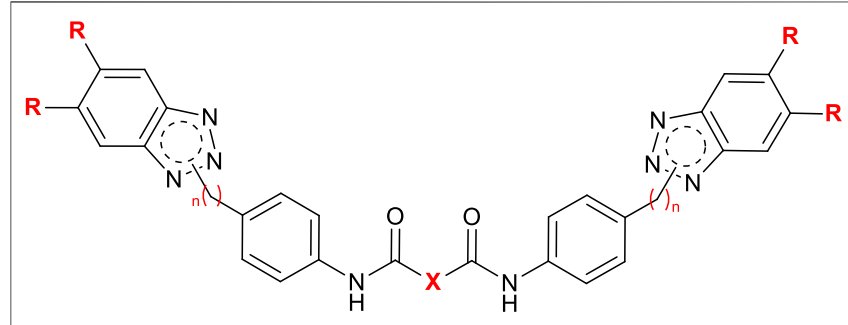

R $\mathrm{H}, \mathrm{CH}_{3}, \mathrm{Cl}$

$\begin{array}{llll}\left(\mathrm{CH}_{2}\right)_{2} & \left(\mathrm{CH}_{2}\right)_{3} & \left(\mathrm{CH}_{2}\right)_{4} \quad \mathrm{CH}=\mathrm{CH}\end{array}$

$\mathrm{n}=0,1$

$\mathbf{X}$

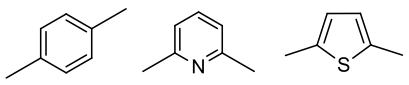

FIGURE 2 | General structure of newly designed derivatives, applied structure-modifications are outlined in red.

Brüning et al., 2012). 5-fluorouracil is a well-known example; it is a widely used anticancer agent which acts as antimetabolite. It was proved active against several viruses such as foot and mouth disease virus (Pariente et al., 2003; Agudo et al., 2009), herpes simplex virus (Dragún et al., 1990), poliovirus (Cooper, 1964). Purine-like antimetabolites enter the metabolic pathway acting as false substrates or mimicking the natural building blocks of RNA and DNA (De Clercq, 2013). For these features, besides humancell targets, viral enzymes involved in RNA and DNA synthesis, such as RNA-dependent-RNA-polymerases (RdRp) (Furuta et al., 2017), helicases (Carta et al., 2007), proteases (Kneller et al., 2019), may be targeted by this class of derivatives. Benzotriazole (BT) derivatives have been widely studied for their broad biological activity (Briguglio et al., 2015). BT derivatives may mimic purine ring acting as antimetabolites interfering with purine metabolism but may also bind the enzymes that naturally interact with purines, mimicking the natural substrate, resulting in potential antitumor (Al-Soud et al., 2003), antibacterial (Sanna et al., 1992; Carta et al., 2011; Ochal et al., 2013), antifungal (Patel et al., 2010) or antiviral (Borowski et al., 2003) agents. In the process of new drug discovery, we designed several promising antiviral active derivatives bearing the benzotriazole scaffold (Ibba et al., 2018; Piras et al., 2019a; Piras et al., 2019b; Sanna et al., 2020). Amongst them, benzotriazole derivatives depicted in Figure $\mathbf{1}$ have been designed, synthesized and proved as antiviral agents against two tested Picornaviruses (Coxsackievirus B2 and Poliovirus Sb-1)
(Carta et al., 2007). Bis-benzotriazole-dicarboxamide derivatives (Figure 1) were proved to exert their antiviral activity as false substrates binding the Poliovirus helicase in in silico assays, performed on the $3 \mathrm{D}$ model of the target protein (Carta et al., 2007). Bis-benzotriazole-dicarboxamide derivatives from series 2 turned out as the most active with $\mathrm{EC}_{50}$ values ranging from 4 to $33 \mu \mathrm{M}$ against Coxsackievirus B2.

Based on this, we designed and synthesized a new series of bisbenzotriazole-dicarboxamide derivatives as potential antiPicornavirus agents, acting as false substrates. The structural modifications applied to the main scaffold are shown in red in Figure 2. We evaluated the substitution on the benzotriazole scaffold in positions 5 and $6(\mathbf{R})$. We also considered the length and the role of the linker amidst the two amidic groups $(\mathbf{X})$, including saturated or unsaturated aliphatic or small aromatic linkers. The insertion of a $\mathrm{CH}_{2}$ bridge between the BT scaffold and the aromatic moiety directly connected to the BT nitrogen was also attempted.

All the synthesized compounds were tested against a panel of Picornaviruses and several cell lines to assess the cytotoxicity. Only a few of the designed molecules turned out active against tested viruses, while some were selected for antiproliferative assays, based on the known antiviral-anticancer correlations. Notably, four derivatives (3b, 3d, 4d, 9b) showed interesting antiproliferative activity inhibiting cell growth and inducing apoptosis. Compound $\mathbf{3 b}$ was selected as the lead compound to be subjected to further structure-modifications in order to improve the antiproliferative activity.

\section{MATERIALS AND METHODS}

\section{Chemistry}

Reaction progression, retention factors $\left(\mathrm{R}_{f}\right)$ and purity of compounds were monitored by TLC using Merck F-254 commercial plates and a proper mixture of solvents as eluent. Melting points were taken in open capillaries in a Köfler hot stage or Digital Electrothermal melting point apparatus. ${ }^{1} \mathrm{H}-\mathrm{NMR}$ spectra were recorded on a Nuclear magnetic resonance $\left({ }^{1} \mathrm{H}-\mathrm{NMR}\right)$ spectra were determined in DMSO- $d_{6}$ and were recorded with a Bruker Avance III 400 NanoBay $(400 \mathrm{MHz})$ and a Varian XL-200 (200 MHz) instruments. Chemical shifts $(\delta$ scale) are reported in parts per million (ppm) downfield from tetramethylsilane (TMS) used as internal standard. The chemical shift values are reported in ppm $(\delta)$ and coupling constants $(J)$ in 
Hertz (Hz). Signal multiplicities are represented as: s (singlet), $\mathrm{d}$ (doublet), $\mathrm{t}$ (triplet), and $\mathrm{m}$ (multiplet). The assignment of exchangeable protons $(\mathrm{OH}$ and $\mathrm{NH})$ was confirmed by the addition of $\mathrm{D}_{2} \mathrm{O} .{ }^{13} \mathrm{C}-\mathrm{NMR}$ were determined in DMSO- $d_{6}$ and were recorded at $100 \mathrm{MHz}$ with Bruker Advance III 400 NanoBay. Mass spectra were performed on combined Liquid Chromatograph-Agilent 1100 series Mass Selective Detector (MSD). Column chromatography was performed using 70-230 mesh (Merck silica gel 60). Petroleum ether (PE) refers to the fraction with b.p. $40-60^{\circ} \mathrm{C}$. Elemental analysis was performed on a Perkin-Elmer 2400 instrument at "Laboratorio di Microanalisi", Department of Chemistry and Pharmacy, University of Sassari, Italy, and the results were within $\pm 0.4 \%$ of theoretical values.

\section{Biology Cells and Viruses}

Cell lines were purchased from American Type Culture Collection (ATCC). Cell lines supporting the multiplication of CV-B5 and Sb-1 are Monkey kidney (Vero-76) [ATCC CRL 1587 Cercopithecus Aethiops]. Viruses were purchased from the American Type Culture Collection (ATCC). Picornaviridae: Coxsackievirus [coxsackie type B5 (CV-B5), strain Faulkner (ATCC VR-185)], and human enterovirus $\mathrm{C}$ [poliovirus type-1 (Sb-1), Sabin strain Chat (ATCC VR-1562)]. Cell cultures were checked periodically for the absence of mycoplasma contamination with MycoTect Kit (Gibco). Viruses were maintained in our laboratory and propagated in appropriate cell lines. The viruses were stored in small aliquots at $-80{ }^{\circ} \mathrm{C}$ until use.

\section{Cytotoxicity Assays}

Vero-76 cells were seeded in 96-well plates at an initial density of $5 \times 10^{5}$ cells $/ \mathrm{ml}$, in Dulbecco's Modified Eagle Medium (D-MEM) with L-glutamine and $25 \mathrm{mg} / \mathrm{L}$ kanamycin, supplemented with $10 \%$ FBS. Cell cultures were then incubated at $37^{\circ} \mathrm{C}$ in a humidified and $5 \% \mathrm{CO}_{2}$ atmosphere, in the absence or presence of serial dilutions of test compounds. The test medium used for the cytotoxic assay as well as for antiviral assay contained $1 \%$ of the appropriate serum. Cell viability was determined after $48-96 \mathrm{~h}$ at $37^{\circ} \mathrm{C}$ by MTT method for Vero-76 (Pauwels et al., 1988).

\section{Antiviral Assays}

Compounds activity against CV-B5 and Sb-1 was determined by plaque reduction assays in infected cell monolayers. Briefly, monolayer of Vero-76 cells was grown overnight on 24-well plate. The cells were then infected for $2 \mathrm{~h}$ with $250 \mu \mathrm{l}$ of proper virus dilutions to give 50-100 PFU/well. Following removal of unadsorbed virus, $500 \mu \mathrm{l}$ of medium (D-MEM with L-glutamine and 4,500 $\mathrm{mg} / \mathrm{L}$ D-glucose, supplemented with $1 \%$ inactivated FBS) containing $0.75 \%$ methyl-cellulose, with serial dilutions of test compounds, were added. The overlayed medium was also added to not treated wells as non-infection controls. Cultures were incubated at $37^{\circ} \mathrm{C}$ for 2 days for Sb-1 and 3 days for CV-B5 and then fixed with PBS containing 50\% ethanol and $0.8 \%$ crystal violet, washed and air-dried. Plaques in the control (no inhibitor) and experimental wells were then counted (Sanna et al., 2015).

\section{Antiproliferative Assays}

Cell lines were purchased from American Type Culture Collection (ATCC). The absence of mycoplasma contamination was checked periodically by the Hoechst staining method. Exponentially growing leukemia and lymphoma cells were seeded at $1 \times 10^{5}$ cells $/ \mathrm{ml}$ in 96 well plates in RPMI-1640 medium, supplemented with $10 \%$ fetal bovine serum, 100 units $/ \mathrm{ml}$ penicillin $\mathrm{G}$, and $100 \mu \mathrm{g} / \mathrm{ml}$ streptomycin, and incubated at $37^{\circ} \mathrm{C}$ in a humidified, $5 \% \mathrm{CO}_{2}$ atmosphere in the absence or presence of serial dilutions of test compounds. Cell viability was determined after $96 \mathrm{~h}$ at $37^{\circ} \mathrm{C}$ by the 3-(4,5-dimethylthiazol-2-yl)-2,5-diphenyl-tetrazolium bromide (MTT) method. Activity against solid-tumor derived cells was evaluated in exponentially growing cultures seeded at $5 \times 10^{4}$ cells $/ \mathrm{ml}$ and allowed to adhere for $16 \mathrm{~h}$ to culture plates before the addition of the drugs. Cell viability was determined by the MTT method 4 days later. Vincristine and doxorubicin were used as reference drugs.

\section{Linear Regression Analysis}

The extent of cell growth/viability and viral multiplication, at each drug concentration tested, were expressed as percentage of untreated controls. Concentrations resulting in 50\% inhibition $\left(\mathrm{CC}_{50}\right.$ or $\left.\mathrm{EC}_{50}\right)$ were determined by linear regression analysis.

\section{NCI60 Human Tumor Cell Lines Screen}

The in vitro anti-cancer screening was performed through the NCI60 Human Tumor Cell Lines Screen, provided by the Developmental Therapeutics Program of the National Cancer Institute (NCI, Bethesda, United States). A single dose of $10 \mu \mathrm{M}$ of each compound is tested in the whole NCI60 cell panel. More details about the NCI60 screen methods are reported on the NCI website (https://dtp.cancer.gov).

\section{Apoptosis Assay}

To assess which death mechanisms our compounds induced, cell apoptosis kit Annexin V/Propidium iodide (PI) double staining uptake (Invitrogen, Life Technologies, Italy) was used. 3b compound was selected as lead and employed in our assay. Human lung cancer cells (SK-MES 1) were seeded at the density of $8 \times 10^{5}$ cells $/ \mathrm{ml}$ in 6 -well plates (Corning, United States) with a complete medium (described in cell culture section). After overnight incubations, the cells were treated with or without different concentrations of $\mathbf{3 b}$ for $96 \mathrm{~h}$. Cells were then labeled with Annexin V and PI as previously described (Ibba et al., 2021). Stained cells were then analyzed by flow cytometry, measuring the fluorescence emission at 530 and $620 \mathrm{~nm}$ using $488 \mathrm{~nm}$ excitation laser (MoFloAstrios EQ, Beckman Coulter). Cell apoptosis was analyzed using Software Summit Version 6.3.1.1, Beckman Coulter.

\section{Experimental}

\section{Intermediates}

5,6-Dichloro- $1 H$-benzo $[d][1,2,3]$ triazole $(21)$ was synthesized as previously described (Carta et al., 2007), while $1 H$-Benzo [d] $[1,2,3]$ triazole 19, 5,6-Dimethyl- $1 H$-benzo $[d][1,2,3]$ triazole 20, 
1- (Chloromethyl)-4-nitrobenzene and the diacyl dichlorides (14a-g) were commercially available. The intermediate 1 (2)(4-Aminophenyl)-5,6-dichlorobenzo $[d][1,2,3]$ triazoles (13 and 15) were prepared according to the procedures previously described (Carta et al., 2007).

\section{General Procedure to Obtain} (5,6-R)-1-(4-Nitrobenzyl)-1H-benzo[d][1,2,3]triazole (22-24)

To a mixture of proper benzotriazole (19) or 5,6Dimethylbenzotriazole (20) or 5,6-Dichlorobenzotriazole (21) $(2.7 \mathrm{mmol})$ and $\mathrm{Cs}_{2} \mathrm{CO}_{3}(2.7 \mathrm{mmol})$ in $30 \mathrm{ml}$ of $\mathrm{N}, \mathrm{N}$-Dimethylformamide (DMF) a solution of 4-Nitrobenzylchloride $(5.4 \mathrm{mmol})$ in $10 \mathrm{ml}$ of DMF was added. The mixture was heated to $60^{\circ} \mathrm{C}$ for $48 \mathrm{~h}$. After cooling down, the solution was filtered off in vacuo to remove the $\mathrm{Cs}_{2} \mathrm{CO}_{3}$ and the mothers were diluted with water until complete precipitation of the products. The filtered solid was in all cases a 3:1 mixture of two isomers: 5,6- $R$-1-(4-Nitrobenzyl)-1H-benzo $[d][1,2,3]$ triazole and 5,6-R-2-(4-Nitrobenzyl)-2H-benzo [d][1,2,3] triazoles. The desired compounds 1-(4-Nitrobenzyl)-1H-benzo $[d][1,2,3]$ triazole $\quad(22), \quad 5,6$-Dimethyl-1-(4-nitrobenzyl)$1 H$-benzo $[d][1,2,3]$ triazole $\quad(23)$ and 5,6-Dichloro-1-(4nitrobenzyl)- $1 H$-benzo $[d][1,2,3]$ triazole (24) were separated and purified by flash chromatography using a mixture of petroleum ether and ethyl acetate in a $8 / 2$ (for 22 and 23) or 7/3 (for 24) ratio.

\section{1-(4-Nitrobenzyl)-1H-Benzo[d][1,2,3] Triazole (22)}

Compound 22 was obtained in $44 \%$ total yield; m.p. $126-128^{\circ} \mathrm{C}$; TLC (petroleum ether/ethyl acetate $8 / 2$ ); $\mathrm{R}_{f}=0.13,{ }^{1} \mathrm{H}-\mathrm{NMR}$ $\left(200 \mathrm{MHz}, \mathrm{DMSO}-d_{6}\right) \delta: 8.22\left(2 \mathrm{H}, \mathrm{d}, J=8.4, \mathrm{H}-3^{\prime}, 5^{\prime}\right), 8.09(1 \mathrm{H}$, $\mathrm{d}, J=8.2, \mathrm{H}-4), 7.87(1 \mathrm{H}, \mathrm{d}, J=8.2, \mathrm{H}-7), 7.70-7.60(1 \mathrm{H}, \mathrm{m}$, $\left.\mathrm{H}_{\text {arom }}\right), 7.54\left(2 \mathrm{H}, \mathrm{d}, J=8.4, \mathrm{H}-2^{\prime}, 6^{\prime}\right), 7.47-7.43\left(1 \mathrm{H}, \mathrm{m}, \mathrm{H}_{\text {arom }}\right)$, $6.19\left(2 \mathrm{H}, \mathrm{s}, \mathrm{CH}_{2}\right) .{ }^{13} \mathrm{C}-\mathrm{NMR}\left(\mathrm{DMSO}-d_{6}\right) \delta: 145.6(\mathrm{C}), 144.9(\mathrm{C})$, $142.3(\mathrm{C}), 132.9(\mathrm{C}), 128.9(2 \mathrm{CH}), 126.3(2 \mathrm{CH}), 123.8(2 \mathrm{CH})$, $118.5(\mathrm{CH}), 110.5(\mathrm{CH}), 52.2\left(\mathrm{CH}_{2}\right)$.

\section{5,6-Dimethyl-1-(4-nitrobenzyl)-1H-Benzo[d] $[1,2,3]$ Triazole $(23)$}

Compound 23 was obtained in $45 \%$ total yield; m.p. $143-145^{\circ} \mathrm{C}$; TLC (petroleum ether/ethyl acetate $8 / 2$ ); $\mathrm{R}_{f}=0.17 ;{ }^{1} \mathrm{H}$-NMR $\left(200 \mathrm{MHz}, \mathrm{DMSO}-d_{6}\right) \delta: 8.28\left(2 \mathrm{H}, \mathrm{d}, J=8.8, \mathrm{H}-3^{\prime}, 5^{\prime}\right), 7.82(1 \mathrm{H}, \mathrm{s}$, H-4) $7.62(1 \mathrm{H}, \mathrm{s}, \mathrm{H}-7), 7.48\left(2 \mathrm{H}, \mathrm{d}, J=8.8, \mathrm{H}-2^{\prime}, 6^{\prime}\right), 6.10(2 \mathrm{H}, \mathrm{s}$, $\left.\mathrm{CH}_{2}\right), 2.35\left(6 \mathrm{H}, \mathrm{s}, 2 \mathrm{CH}_{3}\right) ;{ }^{13} \mathrm{C}-\mathrm{NMR}\left(\mathrm{DMSO}-d_{6}\right) \delta: 145.6(\mathrm{C})$, 144.9 (C), 142.2 (C), 132.9 (C), 131.9 (2C), 127.9 (2CH), 118.5 $(2 \mathrm{CH}), 116.5(2 \mathrm{CH}), 52.1\left(\mathrm{CH}_{2}\right), 18.8\left(2 \mathrm{CH}_{3}\right)$.

\section{5,6-Dichloro-1-(4-Nitrobenzyl)-1H-Benzo[d] $[1,2,3]$ Triazole $(24)$}

Compound 24 was obtained in $32 \%$ total yield; m.p. $158-160^{\circ} \mathrm{C}$; TLC (petroleum ether/ethyl acetate 7.5/2.5); $\mathrm{R}_{f}=0.42 ;{ }^{1} \mathrm{H}-\mathrm{NMR}$ $\left(400 \mathrm{MHz} \mathrm{CDCl}_{3}\right) \delta: 8.21\left(3 \mathrm{H}, \mathrm{d}, J=7.8, \mathrm{H}-3^{\prime}, 5^{\prime}, \mathrm{H}-4\right), 7.88(1 \mathrm{H}$, s, H-7), $7.51\left(2 \mathrm{H}, \mathrm{d}, J=8.6, \mathrm{H}-2^{\prime}, 6^{\prime}\right), 6.03\left(2 \mathrm{H}, \mathrm{s}, \mathrm{CH}_{2}\right) .{ }^{13} \mathrm{C}-\mathrm{NMR}$ $\left(\mathrm{DMSO}-d_{6}\right) \delta: 145.9(\mathrm{C}), 145.3(\mathrm{C}), 142.5(\mathrm{C}), 133.8(2 \mathrm{C}), 132.6$ (C), $128.6(2 \mathrm{CH}), 126.5(2 \mathrm{CH}), 124.3(2 \mathrm{CH}), 52.0\left(\mathrm{CH}_{2}\right)$.

General Procedure to Obtain 4-((5,6-R-1H-Benzo[d] $[1,2,3]$ Triazol-1-yl)Methyl)aniline (16-18)

To a mixture of proper compound 22 or $23(1.77 \mathrm{mmol})$ in Ethanol $(20 \mathrm{ml})$, and Hydrated hydrazine in ratio 1:20 (35.4 $\mathrm{mmol}), \mathrm{Pd} / \mathrm{C}$ in ratio $1: 0.1 \mathrm{w} / \mathrm{w}$ was added. The mixture was stirred and heated at $80^{\circ} \mathrm{C}$ for $1 \mathrm{~h}$. Palladium on carbon was filtered off when the solution was still hot, and the mothers obtained were concentrated into half volume. By cooling down, the resulting solid was filtered out in vacuo. The solid compound was washed twice with diethyl ether $(20 \mathrm{ml})$ and subsequently crystallized from Ethanol. Derivative $24(1.77 \mathrm{mmol})$ was solved in Ethanol $(100 \mathrm{ml})$ and reduced with Methylhydrazine in 1/10 molar ratio, at $100^{\circ} \mathrm{C}$ in autoclave for $48 \mathrm{~h}$.

\section{4-((1H-Benzo[d][1,2,3]Triazol-1-yl)methyl) aniline (16)}

Compound 16 was obtained in $78 \%$ total yield; m.p. $151-153^{\circ} \mathrm{C}$; TLC (petroleum ether/ethyl acetate 4/6); $\mathrm{R}_{f}=0.47 ;{ }^{1} \mathrm{H}-\mathrm{NMR}$ $\left(200 \mathrm{MHz}, \mathrm{DMSO}-d_{6}\right) \delta: 8.03(1 \mathrm{H}, \mathrm{d}, J=8.4, \mathrm{H}-4), 7.81(1 \mathrm{H}, \mathrm{d}$, $J=8.4, \mathrm{H}-7), 7.50(1 \mathrm{H}, \mathrm{t}, \mathrm{H}-5), 7.41(1 \mathrm{H}, \mathrm{t}, \mathrm{H}-6) 7.07(2 \mathrm{H}, \mathrm{d}$, $\left.J=8.2, \mathrm{H}-3^{\prime}, 5^{\prime}\right), 6.49\left(2 \mathrm{H}, \mathrm{d}, J=8.2, \mathrm{H}-2^{\prime}, 6^{\prime}\right), 5.74(2 \mathrm{H}, \mathrm{s}$, $\left.\mathrm{CH}_{2}\right), 5.15\left(2 \mathrm{H}, \mathrm{s}, \mathrm{NH}_{2}\right) .{ }^{13} \mathrm{C}-\mathrm{NMR}\left(\mathrm{DMSO}-d_{6}\right) \delta: 149.2(\mathrm{C})$, $145.5(\mathrm{C}), 132.4(\mathrm{C}), 132.8(\mathrm{C}), 128.7(2 \mathrm{CH}), 126.6(2 \mathrm{CH})$, $119.7(\mathrm{CH}), 114.6(2 \mathrm{CH}), 110.3(\mathrm{CH}), 52.3\left(\mathrm{CH}_{2}\right)$.

\section{4-((5,6-Dimethyl-1H-Benzo[d][1,2,3] Triazol-1-yl)Methyl)aniline (17)}

Compound 17 was obtained in $88 \%$ total yield; m.p. $184-186^{\circ} \mathrm{C}$; TLC (petroleum ether/ethyl acetate 6/4); $\mathrm{R}_{f}=0.17 ;{ }^{1} \mathrm{H}-\mathrm{NMR}$ $\left(200 \mathrm{MHz}, \mathrm{DMSO}-d_{6}\right) \delta: 7.76(1 \mathrm{H}, \mathrm{s}, \mathrm{H}-4), 7.57(1 \mathrm{H}, \mathrm{s}, \mathrm{H}-7), 7.06$ $\left(2 \mathrm{H}, \mathrm{d}, J=8.6, \mathrm{H}-2^{\prime}, 6^{\prime}\right), 6.48\left(2 \mathrm{H}, \mathrm{d}, J=8.6, \mathrm{H}-3^{\prime}, 5^{\prime}\right), 5.65(2 \mathrm{H}, \mathrm{s}$, $\left.\mathrm{CH}_{2}\right), 5.13\left(2 \mathrm{H}, \mathrm{s}, \mathrm{NH}_{2}\right), 2.36\left(6 \mathrm{H}, \mathrm{s}, 2 \mathrm{CH}_{3}\right) .{ }^{13} \mathrm{C}-\mathrm{NMR}$ (DMSO$\left.d_{6}\right) \delta: 149.2(\mathrm{C}), 145.5(\mathrm{C}), 132.5(2 \mathrm{C}), 132.2(\mathrm{C}), 128.8(\mathrm{C}), 128.2$ $(2 \mathrm{CH}), 124.2(2 \mathrm{CH}), 114.3(2 \mathrm{CH}), 52.3\left(\mathrm{CH}_{2}\right), 18.8\left(2 \mathrm{CH}_{3}\right)$.

\section{4-((5,6-Dichloro-1H-Benzo[d][1,2,3] Triazol-1-yl)methyl)aniline (18)}

Compound 18 was obtained in $30 \%$ total yield; m.p. $203-206^{\circ} \mathrm{C}$; TLC (petroleum ether/ethyl acetate $7 / 3$ ); $\mathrm{R}_{f}=0.29 ;{ }^{1} \mathrm{H}-\mathrm{NMR}$ $\left(400 \mathrm{MHz}, \mathrm{CDCl}_{3}\right) \delta: 8.45(1 \mathrm{H}, \mathrm{s}, \mathrm{H}-4), 8.32(1 \mathrm{H}, \mathrm{s}, \mathrm{H}-7), 7.11$ $\left(2 \mathrm{H}, \mathrm{d}, J=8.4, \mathrm{H}-2^{\prime}, 6^{\prime}\right), 6.51\left(2 \mathrm{H}, \mathrm{d}, J=8.4, \mathrm{H}-3^{\prime}, 5^{\prime}\right), 5.75(2 \mathrm{H}, \mathrm{s}$, $\left.\mathrm{CH}_{2}\right), 5.13\left(2 \mathrm{H}, \mathrm{s}, \mathrm{NH}_{2}\right),{ }^{13} \mathrm{C}-\mathrm{NMR}\left(\mathrm{DMSO}-d_{6}\right) \delta: 145.7(\mathrm{C})$, 144.9 (C), 133.8 (2C), 133.0 (C), 129.5 (2CH), $126.6(2 \mathrm{CH}), 125.9$ (C), $115.4(2 \mathrm{CH}), 52.3\left(\mathrm{CH}_{2}\right)$.

General Procedure to Obtain Final Derivatives 3a-g and 4a-d,f; 5e-g and 6f; 7a-g and 10a-g; 8a-g and 11a-g; 9a-g and 12a-d,f

To a solution of $0.3 \mathrm{~g}(1.19 \mathrm{mmol})$ of intermediates 13,15 , or 16-18 and Triethylamine $0.17 \mathrm{ml}(1.19 \mathrm{mmol})$ dissolved in $9 \mathrm{ml}$ 
of DMF, the appropriate acyl dichloride 14a-g (1.44 mmol, ratio 1:1.2) was added. The mixture was left to react at r.t. under stirring for a varying time from 3 to $96 \mathrm{~h}(3 \mathrm{~h}$ for compounds $3 \mathrm{~g}$, 5e, 7a-g, 9a,e; $9 \mathrm{~h}$ for compounds $3 \mathbf{b}, 9 \mathbf{b}, \mathbf{c} ; 24 \mathrm{~h}$ for compounds 3c,e, 5g, 8a-e, 9f,g; $48 \mathrm{~h}$ for compounds 5f, 9d; $72 \mathrm{~h}$ for compounds 3a,d,f; $96 \mathrm{~h}$ for compounds $\mathbf{8 f , g}$ ). Then, Triethylamine hydrochloride was removed by filtration with vacuum and the mothers were diluted with water to obtain a precipitate, which consisted of a mixture of the two products: the bis-benzotriazole dicarboxamides (series $3,5,7,8,9)$ and the corresponding mono-substituted acids (series 4, 6, 10, 11, 12). The separation of the two compounds (dimer and corresponding acid) was obtained by flash chromatography using a mixture of chloroform and methanol (ratio 9.8/0.2) as eluent for the pairs 7/ 10 and 8/11 in which the dimer derivatives is the first to be eluted and represents only $1 / 3$ of the mixture, while derivatives bearing two chlorine atoms in the benzotriazole moiety (pairs $\mathbf{3 / 4}, 5 / 6$, and 9/12) were separated by repeated washing of the solid on a porous septum with a heated $\left(60^{\circ} \mathrm{C}\right)$ mixture of chloroform, acetone and methanol in a 6:3:1 ratio. The mono-substituted acidic derivatives $(\mathbf{4}, \mathbf{6}, \mathbf{1 2})$ were solved by the mixture and thereafter recovered by evaporation in vacuo of the solvent and further purified by fractional crystallization using ethyl acetate and petroleum ether. The dicarboxamide derivative, instead, remained unsolved onto the filter was further purified by repeated washings with acetone.

\section{$N^{1}, N^{4}$-Bis(4-(5,6-Dichloro-1H-Benzo[d] $[1,2,3]$ Triazol-1-yl)phenyl)succinamide (3a)}

Compound 3a was obtained in $20 \%$ total yield; m.p. $264-265^{\circ} \mathrm{C}$; TLC (chloroform/methanol 9.5/0.5); $\mathrm{R}_{f}=0.84 ;{ }^{1} \mathrm{H}-\mathrm{NMR}(400 \mathrm{MHz}$, DMSO- $\left.d_{6}\right) \delta: 10.43(2 \mathrm{H}, \mathrm{s}, \mathrm{NH}), 8.58(2 \mathrm{H}, \mathrm{s}, \mathrm{H}-4), 8.44(2 \mathrm{H}, \mathrm{s}$, $\mathrm{H}-7), 7.91\left(4 \mathrm{H}, \mathrm{d}, J=8.0, \mathrm{H}-3^{\prime}, 5^{\prime}\right), 7.86\left(4 \mathrm{H}, \mathrm{d}, J=8.0, \mathrm{H}-2^{\prime}, 6^{\prime}\right), 2.78$ $\left(4 \mathrm{H}, \mathrm{s}, \mathrm{CH}_{2}-\mathrm{CH}_{2}\right) .{ }^{13} \mathrm{C}-\mathrm{NMR}$ (DMSO- $\left.d_{6}\right) \delta: 170.8(2 \mathrm{CO}), 144.6(\mathrm{C})$ 143.2 (C), 140.9 (C), 140.1 (2C), 133.9 (C), 131.8 (C), 131.1 (C), 130.3 (2C), $127.6(2 \mathrm{C}), 123.6(4 \mathrm{CH}), 121.1(\mathrm{CH}), 120.8(\mathrm{CH}), 119.8(2 \mathrm{CH})$, $119.5(\mathrm{CH}), 119.4(\mathrm{CH}), 112.8(2 \mathrm{CH}), 31.2\left(\mathrm{CH}_{2}\right), 28.7\left(\mathrm{CH}_{2}\right)$. $\mathrm{C}_{28} \mathrm{H}_{18} \mathrm{Cl}_{4} \mathrm{~N}_{8} \mathrm{O}_{2}$; MW 640.31; Elem. Anal.: Calcd. C 52.52, H 2.83, N 17.50 Found C 52.25, H 3.00, N 17.56. LC/MS: $m / z 661[\mathrm{M}+\mathrm{Na}]^{+}$, $641[\mathrm{M}+\mathrm{H}]^{+}, 639[\mathrm{M}+\mathrm{H}]^{+}$.

\section{4-((4-(5,6-Dichloro-1H-Benzo[d][1,2,3] Triazol-1-yl)phenyl)amino)-4-oxobutanoic Acid (4a)}

Compound 4a was obtained in $22 \%$ total yield; m.p. $163-164^{\circ} \mathrm{C}$; TLC (chloroform/methanol 9.5/0.5); $\quad \mathrm{R}_{f}=0.24 ;{ }^{1} \mathrm{H}-\mathrm{NMR}$ $\left(400 \mathrm{MHz}, \mathrm{DMSO}-d_{6}\right) \delta: 10.34(1 \mathrm{H}, \mathrm{s}, \mathrm{NH}), 8.62(1 \mathrm{H}, \mathrm{s}, \mathrm{H}-4)$, $8.22(1 \mathrm{H}, \mathrm{s}, \mathrm{H}-7), 7.89\left(2 \mathrm{H}, \mathrm{d}, J=8.4, \mathrm{H}-3^{\prime}, 5^{\prime}\right), 7.81(2 \mathrm{H}, \mathrm{d}, J=8.4$, $\left.\mathrm{H}-2^{\prime}, 6^{\prime}\right), 2.59\left(2 \mathrm{H}, \mathrm{t}, \mathrm{CH}_{2}\right), 2.57\left(2 \mathrm{H}, \mathrm{t}, \mathrm{CH}_{2}\right) .{ }^{13} \mathrm{C}-\mathrm{NMR}$ (DMSO$\left.d_{6}\right) \delta: 173.8(\mathrm{NHCO}), 170.6(\mathrm{COOH}), 144.6(2 \mathrm{C}), 143.2(\mathrm{C}), 140.9$ (C), 140.1 (2C), 135.1 (C), 131.8 (C), 131.1 (C), 130.3 (C), 127.6 (2C), $123.6(2 \mathrm{CH}), 120.8(\mathrm{CH}), 120.2(2 \mathrm{CH}), 112.8(\mathrm{CH}), 31.1$ $\left(\mathrm{CH}_{2}\right)$, $28.7\left(\mathrm{CH}_{2}\right) . \mathrm{C}_{16} \mathrm{H}_{12} \mathrm{Cl}_{2} \mathrm{~N}_{4} \mathrm{O}_{3}$; MW 379.20; Elem. Anal.: Calcd C 50.68, H 3.19, N 14.78 Found C 50.24, H 3.38, N 14.97. LC/MS: $m / z 417[\mathrm{M}+\mathrm{K}]^{+}, 381[\mathrm{M}+\mathrm{H}]^{+}, 379[\mathrm{M}+\mathrm{H}]^{+}$.

\section{$N^{1}, N^{5}$-Bis(4-(5,6-Dichloro-1H-Benzo[d]} [1,2,3]Triazol-1-yl)phenyl)glutaramide (3b)

Compound $\mathbf{3 b}$ was obtained in $22 \%$ total yield; m.p. $266-267^{\circ} \mathrm{C}$; TLC (chloroform/methanol 9.5/0.5); $\mathrm{R}_{f}=0.62 ;{ }^{1} \mathrm{H}-\mathrm{NMR}$ $\left(400 \mathrm{MHz}, \mathrm{DMSO}-d_{6}\right) \delta: 10.30(2 \mathrm{H}, \mathrm{s}, \mathrm{NH}), 8.61(2 \mathrm{H}, \mathrm{s}, \mathrm{H}-4)$, $8.25(2 \mathrm{H}, \mathrm{s}, \mathrm{H}-7), 7.92\left(4 \mathrm{H}, \mathrm{d}, J=8.0, \mathrm{H}-3^{\prime}, 5^{\prime}\right), 7.82(4 \mathrm{H}, \mathrm{d}, J=8.0$, $\left.\mathrm{H}-2^{\prime}, 6^{\prime}\right), 2.51\left(4 \mathrm{H}, \mathrm{s}, 2 \mathrm{CH}_{2} \mathrm{CO}\right), 2.01\left(2 \mathrm{H}, \mathrm{t},-\mathrm{CH}_{2^{-}}\right) .{ }^{13} \mathrm{C}-\mathrm{NMR}$ $\left(\mathrm{DMSO}-d_{6}\right) \delta$ : 171.2 (2CO), 144.6 (2C), $140.1(2 \mathrm{C}), 131.8(2 \mathrm{C})$, $131.1(2 \mathrm{C}), 130.3(2 \mathrm{C}), 127.6(2 \mathrm{C}), 123.6(4 \mathrm{CH}), 120.8(2 \mathrm{CH})$, $119.9(4 \mathrm{CH}), \quad 112.8 \quad(2 \mathrm{CH}), \quad 35.6 \quad\left(2 \mathrm{CH}_{2}\right), \quad 20.7 \quad\left(\mathrm{CH}_{2}\right)$. $\mathrm{C}_{29} \mathrm{H}_{20} \mathrm{Cl}_{4} \mathrm{~N}_{8} \mathrm{O}_{2}$; MW 654.33; Elem. Anal.: Calcd C 53.23, H 3.08, N 17.12 Found C 52.93, H 3.35, N 17.28. LC/MS: $m / z$ $677[\mathrm{M}+\mathrm{Na}]^{+}, 657[\mathrm{M}+\mathrm{H}]^{+}, 653[\mathrm{M}+\mathrm{H}]^{+}$.

\section{5-((4-(5,6-Dichloro-1H-Benzo[d][1,2,3] Triazol-1-yl)phenyl)amino)-5-oxopentanoic} Acid (4b)

Compound $\mathbf{4 b}$ was obtained in $10 \%$ total yield; m.p. $106-108^{\circ} \mathrm{C}$; TLC (chloroform/methanol 9.5/0.5); $\mathrm{R}_{f}=0.36 ;{ }^{1} \mathrm{H}-\mathrm{NMR}$ $\left(400 \mathrm{MHz}, \mathrm{DMSO}-d_{6}\right) \delta: 10.56(1 \mathrm{H}, \mathrm{s}, \mathrm{NH}), 8.60(1 \mathrm{H}, \mathrm{s}, \mathrm{H}-4)$, $8.22(1 \mathrm{H}, \mathrm{s}, \mathrm{H}-7), 7.90\left(2 \mathrm{H}, \mathrm{d}, J=8.4, \mathrm{H}-3^{\prime}, 5^{\prime}\right), 7.81(2 \mathrm{H}, \mathrm{d}, J=8.4$, $\left.\mathrm{H}-2^{\prime}, 6^{\prime}\right), 2.43\left(2 \mathrm{H}, \mathrm{s}, \mathrm{CH}_{2} \mathrm{CONH}\right), 2.31\left(2 \mathrm{H}, \mathrm{s} \mathrm{CH} \mathrm{CH}_{2} \mathrm{COOH}\right), 1.86$ $\left(2 \mathrm{H}, \mathrm{s}, \mathrm{CH}_{2}\right) .{ }^{13} \mathrm{C}-\mathrm{NMR}$ (DMSO-d $\left.d_{6}\right) \delta: 174.1(\mathrm{CONH}), 171.2$ (COOH), $144.6(\mathrm{C}), 140.1$ (C), 131.8 (C), 131.1 (C), $130.3(\mathrm{C})$, $127.6(\mathrm{C}), 123.6(2 \mathrm{CH}), 120.8(\mathrm{CH}), 119.9(2 \mathrm{CH}), 112.8(\mathrm{CH})$, 35.4 $\left(\mathrm{CH}_{2}\right), 32.9\left(\mathrm{CH}_{2}\right), 20.3\left(\mathrm{CH}_{2}\right) . \mathrm{C}_{17} \mathrm{H}_{14} \mathrm{Cl}_{2} \mathrm{~N}_{4} \mathrm{O}_{3} ; \mathrm{MW} 393.22$; Elem. Anal.: Calcd C 51.93, H 3.59, N 14.25 Found C 52.04, H 3.75, N 14.00. LC/MS: $m / z 415[\mathrm{M}+\mathrm{Na}]^{+}, 393[\mathrm{M}+\mathrm{H}]^{+}$.

\section{$N^{1}, N^{6}$-Bis(4-(5,6-Dichloro-1H-Benzo[d]} $[1,2,3]$ Triazol-1-yl)phenyl)adipamide (3c)

Compound $3 \mathrm{c}$ was obtained in $15 \%$ total yield; m.p. $293-294^{\circ} \mathrm{C}$; TLC (chloroform/methanol 9.5/0.5); $\mathrm{R}_{f}=0.62 ;{ }^{1} \mathrm{H}-\mathrm{NMR}$ (400 MHz, DMSO-d $\left.d_{6}\right) \delta: 10.28(2 \mathrm{H}, \mathrm{s}, \mathrm{NH}), 8.60(2 \mathrm{H}, \mathrm{s}, \mathrm{H}-4)$, $8.22(2 \mathrm{H}, \mathrm{s}, \mathrm{H}-7), 7.90\left(4 \mathrm{H}, \mathrm{d}, J=8.0, \mathrm{H}-3^{\prime}, 5^{\prime}\right), 7.80(4 \mathrm{H}, \mathrm{d}, J=8.0$, $\left.\mathrm{H}-2^{\prime}, 6^{\prime}\right), 2.44\left(4 \mathrm{H}\right.$, s, $\left.2 \mathrm{CH}_{2} \mathrm{CO}\right), 1.23\left(4 \mathrm{H}\right.$, s, $\left.\mathrm{CH}_{2}-\mathrm{CH}_{2}\right)$. ${ }^{13} \mathrm{C}-\mathrm{NMR}$ (DMSO- $d_{6}$ ) $\delta: 171.5$ (2CO) $144.6(\mathrm{C}), 143.2(\mathrm{C})$, 140.9 (C), 140.1 (2C), 134.0 (C), 131.8 (C), 131.1 (C), 130.3 (2C), $127.6(2 \mathrm{C}), 123.6(4 \mathrm{CH}), 121.1(\mathrm{CH}), 120.8(\mathrm{CH}), 119.9$ $(2 \mathrm{CH}), 119.7(\mathrm{CH}), 119.4(\mathrm{CH}), 112.8(2 \mathrm{CH}), 36.3\left(2 \mathrm{CH}_{2}\right), 24.8$ $\left(2 \mathrm{CH}_{2}\right) . \mathrm{C}_{30} \mathrm{H}_{22} \mathrm{Cl}_{4} \mathrm{~N}_{8} \mathrm{O}_{2}$; MW 668.36; Elem. Anal.: Calcd C 53.91, H 3.32, N 16.77 Found C 54.22, H 3.34, N 16.45. LC/M: $m / z 671$ $[\mathrm{M}+\mathrm{H}]^{+}, 669[\mathrm{M}+\mathrm{H}]^{+}, 667[\mathrm{M}+\mathrm{H}]^{+}$.

\section{6-((4-(5,6-Dichloro-1H-Benzo[d][1,2,3] Triazol-1-yl)phenyl)amino)-6-oxohexanoic Acid (4c)}

Compound $4 \mathrm{c}$ was obtained in $10 \%$ total yield; m.p. $148-150^{\circ} \mathrm{C}$; TLC (chloroform/methanol 9.5/0.5); $\mathrm{R}_{f}=0.26 ;{ }^{1} \mathrm{H}-\mathrm{NMR}$ $\left(400 \mathrm{MHz}, \mathrm{DMSO}-d_{6}\right) \delta: 10.26(1 \mathrm{H}, \mathrm{s}, \mathrm{NH}), 8.61(1 \mathrm{H}, \mathrm{s}, \mathrm{H}-4)$, $8.24(1 \mathrm{H}, \mathrm{s}, \mathrm{H}-7), 7.90\left(2 \mathrm{H}, \mathrm{d}, J=8.0, \mathrm{H}-3^{\prime}, 5^{\prime}\right), 7.81(2 \mathrm{H}, \mathrm{d}, J=8.0$, $\left.\mathrm{H}-2^{\prime}, 6^{\prime}\right), 2.38\left(2 \mathrm{H}, \mathrm{t}, \mathrm{CH}_{2} \mathrm{CONH}\right), 2.27\left(2 \mathrm{H}, \mathrm{t}, \mathrm{CH}_{2} \mathrm{COOH}\right)$, 1.70-1.56 (4H, m, $\left.\mathrm{CH}_{2}-\mathrm{CH}_{2}\right) .{ }^{13} \mathrm{C}-\mathrm{NMR}$ (DMSO-d $\left.d_{6}\right) \delta: 174.3$ (CONH), $171.5(\mathrm{COOH}), 144.6(\mathrm{C}), 140.1$ (C), 131.8 (C), 131.1 
(C), $130.3(\mathrm{C}), 127.6(\mathrm{C}), 123.6(2 \mathrm{CH}), 120.8(\mathrm{CH}), 119.9(2 \mathrm{CH})$, $112.8(\mathrm{CH}) . \mathrm{C}_{18} \mathrm{H}_{16} \mathrm{Cl}_{2} \mathrm{~N}_{4} \mathrm{O}_{3}$; MW 407.25; Elem. Anal.: Calcd C 53.09, H 3.96, N 13.76 Found C 52.79, H 4.26, N 14.08. LC/MS: $m$ / $z 429[\mathrm{M}+\mathrm{Na}]^{+}, 411[\mathrm{M}+\mathrm{H}]^{+}, 409[\mathrm{M}+\mathrm{H}]^{+}, 407[\mathrm{M}+\mathrm{H}]^{+}$.

\section{$N^{1}, N^{4}$-Bis(4-(5,6-Dichloro-1H-Benzo[d]} $[1,2,3]$ Triazol-1-yl)phenyl)fumaramide (3d)

Compound $3 \mathbf{d}$ was obtained in $18 \%$ total yield; m.p. $>300^{\circ} \mathrm{C}$; TLC (chloroform/methanol 9.5/0.5); $\mathrm{R}_{f}=0.90 ;{ }^{1} \mathrm{H}-\mathrm{NMR}(400 \mathrm{MHz}$, DMSO- $\left.d_{6}\right) \delta: 10.92(1 \mathrm{H}, \mathrm{s}, \mathrm{NH}), 8.64(2 \mathrm{H}, \mathrm{s}, \mathrm{H}-4), 8.32(2 \mathrm{H}, \mathrm{s}, \mathrm{H}-$ 7), $8.02\left(4 \mathrm{H}, \mathrm{d}, J=8.4, \mathrm{H}-3^{\prime}, 5^{\prime}\right), 7.91\left(4 \mathrm{H}, \mathrm{d}, J=8.4, \mathrm{H}-2^{\prime}, 6^{\prime}\right), 7.31$ $(2 \mathrm{H}, \mathrm{s}, \mathrm{CH}=\mathrm{CH}) .{ }^{13} \mathrm{C}-\mathrm{NMR}$ (DMSO- $\left.d_{6}\right) \delta: 162.3$ (2CO), 144.7 (2C), $141.5(2 \mathrm{C}), 139.5(2 \mathrm{C}), 134.8(2 \mathrm{C}), 134.2(\mathrm{CH}=\mathrm{CH}), 131.1$ (2C), $127.7(2 \mathrm{C}), 123.8(4 \mathrm{CH}), 120.9(2 \mathrm{CH}), 120.5(4 \mathrm{CH}), 112.9$ (2CH). $\mathrm{C}_{28} \mathrm{H}_{16} \mathrm{Cl}_{4} \mathrm{~N}_{8} \mathrm{O}_{2}$; MW 638.29; Elem. Anal.: Calcd C 52.69, H 2.53, N 17.56 Found C 52.59, H 2.75, N 17.22. LC/MS: $m / z 659$ $[\mathrm{M}+\mathrm{Na}]^{+}, 641[\mathrm{M}+\mathrm{H}]^{+}, 637[\mathrm{M}+\mathrm{H}]^{+}$.

\section{(E)-4-((4-(5,6-Dichloro-1H-Benzo[d][1,2,3]} Triazol-1-yl)phenyl)

\section{amino)-4-oxobut-2-enoic Acid (4d)}

Compound 4d was obtained in $20 \%$ total yield; m.p. $231-233^{\circ} \mathrm{C}$; TLC (chloroform/methanol 9.5/0.5); $\mathrm{R}_{f}=0.15 ;{ }^{1} \mathrm{H}-\mathrm{NMR}$ $\left(400 \mathrm{MHz}, \mathrm{DMSO}-d_{6}\right) \delta: 10.99(1 \mathrm{H}, \mathrm{s}, \mathrm{NH}), 8.63(1 \mathrm{H}, \mathrm{s}, \mathrm{H}-4)$, $8.35(1 \mathrm{H}, \mathrm{s}, \mathrm{H}-7), 8.09\left(2 \mathrm{H}, \mathrm{d}, J=8.0, \mathrm{H}_{-} 3^{\prime}, 5^{\prime}\right), 7.92(2 \mathrm{H}, \mathrm{d}, J=8.0$, $\left.\mathrm{H}-2^{\prime}, 6^{\prime}\right), 7.31(1 \mathrm{H}, \mathrm{d}, J=15.2,=\mathrm{CH}-\mathrm{COOH}), 6.78(1 \mathrm{H}, \mathrm{d}, J=15.2$, $\mathrm{NHCO}-\mathrm{CH}=) .{ }^{13} \mathrm{C}-\mathrm{NMR}\left(\mathrm{DMSO}-d_{6}\right) \delta: 166.2(\mathrm{CONH}), 162.0$ $(\mathrm{COOH}), 144.6(\mathrm{C}), 139.3(\mathrm{C}), 136.8$ (HNOC-CH=), $131.8(\mathrm{C})$, 131.2 (=ㄷH-COOH), 131.1 (C), 130.5 (C), 127.7 (C), 123.7 (2CH), $120.9(\mathrm{CH}) 120.5(2 \mathrm{CH}), 112.9(\mathrm{CH}) . \mathrm{C}_{16} \mathrm{H}_{10} \mathrm{Cl}_{2} \mathrm{~N}_{4} \mathrm{O}_{3}$; MW 377.18; Elem. Anal.: Calcd C 50.95, H 2.67, N 14.85 Found C 51.00, H 2.44, N 15.10. LC/MS: $m / z 379[\mathrm{M}+\mathrm{H}]^{+}, 377[\mathrm{M}+\mathrm{H}]^{+}$.

\section{$N^{1}, N^{4}$-Bis(4-(5,6-Dichloro-1H-Benzo[d] $[1,2,3]$ Triazol-1-yl)phenyl) terephthalamide (3e)}

Compound 3e was obtained in $17 \%$ total yield; m.p. $197-199^{\circ} \mathrm{C}$; TLC (chloroform/methanol 9/1); $\mathrm{R}_{f}=0.81 ;{ }^{1} \mathrm{H}-\mathrm{NMR}(400 \mathrm{MHz}$, DMSO- $\left.d_{6}\right) \delta: 10.76(2 \mathrm{H}, \mathrm{s}, \mathrm{NH}), 8.63(2 \mathrm{H}, \mathrm{s}, 2 \mathrm{H}-4), 8.31(2 \mathrm{H}, \mathrm{s}$, $2 \mathrm{H}-7), 8.12-8.04\left(6 \mathrm{H}, \mathrm{m}, \mathrm{H}-2^{\prime \prime}, 3^{\prime \prime}, 5^{\prime \prime}, 6^{\prime \prime}, 2^{\prime}, 6^{\prime}\right), 8.02(2 \mathrm{H}, \mathrm{m}, \mathrm{H}-$ $\left.2^{\prime}, 6^{\prime}\right), 7.91\left(4 \mathrm{H}, \mathrm{m}, 2 \mathrm{H}-3^{\prime}, 5^{\prime}\right) .{ }^{13} \mathrm{C}-\mathrm{NMR}$ (DMSO- $\left.d_{6}\right) \delta: 166.7$ (2CO), 144.7 (2C), 139.8 (2C), 138.3 (2C), 134.5 (2C), 131.9 (2C), $131.1(2 \mathrm{C}), 129.4(8 \mathrm{CH}), 128.0(2 \mathrm{CH}), 127.7(2 \mathrm{C}), 123.5(4 \mathrm{CH})$, $121.3(2 \mathrm{CH}) . \mathrm{C}_{32} \mathrm{H}_{18} \mathrm{Cl}_{4} \mathrm{~N}_{8} \mathrm{O}_{2}$; MW 688.34; Elem. Anal.: Calcd C 55.84, H 2.64, N 16.28 Found C 55.42, H 2.91, N 15.98. LC/MS: $m$ / $z 689[\mathrm{M}+\mathrm{H}]^{+}, 687[\mathrm{M}+\mathrm{H}]^{+}$.

\section{$N^{2}, N^{6}$-Bis(4-(5,6-Dichloro-1H-Benzo[d] $[1,2,3]$ Triazol-1-yl)phenyl) pyridine-2,6-dicarboxamide (3f)}

Compound $\mathbf{3 f}$ was obtained in $6 \%$ total yield; m.p. $>300^{\circ} \mathrm{C}$; TLC (chloroform/methanol 9/1); $\mathrm{R}_{f}=0.8 ;{ }^{1} \mathrm{H}-\mathrm{NMR} \quad(400 \mathrm{MHz}$, DMSO- $\left.d_{6}\right) \delta: 11.35(2 \mathrm{H}, \mathrm{s}, \mathrm{NH}), 8.65$ (2H, s, H-4), 8.52-8.48 $\left(3 \mathrm{H}, \mathrm{m}, 2 \mathrm{H}-7, \mathrm{H}-4^{\prime \prime}\right), 8.43-8.30\left(6 \mathrm{H}, \mathrm{m}, 2 \mathrm{H}-2^{\prime}, 2 \mathrm{H}-6^{\prime}, \mathrm{H}-3^{\prime \prime}, \mathrm{H}-\right.$ $\left.5^{\prime \prime}\right), 8.04-8.02\left(4 \mathrm{H}, \mathrm{m}, 2 \mathrm{H}-3^{\prime}, 2 \mathrm{H}-5^{\prime}\right) .{ }^{13} \mathrm{C}-\mathrm{NMR}$ (DMSO- $\left.d_{6}\right) \delta$ : 162.0 (2CO), 148.6 (2C), 144.7 (2C), 143.4 (C), 139.9 (C), 138.9 (2C), 132.0 (2C), $131.6(\mathrm{C}), 131.1(\mathrm{C}), 130.6(\mathrm{C}), 127.8(\mathrm{C}), 125.7$ $(\mathrm{CH}), 123.6(4 \mathrm{CH}), 121.8(4 \mathrm{CH}), 121.2(\mathrm{CH}), 120.9(\mathrm{CH}), 119.5$ $(2 \mathrm{CH}), 113.0(2 \mathrm{CH}) . \mathrm{C}_{31} \mathrm{H}_{17} \mathrm{Cl}_{4} \mathrm{~N}_{9} \mathrm{O}_{2}$; MW 689.33; Elem. Anal.: Calcd C 54.02, H 2.49, N 16.28 Found C 54.38, H 2.50, N 16.45. LC/MS: $m / z 690[\mathrm{M}+\mathrm{H}]^{+}, 692[\mathrm{M}+\mathrm{H}]^{+}$.

\section{6-((4-(5,6-Dichloro-1H-Benzo[d][1,2,3] Triazol-1-yl)phenyl)carbamoyl)picolinic \\ Acid (4f)}

Compound $\mathbf{4 f}$ was obtained in $30 \%$ total yield; m.p. $240^{\circ} \mathrm{C}$; TLC (chloroform/methanol 9/1); $\mathrm{R}_{f}=0.1 ;{ }^{1} \mathrm{H}-\mathrm{NMR}(400 \mathrm{MHz}$, DMSO- $\left.d_{6}\right) \delta: 11.39(1 \mathrm{H}, \mathrm{s}, \mathrm{OH}), 11.16(1 \mathrm{H}, \mathrm{s}, \mathrm{NH}), 8.80$ $(1 \mathrm{H}, \mathrm{s}, \mathrm{H}-4), 8.58\left(1 \mathrm{H}, \mathrm{t}, \mathrm{H}-4^{\prime \prime}\right), 8.31(5 \mathrm{H}, \mathrm{s}, \mathrm{H}-7, \mathrm{H}-$ $\left.2^{\prime}, 3^{\prime}, 5^{\prime}, 6^{\prime}\right), 8.16\left(1 \mathrm{H}, \mathrm{d}, J=8.0, \mathrm{H}-3^{\prime \prime}\right), 7.98(1 \mathrm{H}, \mathrm{d}, J=8.0$, $\left.\mathrm{H}-5^{\prime \prime}\right) .{ }^{13} \mathrm{C}-\mathrm{NMR}$ (DMSO- $\left.d_{6}\right) \delta$ : 164.9 (CO), 161.9 (CO), 148.9 (C), $146.7(\mathrm{C}), 144.7(\mathrm{C}), 140.1(\mathrm{CH}), 138.8(\mathrm{C}), 131.9(\mathrm{C})$, $131.5(\mathrm{C}), 131.0(\mathrm{C}), 127.7(\mathrm{C}), 127.2(\mathrm{CH}), 125.8(\mathrm{CH}), 123.5$ $(\mathrm{CH}), 123.4(\mathrm{CH}), 121.8(\mathrm{CH}), 121.61 \mathrm{CH}), 120.9(\mathrm{CH}), 113.0$ (CH). $\mathrm{C}_{19} \mathrm{H}_{11} \mathrm{Cl}_{2} \mathrm{~N}_{5} \mathrm{O}_{3}$; MW 428.22; Elem. Anal.: Calcd C 53.29, H 2.59, N 16.56 Found C 53.39, H 2.79, N 16.25. LC/ MS: $m / z 429[\mathrm{M}+\mathrm{H}]^{+}, 427[\mathrm{M}+\mathrm{H}]^{+}$.

\section{$N^{2}, N^{5}$-Bis(4-(5,6-Dichloro-1H-Benzo[d] $[1,2,3]$ Triazol-1-yl)phenyl) thiophene-2,5-dicarboxamide (3g)}

Compound $3 \mathrm{~g}$ was obtained in $15 \%$ total yield; m.p. 208-209 ${ }^{\circ} \mathrm{C}$; TLC (chloroform/methanol 9/1); $\mathrm{R}_{f}=0.87$; ${ }^{1} \mathrm{H}-\mathrm{NMR}\left(400 \mathrm{MHz}, \mathrm{DMSO}-d_{6}\right) \delta: 10.75(2 \mathrm{H}, \mathrm{s}, \mathrm{NH}), 8.64$ $(2 \mathrm{H}, \mathrm{s}, 2 \mathrm{H}-4), 8.34(2 \mathrm{H}, \mathrm{s}, 2 \mathrm{H}-7), 8.12(2 \mathrm{H}, \mathrm{d}, J=8.01, \mathrm{H}-$ $\left.3^{\prime \prime}, 4^{\prime \prime}\right), 8.08\left(4 \mathrm{H}, \mathrm{s}, 2 \mathrm{H}-2^{\prime}, 6^{\prime}\right), 7.93\left(4 \mathrm{H}, \mathrm{s}, 2 \mathrm{H}-3^{\prime}, 5^{\prime}\right) .{ }^{13} \mathrm{C}-\mathrm{NMR}$ $\left(\mathrm{DMSO}-d_{6}\right) \delta: 159.6(\mathrm{CO}), 159.5(\mathrm{CO}), 144.7(2 \mathrm{C}), 143.8(2 \mathrm{C})$, 139.3 (2C), 131.9 (2C), $131.3(2 \mathrm{C}), 131.1(2 \mathrm{C}), 129.8(2 \mathrm{CH})$, $127.7(2 \mathrm{C}), 123.6(4 \mathrm{CH}), 121.4(4 \mathrm{CH}), 120.9(2 \mathrm{CH}), 112.9$ $(2 \mathrm{CH}) . \mathrm{C}_{30} \mathrm{H}_{16} \mathrm{Cl}_{4} \mathrm{~N}_{8} \mathrm{O}_{2} \mathrm{~S}$; MW 694.37; Elem. Anal.: Calcd C 51.90, H 2.32, N 16.14 Found C 51.90, H 2.32, N 16.14. LC/MS: $m / z 495[\mathrm{M}+\mathrm{H}]^{+}, 493[\mathrm{M}+\mathrm{H}]^{+}$.

\section{$N^{1}, N^{4}$-Bis(4-(5,6-Dichloro-2H-Benzo[d] [1,2,3]Triazol-2-yl)phenyl) terephthalamide (5e)}

Compound 5e was obtained in $30 \%$ total yield; m.p. $>300^{\circ} \mathrm{C}$; TLC (chloroform/methanol 9/1); $\mathrm{R}_{f}=0.64 ;{ }^{1} \mathrm{H}-\mathrm{NMR}$ $\left(400 \mathrm{MHz}, \mathrm{DMSO}-d_{6}\right) \delta: 10.77(2 \mathrm{H}, \mathrm{s}, \mathrm{NH}), 8.50(4 \mathrm{H}, \mathrm{s}$, $2 \mathrm{H}-4,2 \mathrm{H}-7), 8.31\left(4 \mathrm{H}, \mathrm{d}, J=8.0,2 \mathrm{H}-2^{\prime}, 2 \mathrm{H}-6^{\prime}\right), 8.12-8.09$ $\left(6 \mathrm{H}, \mathrm{m}, 2 \mathrm{H}-3^{\prime}, 2 \mathrm{H}-5^{\prime}, \mathrm{H}-2^{\prime \prime}, 6^{\prime \prime}\right), 8.04$ (2H, s, H-3", $\left.5^{\prime \prime}\right)$. ${ }^{13} \mathrm{C}$-NMR (DMSO- $d_{6}$ ) $\delta$ : 166.6 (CO), 165.2 (CO), 143.3 (4C), 140.6 (2C), 138.3 (2C), 134.7 (C), $134.4(2 \mathrm{C}), 133.5$ (C), $130.5(2 \mathrm{C}), 129.4(4 \mathrm{CH}), 129.3(2 \mathrm{CH}), 128.0(2 \mathrm{CH})$, $121.0(4 \mathrm{CH}), 119.5(4 \mathrm{CH}) . \mathrm{C}_{32} \mathrm{H}_{18} \mathrm{Cl}_{4} \mathrm{~N}_{8} \mathrm{O}_{2} ; \mathrm{MW}$ 688.34; Elem. Anal.: Calcd C 55.84, H 2.64, N 18.28 Found C 55.56, H 2.34, N 18.59. LC/MS: $m / z 689[\mathrm{M}+\mathrm{H}]^{+}, 687[\mathrm{M}+\mathrm{H}]^{+}$. 


\section{$N^{2}, N^{6}$-Bis(4-(5,6-Dichloro-2H-Benzo[d] [1,2,3]Triazol-2-yl)phenyl) pyridine-2,6-dicarboxamide (5f)}

Compound $5 \mathbf{f}$ was obtained in $13 \%$ total yield; m.p. $>300^{\circ} \mathrm{C}$; TLC (chloroform/methanol 9/1); $\mathrm{R}_{f}=0.20 ;{ }^{1} \mathrm{H}-\mathrm{NMR}(400 \mathrm{MHz}$, DMSO- $\left.d_{6}\right) \delta: 11.16(2 \mathrm{H}, \mathrm{s}, \mathrm{NH}), 8.51(4 \mathrm{H}, \mathrm{s}, 2 \mathrm{H}-4,2 \mathrm{H}-7)$, 8.45-8.34 (7H, m, H-3" $\left.4^{\prime \prime}, 5^{\prime \prime}, 2^{\prime}, 6^{\prime}\right), 8.16(4 \mathrm{H}, \mathrm{d}, J=8.8,2 \mathrm{H}-$ $\left.3^{\prime}, 5^{\prime}\right) .{ }^{13} \mathrm{C}-\mathrm{NMR}$ (DMSO- $\left.d_{6}\right) \delta$ : 150.8 (2CO), 143.3 (2C), 143.0 (4C), 130.5 (2C), 129.4 (4C), 128.3 (2C), $121.7(4 \mathrm{CH}), 121.2$ (1CH), $119.5(2 \mathrm{CH}), 118.9(4 \mathrm{CH}), 113.7(4 \mathrm{CH}) . \mathrm{C}_{31} \mathrm{H}_{17} \mathrm{Cl}_{4} \mathrm{~N}_{9} \mathrm{O}_{2}$; MW 689.33; Elem. Anal.: Calcd C 54.02, H 2.49, N 16.28 Found C 53.70, H 2.19, N 16.58. LC/MS: $m / z 690[\mathrm{M}+\mathrm{H}]^{+}, 688[\mathrm{M}+\mathrm{H}]^{+}$.

\section{6-((4-(5,6-Dichloro-2H-Benzo[d][1,2,3] Triazol-2-yl)phenyl)carbamoyl)picolinic Acid (6f)}

Compound $\mathbf{6 f}$ was obtained in $30 \%$ total yield; m.p. $240^{\circ} \mathrm{C}$; TLC (chloroform/methanol 9/1); $\mathrm{R}_{f}=0.1 ;{ }^{1} \mathrm{H}-\mathrm{NMR} \quad(400 \mathrm{MHz}$, DMSO- $\left.d_{6}\right) \delta: 11.39(1 \mathrm{H}, \mathrm{s}, \mathrm{OH}), 11.16(1 \mathrm{H}, \mathrm{s}, \mathrm{NH}), 8.80(1 \mathrm{H}$, s, H-4), $8.58\left(1 \mathrm{H}, \mathrm{t}, \mathrm{H}-4^{\prime \prime}\right), 8.31\left(5 \mathrm{H}, \mathrm{s}, \mathrm{H}-7, \mathrm{H}-2^{\prime}, 3^{\prime}, 5^{\prime}, 6^{\prime}\right), 8.16$ $\left(1 \mathrm{H}, \mathrm{d}, J=8.0, \mathrm{H}-3^{\prime \prime}\right), 7.98\left(1 \mathrm{H}, \mathrm{d}, J=8.0, \mathrm{H}-5^{\prime \prime}\right) .{ }^{13} \mathrm{C}-\mathrm{NMR}$ (DMSO- $d_{6}$ ) $\delta$ : 164.9 (CO), 161.9 (CO), $148.9(\mathrm{C}), 146.7$ (C), 144.7 (C), $140.1(\mathrm{CH}), 138.8(\mathrm{C}), 131.9(\mathrm{C}), 131.5(\mathrm{C}), 131.0(\mathrm{C}), 127.7$ (C), $127.2(\mathrm{CH}), 125.8(\mathrm{CH}), 123.5(\mathrm{CH}), 123.4(\mathrm{CH}), 121.8(\mathrm{CH})$, $121.6(\mathrm{CH}), 120.9(\mathrm{CH}), 113.0(\mathrm{CH}) . \mathrm{C}_{19} \mathrm{H}_{11} \mathrm{Cl}_{2} \mathrm{~N}_{5} \mathrm{O}_{3} ; \mathrm{MW}$ 428.22; Elem. Anal.: Calcd C 53.29, H 2.59, N 16.56 Found C 53.59, H 2.72, N 16.64. LC/MS: $m / z 429[\mathrm{M}+\mathrm{H}]^{+}, 428[\mathrm{M}+\mathrm{H}]^{+}$.

\section{$N^{2}, N^{5}$-Bis(4-(5,6-Dichloro-2H-Benzo[d] $[1,2,3]$ Triazol-2-yl)phenyl) thiophene-2,5-Dicarboxamide $(5 \mathrm{~g})$}

Compound $\mathbf{5 g}$ was obtained in $11 \%$ total yield; m.p. $>300^{\circ} \mathrm{C}$; TLC (chloroform/methanol 9/1); $\mathrm{R}_{f}=0.74 ;{ }^{1} \mathrm{H}-\mathrm{NMR}(400 \mathrm{MHz}$, DMSO- $\left.d_{6}\right) \delta$ : $10.73(2 \mathrm{H}, \mathrm{s}, \mathrm{NH}), 8.51(4 \mathrm{H}, \mathrm{s}, 2 \mathrm{H}-4,2 \mathrm{H}-7)$, $8.32\left(4 \mathrm{H}, \mathrm{d}, J=8.8,2 \mathrm{H}-2^{\prime}, 6^{\prime}\right), 8.06\left(6 \mathrm{H}, \mathrm{m}, 2 \mathrm{H}-3^{\prime}, 5^{\prime}, \mathrm{H}-\right.$ $\left.3^{\prime \prime}, 4^{\prime \prime}\right) .{ }^{13} \mathrm{C}-\mathrm{NMR}$ (DMSO- $\left.d_{6}\right) \quad \delta: 162.5$ (CO), 159.7 (CO), 143.3 (4C), 140.1 (4C), 134.8 (2C), 130.5 (4C), $129.8(2 \mathrm{CH})$, $121.1(8 \mathrm{CH}), 119.5(4 \mathrm{CH}) . \mathrm{C}_{30} \mathrm{H}_{16} \mathrm{Cl}_{4} \mathrm{~N}_{8} \mathrm{O}_{2}$; MW 694.37; Elem. Anal.: Calcd C 51.90, H 2.32, N 16.14 Found C 52.00, H 2.55, N 15.90. LC/MS: $m / z 695[\mathrm{M}+\mathrm{H}]^{+}, 697[\mathrm{M}+\mathrm{H}]^{+}$.

\section{$N^{1}, N^{4}-B i s(4-((1 H-B e n z o[d][1,2,3]$}

Triazol-1-yl)methyl)phenyl)succinamide (7a) Compound $7 \mathbf{a}$ was obtained in $10 \%$ total yield; m.p. $255-257^{\circ} \mathrm{C}$; TLC (chloroform/methanol 9.5/0.5); $\mathrm{R}_{f}=0.55 ;{ }^{1} \mathrm{H}-\mathrm{NMR}$ $\left(200 \mathrm{MHz}, \mathrm{DMSO}-d_{6}\right) \delta: 10.04(2 \mathrm{H}, \mathrm{s}, 2 \mathrm{NH}), 8.04(2 \mathrm{H}, \mathrm{d}, J=$ $8.2,2 \mathrm{H}-4), 7.81(2 \mathrm{H}, \mathrm{d}, J=8.2,2 \mathrm{H}-7), 7.53\left(4 \mathrm{H}, \mathrm{d}, J=8.4,2 \mathrm{H}-2^{\prime}\right.$, $\left.2 \mathrm{H}-6^{\prime}\right), 7.51-7.48(2 \mathrm{H}, \mathrm{m}, 2 \mathrm{H}-5) 7.39(2 \mathrm{H}, \mathrm{t}, \mathrm{H}-6) 7.27(4 \mathrm{H}, \mathrm{d}, J=$ $\left.8.4,2 \mathrm{H}-3^{\prime}, 2 \mathrm{H}-5^{\prime}\right), 5.90\left(4 \mathrm{H}, \mathrm{s}, 2 \mathrm{CH}_{2}\right), 2.59\left(4 \mathrm{H}, \mathrm{s}, 2 \mathrm{CH}_{2}\right)$. ${ }^{13} \mathrm{C}-\mathrm{NMR}$ (DMSO- $\left.d_{6}\right) \delta: 170.4(2 \mathrm{CO}), 145.3(2 \mathrm{C}), 139.1(2 \mathrm{C})$, $132.5(2 \mathrm{C}), 130.0(2 \mathrm{C}), 128.4(4 \mathrm{CH}), 127.3(2 \mathrm{CH}), 123.9(2 \mathrm{CH})$, $119.2(2 \mathrm{CH}), 119.1(4 \mathrm{CH}), 110.7(2 \mathrm{CH}), 50.7\left(2 \mathrm{CH}_{2}\right), 31.1$ $\left(2 \mathrm{CH}_{2}\right) . \mathrm{C}_{30} \mathrm{H}_{26} \mathrm{~N}_{8} \mathrm{O}_{2}$; MW 530.58; Elem. Anal.: Calcd C 67.91,
$\mathrm{H} 4.94, \mathrm{~N} 21.12$ Found C 68.00, H 4.55, N 16.35. LC/MS $m / z 531$ $[\mathrm{M}+\mathrm{H}]^{+}$.

\section{4-((4-((1H-Benzo[d][1,2,3]Triazol-1-yl) methyl)phenyl)amino)-4-Oxobutanoic Acid (10a)}

Compound 10a was obtained in $10 \%$ total yield; m.p. $193-195{ }^{\circ} \mathrm{C}$; TLC (chloroform/methanol 9.5/0.5); $\quad \mathrm{R}_{f}=0.15 ;{ }^{1} \mathrm{H}-\mathrm{NMR}$ $\left(200 \mathrm{MHz}, \mathrm{DMSO}-d_{6}\right) \delta: 10.04(\mathrm{H}, \mathrm{s}, \mathrm{NH}), 8.02(\mathrm{H}, \mathrm{d}, J=8.2$, $\mathrm{H}-4), 7.81(\mathrm{H}, \mathrm{d}, J=8.2, \mathrm{H}-7), 7.62-7.50\left(3 \mathrm{H}, \mathrm{m}, \mathrm{H}-2^{\prime}, 6^{\prime}\right.$ and $\mathrm{H}-$ 5), $7.40(\mathrm{H}, \mathrm{t}, \mathrm{H}-6) 7.31\left(2 \mathrm{H}, \mathrm{d}, J=9.2, \mathrm{H}-3^{\prime}, 5^{\prime}\right), 5.90\left(\mathrm{H}, \mathrm{s}, \mathrm{CH}_{2}\right)$, $2.53\left(4 \mathrm{H}, \mathrm{s}, 2 \mathrm{CH}_{2}\right) .{ }^{13} \mathrm{C}-\mathrm{NMR}$ (DMSO- $\left.d_{6}\right) \delta: 173.7$ (CO), 170.1 (CO), $145.3(\mathrm{C}), 139.1$ (C), $132.5(\mathrm{C}), 130.0(\mathrm{C}), 128.4(2 \mathrm{CH})$, $127.3(\mathrm{CH}), 124.0(\mathrm{CH}), 119.2(\mathrm{CH}), 119.1(2 \mathrm{CH}), 110.7(\mathrm{CH})$, $50.7\left(\mathrm{CH}_{2}\right), 31.1\left(\mathrm{CH}_{2}\right), 28.7\left(\mathrm{CH}_{2}\right) . \mathrm{C}_{17} \mathrm{H}_{16} \mathrm{~N}_{4} \mathrm{O}_{3} ; \mathrm{MW} \mathrm{324.33;}$ Elem. Anal.: Calcd C 62.95, H 4.97, N 17.27 Found C 62.65, H 4.78, N 17.54. LC/MS $m / z 325[\mathrm{M}+\mathrm{H}]^{+}$.

\section{$N^{1}, N^{5}$-Bis $(4-((1 H$-benzo[d] $[1,2,3]$}

Triazol-1-yl)methyl)phenyl)GlutAramide (7b)

Compound $7 \mathbf{b}$ was obtained in $12 \%$ total yield; m.p. $237-238^{\circ} \mathrm{C}$; TLC (chloroform/methanol 9.5/0.5); $\mathrm{R}_{f}=0.46 ;{ }^{1} \mathrm{H}-\mathrm{NMR}$ $\left(200 \mathrm{MHz}, \mathrm{DMSO}-d_{6}\right) \delta: 9.94(2 \mathrm{H}, \mathrm{s}, 2 \mathrm{NH}), 8.06(2 \mathrm{H}, \mathrm{d}, J=$ $8.2,2 \mathrm{H}-4), 7.82(2 \mathrm{H}, \mathrm{d}, J=8.6, \mathrm{H}-7), 7.60-7.48\left(6 \mathrm{H}, \mathrm{m}, 2 \mathrm{H}-2^{\prime}, 6^{\prime}\right.$ and $2 \mathrm{H}-5), 7.39(2 \mathrm{H}, \mathrm{t}, 2 \mathrm{H}-6), 7.28\left(4 \mathrm{H}, \mathrm{d}, J=8.4,2 \mathrm{H}-3^{\prime}, 5^{\prime}\right), 5.90$ $\left(4 \mathrm{H}, \mathrm{s}, 2 \mathrm{CH}_{2}\right), 2.31\left(4 \mathrm{H}, \mathrm{t}, 2 \mathrm{CH}_{2} \mathrm{CO}\right), 1.84\left(2 \mathrm{H}, \mathrm{m}, \mathrm{CH}_{2} \mathrm{CH}_{2} \mathrm{CH}_{2}\right)$. ${ }^{13} \mathrm{C}-\mathrm{NMR}$ (DMSO- $\left.d_{6}\right) \delta$ : 170.8 (2CO), 145.3 (2C), 139.1 (2C), $132.5(2 \mathrm{C}), 130.1(2 \mathrm{C}), 128.7(2 \mathrm{CH}), 128.4(2 \mathrm{CH}), 127.3(2 \mathrm{CH})$, $123.8(2 \mathrm{CH}), 119.6(2 \mathrm{CH}), 119.2(2 \mathrm{CH}), 110.7(2 \mathrm{CH}), 110.4$ $(2 \mathrm{CH}), 50.7\left(2 \mathrm{CH}_{2}\right), 35.5\left(2 \mathrm{CH}_{2}\right), 20.8\left(\mathrm{CH}_{2}\right) . \mathrm{C}_{31} \mathrm{H}_{28} \mathrm{~N}_{8} \mathrm{O}_{2}$; MW 544.61; Elem. Anal.: Calcd C 68.37, H 5.18, N 20.58 Found C 68.64, H 5.18, N 20.80. LC/MS $m / z 545[\mathrm{M}+\mathrm{H}]^{+}$.

\section{5-((4-((1H-Benzo[d][1,2,3]Triazol-1-y) methyl)phenyl)amino)-5-Oxopentanoic Acid (10b)}

Compound 10b was obtained in $25 \%$ total yield; m.p. $152-154^{\circ} \mathrm{C}$; TLC (chloroform/methanol 9.5/0.5); $\quad \mathrm{R}_{f}=0.20 ;{ }^{1} \mathrm{H}-\mathrm{NMR}$ $\left(200 \mathrm{MHz}, \mathrm{DMSO}-\mathrm{d}_{6}\right) \delta: 9.99(1 \mathrm{H}, \mathrm{s}, \mathrm{NH}), 8.04(1 \mathrm{H}, \mathrm{d}, J=$ 7.6, H-4), $7.82(1 \mathrm{H}, \mathrm{d}, J=7.0, \mathrm{H}-7), 7.56-7.42\left(3 \mathrm{H}, \mathrm{m}, \mathrm{H}-2^{\prime}, 6^{\prime}, \mathrm{H}-\right.$ 5), $7.38(1 \mathrm{H}, \mathrm{t}, \mathrm{H}-6), 7.28\left(2 \mathrm{H}, \mathrm{d}, J=8.4, \mathrm{H}-3^{\prime}, 5^{\prime}\right), 5.90(2 \mathrm{H}, \mathrm{s}$, $\left.\mathrm{CH}_{2}\right), 2.31\left(2 \mathrm{H}, \mathrm{t}, \mathrm{CH}_{2} \mathrm{CO}\right), 2.22\left(2 \mathrm{H}, \mathrm{t}, \mathrm{CH}_{2} \mathrm{CO}\right), 1.77(2 \mathrm{H}, \mathrm{m}$, $\left.\mathrm{CH}_{2} \mathrm{CH}_{2} \mathrm{CH}_{2}\right) .{ }^{13} \mathrm{C}-\mathrm{NMR}$ (DMSO- $\left.d_{6}\right) \delta: 174.5(\mathrm{CO}), 170.9$ (CO), $145.3(\mathrm{C}), 139.1(\mathrm{C}), 132.5(\mathrm{C}), 130.1(\mathrm{C}), 128.6(2 \mathrm{CH}), 128.3$ $(\mathrm{CH}), 124.0(\mathrm{CH}), 119.2(\mathrm{CH}), 119.1(2 \mathrm{CH}), 110.7(\mathrm{CH}), 50.7$ $\left(\mathrm{CH}_{2}\right), 35.4\left(2 \mathrm{CH}_{2}\right), 20.5\left(\mathrm{CH}_{2}\right) . \mathrm{C}_{18} \mathrm{H}_{18} \mathrm{~N}_{4} \mathrm{O}_{3}$; MW 338.36; Elem. Anal.: Calcd C 63.89, H 5.36, N 16.56 Found C 63.53, H 5.26, N 16.64. LC/MS $m / z 339[\mathrm{M}+\mathrm{H}]^{+}$.

\section{$N^{1}, N^{6}-B i s(4-((1 H-B e n z o[d][1,2,3]$}

\section{Triazol-1-yl)methyl)phenyl)Adipamide (7c)}

Compound $7 \mathrm{c}$ was obtained in $16 \%$ total yield; m.p. $231-232^{\circ} \mathrm{C}$; TLC (chloroform/methanol 9.5/0.5); $\quad \mathrm{R}_{f}=0.39 ;{ }^{1} \mathrm{H}-\mathrm{NMR}$ 
$\left(200 \mathrm{MHz}, \mathrm{DMSO}-d_{6}\right) \delta: 9.91(2 \mathrm{H}, \mathrm{s}, 2 \mathrm{NH}), 8.03(2 \mathrm{H}, \mathrm{d}, J=8.0$, $2 \mathrm{H}-4), 7.80(2 \mathrm{H}, \mathrm{d}, J=8.2,2 \mathrm{H}-7), 7.58-7.41\left(6 \mathrm{H}, \mathrm{m}, 2 \mathrm{H}-2^{\prime}, 6^{\prime}\right.$, $2 \mathrm{H}-5), 7.38(2 \mathrm{H}, \mathrm{t}, 2 \mathrm{H}-7), 7.27\left(4 \mathrm{H}, \mathrm{d}, J=8.6,2 \mathrm{H}-3^{\prime}, 5^{\prime}\right), 5.90(4 \mathrm{H}$, s, $\left.2 \mathrm{CH}_{2}\right), 2.27\left(4 \mathrm{H}, \mathrm{t}, 2 \mathrm{CH}_{2} \mathrm{CO}\right), 1.54\left(4 \mathrm{H}, \mathrm{m}, \mathrm{CH}_{2} \mathrm{CH}_{2}\right)$. ${ }^{13} \mathrm{C}-\mathrm{NMR}$ (DMSO- $d_{6}$ ) $\delta: 171.6(2 \mathrm{CO}), 145.8(2 \mathrm{C}), 139.6(2 \mathrm{C})$, $133.0(2 \mathrm{C}), 130.6(2 \mathrm{C}), 128.8(4 \mathrm{CH}), 127.8(2 \mathrm{CH}), 124.4(2 \mathrm{CH})$, $119.7(2 \mathrm{CH}), 119.6(4 \mathrm{CH}), 111.2(2 \mathrm{CH}), 51.2\left(2 \mathrm{CH}_{2}\right), 36.6$ $\left(2 \mathrm{CH}_{2}\right), 25.2\left(2 \mathrm{CH}_{2}\right), \mathrm{C}_{32} \mathrm{H}_{30} \mathrm{~N}_{8} \mathrm{O}_{2}$; MW 558.63; Elem. Anal.: Calcd C 68.80, H 5.41, N 20.06 Found C 68.44, H 5.61, N 20.26. $\mathrm{LC} / \mathrm{MS} m / z 559[\mathrm{M}+\mathrm{H}]^{+}$.

\section{6-((4-((1H-Benzo[d] $[1,2,3]$ triazol-1-yl) methyl)phenyl)amino)-6-oxohexanoic Acid (10c)}

Compound 10c was obtained in $33 \%$ total yield; m.p. $134-136{ }^{\circ} \mathrm{C}$; TLC (chloroform/methanol 9.5/0.5); $\mathrm{R}_{f}=0.23 ;{ }^{1} \mathrm{H}-\mathrm{NMR}$ $\left(200 \mathrm{MHz}, \mathrm{DMSO}-d_{6}\right) \delta: 9.93(1 \mathrm{H}, \mathrm{s}, \mathrm{NH}), 8.04(1 \mathrm{H}, \mathrm{d}, J=$ 8.2, H-4), $7.82(1 \mathrm{H}, \mathrm{d}, J=8.2 \mathrm{H}-7), 7.57-7.48\left(3 \mathrm{H}, \mathrm{m}, \mathrm{H}-2^{\prime}, 6^{\prime}, \mathrm{H}-\right.$ 5), 7.39 (1H, t, H-7), $7.29\left(2 \mathrm{H}, \mathrm{d}, J=8.2, \mathrm{H}-3^{\prime}, 5^{\prime}\right), 5.90(2 \mathrm{H}, \mathrm{s}$, $\left.\mathrm{CH}_{2}\right), 2.27\left(2 \mathrm{H}, \mathrm{t}, \mathrm{CH}_{2} \mathrm{CO}\right), 2.21\left(2 \mathrm{H}, \mathrm{m}, \mathrm{CH}_{2} \mathrm{CO}\right), 1.54(4 \mathrm{H}, \mathrm{m}$, $\mathrm{CH}_{2} \mathrm{CH}_{2}$ ). ${ }^{13} \mathrm{C}-\mathrm{NMR}$ (DMSO- $\left.d_{6}\right) \delta: 174.3(\mathrm{CO}), 171.1(\mathrm{CO})$, 145.3 (C), 139.1 (C), 132.5 (C), 130.1 (C), $128.4(2 \mathrm{CH}), 127.3$ $(\mathrm{CH}), 124.0(\mathrm{CH}), 119.2(\mathrm{CH}), 119.2(2 \mathrm{CH}), 110.7(\mathrm{CH}), 50.7$ $\left(\mathrm{CH}_{2}\right), 36.0\left(\mathrm{CH}_{2}\right), 33.4\left(\mathrm{CH}_{2}\right), 24.6\left(\mathrm{CH}_{2}\right), 24.1 \quad\left(\mathrm{CH}_{2}\right)$. $\mathrm{C}_{19} \mathrm{H}_{20} \mathrm{~N}_{4} \mathrm{O}_{3}$; MW 352.39; Elem. Anal.: Calcd C 64.76, H 5.72, N 15.90 Found C 65.00, H 5.93, N 16.00. LC/MS: $m / z 353[\mathrm{M}$ $+\mathrm{H}]^{+}$.

\section{$N^{1}, N^{4}-B i s(4-((1 H-B e n z o[d][1,2,3]$}

Triazol-1-yl)methyl)phenyl)Fumaramide (7d) Compound 7d was obtained in $12 \%$ total yield; m.p. $268-269^{\circ} \mathrm{C}$; TLC (chloroform/methanol 9.5/0.5); $\mathrm{R}_{f}=0.41 ;{ }^{1} \mathrm{H}-\mathrm{NMR}$ $\left(200 \mathrm{MHz}, \mathrm{DMSO}-d_{6}\right) \delta: 10.58(2 \mathrm{H}, \mathrm{s}, 2 \mathrm{NH}), 8.04(2 \mathrm{H}, \mathrm{d}, J=$ $8.2,2 \mathrm{H}-4), 7.83(2 \mathrm{H}, \mathrm{d}, J=8.2,2 \mathrm{H}-7), 7.65(4 \mathrm{H}, \mathrm{d}, J=8.2,2 \mathrm{H}-$ $\left.2^{\prime}, 6^{\prime}\right), 7.53(2 \mathrm{H}, \mathrm{t}, 2 \mathrm{H}-5) 7.43(2 \mathrm{H}, \mathrm{t}, 2 \mathrm{H}-6) 7.34(4 \mathrm{H}, \mathrm{d}, J=8.4$, $\left.2 \mathrm{H}-3^{\prime}, 5^{\prime}\right), 7.14(2 \mathrm{H}, \mathrm{s}, \mathrm{CH}=\mathrm{CH}), 5.94\left(4 \mathrm{H}, \mathrm{s}, 2 \mathrm{CH}_{2}\right) .{ }^{13} \mathrm{C}-\mathrm{NMR}$ $\left(\mathrm{DMSO}-d_{6}\right) \delta$ : $162.1(2 \mathrm{CO}), 143.3(2 \mathrm{C}), 138.6(2 \mathrm{C}), 134.0(2 \mathrm{CH})$, $132.5(2 \mathrm{C}), 131.1(2 \mathrm{C}), 128.5(2 \mathrm{CH}), 128.4(2 \mathrm{CH}), 127.4(2 \mathrm{CH})$, $124.0(2 \mathrm{CH}), 119.6(2 \mathrm{CH}), 119.5(2 \mathrm{CH}), 119.2(2 \mathrm{CH}), 110.7$ $(2 \mathrm{CH}), 50.7\left(2 \mathrm{CH}_{2}\right) . \mathrm{C}_{30} \mathrm{H}_{24} \mathrm{~N}_{8} \mathrm{O}_{2}$; $\mathrm{MW}$ 528.56; Elem. Anal.: Calcd C 64.76, H 5.72, N 15.90 Found C 64.33, H 5.54, N 16.20. LC/MS: $m / z 353[\mathrm{M}+\mathrm{H}]^{+}$.

\section{(E)-4-((4-((1H-Benzo[d][1,2,3]Triazol-1-yl) methyl)phenyl)amino)-4-oxobut-2-enoic}

\section{Acid (10d)}

Compound 10d was obtained in $30 \%$ total yield; m.p. $290-293^{\circ} \mathrm{C}$; TLC (chloroform/methanol 9.5/0.5); $\quad \mathrm{R}_{f}=0.11 ;{ }^{1} \mathrm{H}-\mathrm{NMR}$ $\left(200 \mathrm{MHz}, \mathrm{DMSO}-d_{6}\right) \delta: 10.22(1 \mathrm{H}, \mathrm{s}, \mathrm{NH}), 8.04(1 \mathrm{H}, \mathrm{d}, J=$ 7.6, H-4), $7.82(1 \mathrm{H}, \mathrm{d}, J=9.0, \mathrm{H}-7), 7.63\left(2 \mathrm{H}, \mathrm{d}, J=8.2, \mathrm{H}-2^{\prime}, 6^{\prime}\right)$, $7.52(1 \mathrm{H}, \mathrm{t}, \mathrm{H}-5) 7.42(1 \mathrm{H}, \mathrm{t}, \mathrm{H}-6) 7.30\left(2 \mathrm{H}, \mathrm{d}, J=8.2, \mathrm{H}-3^{\prime}, 5^{\prime}\right)$, $6.61(2 \mathrm{H}, \mathrm{s}, \mathrm{CH}=\mathrm{CH}), 5.91\left(2 \mathrm{H}, \mathrm{s}, \mathrm{CH}_{2}\right) .{ }^{13} \mathrm{C}-\mathrm{NMR}\left(\mathrm{DMSO}-d_{6}\right)$ $\delta$ : $168.1(\mathrm{CO}), 164.0(\mathrm{CO}), 145.4(\mathrm{C}), 139.1(\mathrm{C}), 134.0(2 \mathrm{CH})$, $132.5(\mathrm{C}), 130.5(\mathrm{C}), 130.0(\mathrm{CH}), 128.4(2 \mathrm{CH}), 127.3(\mathrm{CH}), 124.0$
$(\mathrm{CH}), 119.6(\mathrm{CH}), 119.4(\mathrm{CH}), 119.2(\mathrm{CH}), 110.7(\mathrm{CH}), 50.7$ $\left(\mathrm{CH}_{2}\right) \cdot \mathrm{C}_{17} \mathrm{H}_{14} \mathrm{~N}_{4} \mathrm{O}_{3}$; MW 322.32; Elem. Anal.: Calcd C 63.35, H 4.38, N 17.38 Found C 63.35, H 4.40, N 17.25. LC/MS: $m / z 353$ $[\mathrm{M}+\mathrm{H}]^{+}$.

\section{$N^{1}, N^{4}-B i s(4-((1 H-B e n z o[d][1,2,3]$ Triazol-1-yl)methyl)phenyl) Terephthalamide (7e)}

Compound 7e was obtained in $15 \%$ total yield; m.p. $>300^{\circ} \mathrm{C}$; TLC (chloroform/methanol 9.5/0.5); $\mathrm{R}_{f}=0.43 ;{ }^{1} \mathrm{H}-\mathrm{NMR}(200 \mathrm{MHz}$, DMSO- $\left.d_{6}\right) \delta: 10.44(2 \mathrm{H}, s, 2 \mathrm{NH}), 8.04-8.01(4 \mathrm{H}, \mathrm{m}, \mathrm{H}-$ $\left.2^{\prime \prime}, 3^{\prime \prime}, 5^{\prime \prime}, 6^{\prime \prime}\right), 7.87-7.82\left(4 \mathrm{H}, \mathrm{m}, 4 \mathrm{H}_{\text {arom }}\right), 7.75(4 \mathrm{H}, \mathrm{d}, J=8.4$, $\left.2 \mathrm{H}-2^{\prime}, 6^{\prime}\right), 7.60-7.42\left(4 \mathrm{H}, \mathrm{m}, 4 \mathrm{H}_{\text {arom }}\right), 7.36(4 \mathrm{H}, \mathrm{d}, J=8.4,2 \mathrm{H}-$ $\left.3^{\prime}, 5^{\prime}\right), 5.95\left(4 \mathrm{H}, \mathrm{s}, 2 \mathrm{CH}_{2}\right) .{ }^{13} \mathrm{C}-\mathrm{NMR}\left(\mathrm{DMSO}-d_{6}\right) \delta: 164.8(2 \mathrm{CO})$, 145.4 (2C), 138.8 (2C), 138.5 (C), 133.4 (C), 132.6 (2C), 131.1 (2C), $129.4(2 \mathrm{CH}), 129.2(2 \mathrm{CH}), 128.3(4 \mathrm{CH}), 127.9(4 \mathrm{CH}), 127.4$ $(\mathrm{CH}), 124.0(\mathrm{CH}), 120.6(4 \mathrm{CH}), 119.2(\mathrm{CH}), 110.7(\mathrm{CH}), 50.7$ $\left(2 \mathrm{CH}_{2}\right) \cdot \mathrm{C}_{34} \mathrm{H}_{26} \mathrm{~N}_{8} \mathrm{O}_{2}$; MW 578.62; Elem. Anal.: Calcd C 70.58, $\mathrm{H}$ 4.53, N 19.37 Found C 70.43, H 4.88, N 19.39. LC/MS: $m / z 579$ $[\mathrm{M}+\mathrm{H}]^{+}$.

\section{4-(4-((1H-Benzo[d][1,2,3]Triazol-1-yl)} methyl)phenylcarbamoyl)Benzoic Acid (10e) Compound 10e was obtained in $30 \%$ total yield; m.p. $>300^{\circ} \mathrm{C}$; TLC (chloroform/methanol 9.5/0.5); $\quad \mathrm{R}_{f}=0.12 ;{ }^{1} \mathrm{H}-\mathrm{NMR}$ $\left(200 \mathrm{MHz}, \mathrm{DMSO}-d_{6}\right) \delta: 10.44(\mathrm{H}, \mathrm{s}, \mathrm{NH}), 8.06-8.00(4 \mathrm{H}, \mathrm{m}$, $\left.\mathrm{H}-2^{\prime \prime}, 3^{\prime \prime}, 5^{\prime \prime}, 6^{\prime \prime}\right), 7.85\left(1 \mathrm{H}, \mathrm{d}, J=8.0,1 \mathrm{H}_{\text {arom }}\right), 7.78(2 \mathrm{H}, \mathrm{d}, J=8.4$, $\left.\mathrm{H}-2^{\prime}, 6^{\prime}\right), 7.54\left(1 \mathrm{H}, \mathrm{t}, J=7.2,1 \mathrm{H}_{\text {arom }}\right), 7.42-7.40\left(2 \mathrm{H}, \mathrm{m}, 2 \mathrm{H}_{\text {arom }}\right)$, $7.36\left(2 \mathrm{H}, \mathrm{d}, J=8.4, \mathrm{H}-3^{\prime}, 5^{\prime}\right), 5.95\left(2 \mathrm{H}, \mathrm{s}, \mathrm{CH}_{2}\right) .{ }^{13} \mathrm{C}-\mathrm{NMR}$ $\left(\mathrm{DMSO}-d_{6}\right) \delta: 167.8(\mathrm{CO}), 165.4(\mathrm{CO}), 145.4(\mathrm{C}), 138.9$ (C), 137.0 (2C), $132.6(\mathrm{C}), 131.5(\mathrm{C}), 129.1(\mathrm{CH}), 127.5$ $(\mathrm{CH}), 127.4(\mathrm{CH}), 126.7(\mathrm{CH}), 126.5(2 \mathrm{CH}), 124.0(\mathrm{CH})$, $120.7(2 \mathrm{CH}), 120.6(\mathrm{CH}), 117.8(\mathrm{CH}), 110.7(\mathrm{CH}), 50.7$ $\left(\mathrm{CH}_{2}\right) . \mathrm{C}_{21} \mathrm{H}_{16} \mathrm{~N}_{4} \mathrm{O}_{3}$; MW 372,38; Elem. Anal.: Calcd C 67.73, H 4.33, N 15.05 Found C 67.63, H 4.22, N 15.35. LC/MS: $m / z 373[\mathrm{M}+\mathrm{H}]^{+}$.

\section{$N^{2}, N^{6}-\operatorname{Bis}(4-((1 H-B e n z o[d][1,2,3]$ Triazol-1-yl)methyl)phenyl) Pyridine-2,6-dicarboxamide (7f)}

Compound 7f was obtained in 25\% total yield; m.p. 111-112 ${ }^{\circ} \mathrm{C}$; TLC (chloroform/methanol 9.5/0.5); $\mathrm{R}_{f}=0.50 ;{ }^{1} \mathrm{H}-\mathrm{NMR}$ $\left(200 \mathrm{MHz}, \mathrm{DMSO}-d_{6}\right) \delta: 11.00(2 \mathrm{H}, \mathrm{s}, 2 \mathrm{NH}), 8.38-8.28(3 \mathrm{H}, \mathrm{m}$, $\left.\mathrm{H}-3^{\prime \prime}, 4^{\prime \prime}, 5^{\prime \prime}\right), 8.06\left(4 \mathrm{H}, \mathrm{d}, J=8.2,4 \mathrm{H}_{\text {arom }}\right), 7.86(4 \mathrm{H}, \mathrm{d}, J=7.8$, $\left.2 \mathrm{H}-2^{\prime}, 6^{\prime}\right), 7.57-7.50\left(4 \mathrm{H}, \mathrm{m}, 4 \mathrm{H}_{\text {arom }}\right), 7.42(4 \mathrm{H}, \mathrm{d}, J=7.8,2 \mathrm{H}-$ $\left.3^{\prime}, 5^{\prime}\right), 5.99\left(4 \mathrm{H}, \mathrm{s}, 2 \mathrm{CH}_{2}\right) .{ }^{13} \mathrm{C}-\mathrm{NMR}$ (DMSO- $\left.d_{6}\right) \delta: 161.6$ (2CO), $148.7(2 \mathrm{C}), 145.4(2 \mathrm{C}), 140.0(\mathrm{CH}), 137.8(2 \mathrm{C})$, $132.6(2 \mathrm{C}), 131.7(2 \mathrm{C}), 128.4(4 \mathrm{CH}), 127.4(2 \mathrm{CH}), 125.3$ $(2 \mathrm{CH}), \quad 124.0(2 \mathrm{CH}), 121.3(4 \mathrm{CH}), 119.2(2 \mathrm{CH}), 110.7$ (2CH), $50.7\left(2 \mathrm{CH}_{2}\right) . \mathrm{C}_{33} \mathrm{H}_{25} \mathrm{~N}_{9} \mathrm{O}_{2}$; MW 579.61; Elem. Anal.: Calcd C 68.38, H 4.35, N 21.75 Found C 68.40, H 4.35, N 22.00. LC/MS: $m / z 580[\mathrm{M}+\mathrm{H}]^{+}$. 
6-(4-((1H-Benzo[d][1,2,3]Triazol-1-yl) methyl)phenylcarbamoyl)Picolinic Acid (10f) Compound 10f was obtained in $30 \%$ total yield; m.p. $230-232{ }^{\circ} \mathrm{C}$; TLC (chloroform/methanol 9.5/0.5); $\quad \mathrm{R}_{f}=0.10 ;{ }^{1} \mathrm{H}-\mathrm{NMR}$ $\left(200 \mathrm{MHz}, \mathrm{DMSO}-d_{6}\right) \delta: 11.00(\mathrm{H}, \mathrm{s}, \mathrm{NH}), 8.40-8.32(3 \mathrm{H}, \mathrm{m}$, $\left.\mathrm{H}-3^{\prime \prime}, 4^{\prime \prime}, 5^{\prime \prime}\right), 8.06\left(2 \mathrm{H}, \mathrm{d}, J=8.2,2 \mathrm{H}_{\text {arom }}\right), 7.86(2 \mathrm{H}, \mathrm{d}, J=7.8, \mathrm{H}-$ $\left.2^{\prime}, 6^{\prime}\right), 7.57-7.50\left(2 \mathrm{H}, \mathrm{m}, 2 \mathrm{H}_{\text {arom }}\right), 7.42\left(\mathrm{H}, \mathrm{d}, J=7.8, \mathrm{H}-3^{\prime}, 5^{\prime}\right), 5.99$ $\left(2 \mathrm{H}, \mathrm{s}, \mathrm{CH}_{2}\right) .{ }^{13} \mathrm{C}-\mathrm{NMR}\left(\mathrm{DMSO}-d_{6}\right) \delta: 166.8(\mathrm{CO}), 162.8(\mathrm{CO})$, $153.2(\mathrm{C}), 148.9$ (C), $145.4(2 \mathrm{C}), 138.4$ (C), 132.6 (C), 127.4 $(2 \mathrm{CH}), 124.0(2 \mathrm{CH}), 123.2(\mathrm{CH}), 120.6(2 \mathrm{CH}), 119.2(2 \mathrm{CH})$, $110.7(2 \mathrm{CH}), 50.7\left(\mathrm{CH}_{2}\right) . \mathrm{C}_{20} \mathrm{H}_{15} \mathrm{~N}_{5} \mathrm{O}_{3}$; MW 373.36; Elem. Anal.: Calcd C 64.34, H 4.05, N 18.76 Found C 64.34, H 4.35, N 18.80 LC/MS: $m / z 374[\mathrm{M}+\mathrm{H}]^{+}$.

\section{$N^{2}, N^{5}-B i s(4-((1 H-B e n z o[d][1,2,3]$ Triazol-1-yl)methyl)phenyl) \\ Thiophene-2,5-Dicarboxamide (7g)}

Compound $7 \mathbf{g}$ was obtained in $20 \%$ total yield; m.p. $>300{ }^{\circ} \mathrm{C}$; TLC (chloroform/methanol 9.5/0.5); $\mathrm{R}_{f}=0.31 ;{ }^{1} \mathrm{H}-\mathrm{NMR}(200 \mathrm{MHz}$, DMSO- $\left.d_{6}\right) \delta: 10.27(2 \mathrm{H}, \mathrm{s}, 2 \mathrm{NH}), 8.15-8.07(2 \mathrm{H}, \mathrm{d}, J=8.4, \mathrm{H}-$ $\left.3^{\prime \prime}, 4^{\prime \prime}\right), 7.80-7.76\left(4 \mathrm{H}, \mathrm{m}, 4 \mathrm{H}_{\text {arom }}\right), 7.64\left(4 \mathrm{H}, \mathrm{d}, J=8.2,2 \mathrm{H}-2^{\prime}, 6^{\prime}\right)$, $7.46\left(2 \mathrm{H}, \mathrm{t}, J=7.2,2 \mathrm{H}_{\text {arom }}\right), 7.32\left(2 \mathrm{H}, \mathrm{t}, J=7.2,2 \mathrm{H}_{\text {arom }}\right), 7.70(4 \mathrm{H}$, $\left.\mathrm{d}, J=8.2,2 \mathrm{H}-3^{\prime}, 5^{\prime}\right), 5.94\left(4 \mathrm{H}, \mathrm{s}, 2 \mathrm{CH}_{2}\right) .{ }^{13} \mathrm{C}-\mathrm{NMR}\left(\mathrm{DMSO}-d_{6}\right) \delta$ : 160.1 (2CO), 145.3 (2C), 140.9 (2C), 138.6 (2C), 132.6 (2C), 130.9 (2C), $129.5(2 \mathrm{CH}), 128.3(4 \mathrm{CH}), 127.4(2 \mathrm{CH}), 124.0(2 \mathrm{CH}), 120.6$ $(2 \mathrm{CH}), 120.5(2 \mathrm{CH}), 119.2(2 \mathrm{CH}), 110.7(2 \mathrm{CH}), 50.7\left(2 \mathrm{CH}_{2}\right)$. $\mathrm{C}_{32} \mathrm{H}_{24} \mathrm{~N}_{8} \mathrm{O}_{2} \mathrm{~S}$; MW 584.65; Elem. Anal.: Calcd C 65.74, H 4.14, N 19.17 Found C 65.44, H 4.24, N 19.32 LC/MS: $m / z 585[\mathrm{M}+\mathrm{H}]^{+}$.

\section{5-(4-((1H-Benzo[d][1,2,3]Triazol-1-yl) methyl)phenylcarbamoyl) thiophene-2-Carboxylic Acid (10g)}

Compound $10 \mathrm{~g}$ was obtained in $25 \%$ total yield; m.p. $>300^{\circ} \mathrm{C}$; TLC (chloroform/methanol 9.5/0.5); $\quad \mathrm{R}_{f}=0.10 ;{ }^{1} \mathrm{H}-\mathrm{NMR}$ $\left(200 \mathrm{MHz}, \mathrm{DMSO}-d_{6}\right) \delta: 10.27(\mathrm{H}, \mathrm{s}, \mathrm{NH}), 8.06-8.04(2 \mathrm{H}, \mathrm{d}$, $\left.J=8.4, \mathrm{H}-3^{\prime \prime}, 4^{\prime \prime}\right), 7.85\left(2 \mathrm{H}, \mathrm{d}, J=8.2,2 \mathrm{H}-2^{\prime}, 6^{\prime}\right), 7.70(4 \mathrm{H}, \mathrm{d}, J=$ $\left.8.2,2 \mathrm{H}-3^{\prime}, 5^{\prime}\right), 7.52\left(\mathrm{H}, \mathrm{t}, J=7.2, \mathrm{H}_{\text {arom }}\right), 7.40\left(\mathrm{H}, \mathrm{t}, J=7.2, \mathrm{H}_{\text {arom }}\right)$, $7.35\left(2 \mathrm{H}, \mathrm{d}, J=8.2,2 \mathrm{H}_{\text {arom }}\right) 5.94\left(2 \mathrm{H}, \mathrm{s}, \mathrm{CH}_{2}\right) .{ }^{13} \mathrm{C}-\mathrm{NMR}$ (DMSO$\left.d_{6}\right) \delta: 160.1(2 \mathrm{CO}), 145.3(2 \mathrm{C}), 140.9(2 \mathrm{C}), 138.6(2 \mathrm{C}), 132.6(2 \mathrm{C})$, $130.9(2 \mathrm{C}), 129.5(2 \mathrm{CH}), 128.3(4 \mathrm{CH}), 127.4(2 \mathrm{CH}), 124.0(2 \mathrm{CH})$, $120.6(2 \mathrm{CH}), 120.5(2 \mathrm{CH}), 119.2(2 \mathrm{CH}), 110.7(2 \mathrm{CH}), 50.7$ $\left(2 \mathrm{CH}_{2}\right) . \mathrm{C}_{19} \mathrm{H}_{14} \mathrm{~N}_{4} \mathrm{O}_{3} \mathrm{~S}$; MW 378.40; Elem. Anal.: Calcd C 60.31, H 3.73, N 14.81 Found C 60.05, H 3.71, N 14.65 LC/ MS: $m / z 379[\mathrm{M}+\mathrm{H}]^{+}$.

\section{$N^{1}, N^{4}$-Bis(4-((5,6-Dimethyl-1H-Benzo[d] $[1,2,3]$ Triazol-1-yl)methyl)phenyl) Succinamide (8a)}

Compound 8a was obtained in $20 \%$ total yield; m.p. $270-272^{\circ} \mathrm{C}$; TLC (chloroform/methanol 9.8/0.2); $\mathrm{R}_{f}=0.31 ;{ }^{1} \mathrm{H}-\mathrm{NMR}$ $\left(200 \mathrm{MHz}, \mathrm{DMSO}-d_{6}\right) \delta: 10.02(2 \mathrm{H}, \mathrm{s}, 2 \mathrm{NH}), 7.78(2 \mathrm{H}, \mathrm{s}, 2 \mathrm{H}-$ 4), $7.56(2 \mathrm{H}, \mathrm{s}, 2 \mathrm{H}-7), 7.54\left(4 \mathrm{H}, \mathrm{d}, J=10.0,2 \mathrm{H}-2^{\prime}, 6^{\prime}\right), 7.23(4 \mathrm{H}, \mathrm{d}$, $\left.J=10.0,2 \mathrm{H}-3^{\prime}, 5^{\prime}\right), 5.82\left(4 \mathrm{H}, \mathrm{s}, 2 \mathrm{CH}_{2}\right), 2.40\left(4 \mathrm{H}, \mathrm{s}, 2 \mathrm{CH}_{2}\right), 2.35$ $\left(12 \mathrm{H}, \mathrm{s}, 4 \mathrm{CH}_{2}\right),{ }^{13} \mathrm{C}-\mathrm{NMR}$ (DMSO- $\left.d_{6}\right) \delta: 170.3(2 \mathrm{CO}), 144.6$ (2C), 139.0 (2C), 137.3 (2C), 133.4 (2C), 131.7 (2C), 130.3 (2C), $128.2(4 \mathrm{CH}), 119.1(4 \mathrm{CH}), 118.2(2 \mathrm{CH}), 109.6(2 \mathrm{CH}), 50.5$ $\left(2 \mathrm{CH}_{2}\right), 29.0\left(\mathrm{CH}_{2}\right), 28.7\left(\mathrm{CH}_{2}\right), 20.3\left(2 \mathrm{CH}_{3}\right), 19.8\left(2 \mathrm{CH}_{3}\right)$. $\mathrm{C}_{34} \mathrm{H}_{34} \mathrm{~N}_{8} \mathrm{O}_{2}$; MW 586.69; Elem. Anal.: Calcd C 69.61, H 5.84, N 19.10 Found C 69.64, H 5.74, N 19.00. LC/MS: $m / z 587[\mathrm{M}$ $+\mathrm{H}]^{+}$.

\section{4-((4-)(5,6-Dimethyl-1H-Benzo[d][1,2,3] Triazol-1-yl)methyl)phenyl) amino)-4-Oxobutanoic Acid (11a)}

Compound 11a was obtained in $10 \%$ total yield; m.p. $218-220^{\circ} \mathrm{C}$; TLC (chloroform/methanol 9/1); $\mathrm{R}_{f}=0.41 ;{ }^{1} \mathrm{H}-\mathrm{NMR}(200 \mathrm{MHz}$, DMSO- $\left.d_{6}\right) \delta: 10.02(1 \mathrm{H}, \mathrm{s}, \mathrm{NH}), 7.78(1 \mathrm{H}, \mathrm{s}, \mathrm{H}-4), 7.55(1 \mathrm{H}, \mathrm{s}$, $\mathrm{H}-7), 7.53\left(2 \mathrm{H}, \mathrm{d}, J=8.6, \mathrm{H}-2^{\prime}, 6^{\prime}\right), 7.23\left(2 \mathrm{H}, \mathrm{d}, J=8.6, \mathrm{H}-3^{\prime}, 5^{\prime}\right)$, $5.80\left(2 \mathrm{H}, \mathrm{s}, \mathrm{CH}_{2}\right), 2.50\left(4 \mathrm{H}, \mathrm{s}, 2 \mathrm{CH}_{2}\right), 2.34\left(6 \mathrm{H}, \mathrm{s}, \mathrm{CH}_{3}\right)$. ${ }^{13} \mathrm{C}$-NMR (DMSO- $d_{6}$ ) $\delta: 174.1(\mathrm{CO}), 170.3$ (CO), $144.6(\mathrm{C})$, $139.1(\mathrm{C}), 137.3(\mathrm{C}), 133.4(\mathrm{C}), 131.6(\mathrm{C}), 130.2(\mathrm{C}), 128.1(2 \mathrm{CH})$, $119.0(\mathrm{CH}), 109.7(\mathrm{CH}), 50.5\left(\mathrm{CH}_{2}\right), 32.0\left(\mathrm{CH}_{2}\right), 31.3\left(\mathrm{CH}_{2}\right), 19.8$ $\left(\mathrm{CH}_{3}\right), 18.6\left(\mathrm{CH}_{3}\right) . \mathrm{C}_{19} \mathrm{H}_{20} \mathrm{~N}_{4} \mathrm{O}_{3}$; MW 352.39; Elem. Anal.: Calcd C 64.76, H 5.72, N 15.90 Found C 64.72, H 5.72, N 15.80. LC/MS: $\mathrm{m} / z 353[\mathrm{M}+\mathrm{H}]^{+}$.

\section{$N^{1}, N^{5}$-Bis(4-((5,6-Dimethyl-1H-Benzo[d] $[1,2,3]$ Triazol-1-yl)methyl)phenyl) Glutaramide (8b)}

Compound $\mathbf{8 b}$ was obtained in $18 \%$ total yield; m. p. $253-255^{\circ} \mathrm{C}$; TLC (chloroform/methanol 9.8/0.2); $\mathrm{R}_{f}=0.54 ;{ }^{1} \mathrm{H}-\mathrm{NMR}$ $\left(200 \mathrm{MHz}, \mathrm{DMSO}-d_{6}\right) \delta: 9.95(2 \mathrm{H}, \mathrm{s}, 2 \mathrm{NH}), 7.79(2 \mathrm{H}, \mathrm{s}, 2 \mathrm{H}-$ 4), $7.65(2 \mathrm{H}, \mathrm{s} 2 \mathrm{H}-7), 7.60\left(4 \mathrm{H}, \mathrm{d}, J=8.6, \mathrm{H}-2^{\prime}, 6^{\prime}\right), 7.28(4 \mathrm{H}, \mathrm{d}, J=$ 8.6, $\left.2 \mathrm{H}-3^{\prime}, 5^{\prime}\right), 5.81\left(4 \mathrm{H}, \mathrm{s}, 2 \mathrm{CH}_{2}\right), 2.42\left(4 \mathrm{H}, \mathrm{t}, 2 \mathrm{CH}_{2} \mathrm{CO}\right), 2.35$ $\left(12 \mathrm{H}, \mathrm{s}, 4 \mathrm{CH}_{3}\right), 1.86\left(2 \mathrm{H}, \mathrm{m}, \mathrm{CH}_{2}\right) .{ }^{13} \mathrm{C}-\mathrm{NMR}$ (DMSO- $\left.d_{6}\right) \delta$ : 171.7 (2CO), 144.0 (2C), $139.6(2 \mathrm{C}), 137.8(2 \mathrm{C}), 133.9(2 \mathrm{C}), 132.0$ (2C), $130.7(2 \mathrm{C}), 128.6(4 \mathrm{CH}), 119.7(2 \mathrm{CH}), 119.6(2 \mathrm{CH}), 118.5$ $(2 \mathrm{CH}), 109.6(2 \mathrm{CH}), 51.0\left(2 \mathrm{CH}_{2}\right), 36.3\left(2 \mathrm{CH}_{2}\right), 21.7\left(\mathrm{CH}_{2}\right), 20.7$ $\left(2 \mathrm{CH}_{3}\right), 20.3\left(2 \mathrm{CH}_{3}\right) . \mathrm{C}_{35} \mathrm{H}_{36} \mathrm{~N}_{8} \mathrm{O}_{2}$; $\mathrm{MW}$ 600.71; Elem. Anal.: Calcd C 69.98, H 6.04, N 18.65 Found C 70.00, H 6.21, N 18.70. LC/MS: $m / z 601[\mathrm{M}+\mathrm{H}]^{+}$.

\section{5-((4-((5,6-Dimethyl-1H-Benzo[d] $[1,2,3]$ Triazol-1-yl)methyl)phenyl) amino)-5-Oxopentanoic Acid (11b)}

Compound $11 \mathbf{b}$ was obtained in $25 \%$ total yield; m.p. $270-272^{\circ} \mathrm{C}$; TLC (chloroform/methanol 9/1); $\mathrm{R}_{f}=0.35 ;{ }^{1} \mathrm{H}-\mathrm{NMR}(200 \mathrm{MHz}$, DMSO- $\left.d_{6}\right) \delta: 10.35(1 \mathrm{H}, \mathrm{s}, \mathrm{NH}), 7.78(1 \mathrm{H}, \mathrm{s}, \mathrm{H}-4), 7.55(3 \mathrm{H}, \mathrm{d}$, $J=8.6, \mathrm{H}-7$ e H-2 $\left.{ }^{\prime}, 6^{\prime}\right), 7.23\left(2 \mathrm{H}, \mathrm{d}, J=8.4, \mathrm{H}-3^{\prime}, 5^{\prime}\right), 5.80(2 \mathrm{H}, \mathrm{s}$, $\left.\mathrm{CH}_{2}\right), 2.34\left(6 \mathrm{H}, \mathrm{s}, 2 \mathrm{CH}_{3}\right), 2.02\left(4 \mathrm{H}, \mathrm{t}, 2 \mathrm{CH}_{2} \mathrm{CO}\right), 1.72(2 \mathrm{H}, \mathrm{m}$, $\mathrm{CH}_{2}$ ). ${ }^{13} \mathrm{C}-\mathrm{NMR}$ (DMSO- $d_{6}$ ) $\delta: 174.5(\mathrm{CO}), 170.9(\mathrm{CO}), 145.3$ (C), $139.1(\mathrm{C}), 136.8(2 \mathrm{C}) 132.5(\mathrm{C}), 130.1(\mathrm{C}), 128.6(2 \mathrm{CH}), 124.3$ $(2 \mathrm{CH}), 122.0(2 \mathrm{CH}), 50.7\left(\mathrm{CH}_{2}\right), 35.4\left(2 \mathrm{CH}_{2}\right), 20.5\left(\mathrm{CH}_{2}\right)$. $\mathrm{C}_{20} \mathrm{H}_{22} \mathrm{~N}_{4} \mathrm{O}_{3}$; MW 366.41; Elem. Anal.: Calcd C 65.56, H 6.05, $\mathrm{N} 15.29$ Found C 70.00, H 6.21, N 18.70. LC/MS: $\mathrm{m} / z 367$ $[\mathrm{M}+\mathrm{H}]^{+}$. 


\section{$N^{1}, N^{6}$-Bis(4-((5,6-Dimethyl-1H-Benzo[d] $[1,2,3]$ Triazol-1-yl)methyl)phenyl) Adipamide (8c)}

Compound 8c was obtained in $23 \%$ total yield; m.p. 283-285 ${ }^{\circ}$; TLC (chloroform/methanol 9.8/0.2); $\mathrm{R}_{f}=0.30$; ${ }^{1} \mathrm{H}-\mathrm{NMR}\left(200 \mathrm{MHz}, \mathrm{DMSO}-d_{6}\right) \delta: 9.90(2 \mathrm{H}, \mathrm{s}, 2 \mathrm{NH}), 7.78$ (2H, s, 2H-4), 7.57 (2H, s 2H-7), $7.52\left(4 \mathrm{H}, \mathrm{d}, J=8.6, \mathrm{H}-2^{\prime}, 6^{\prime}\right)$, $7.23\left(4 \mathrm{H}, \mathrm{d}, J=8.6,2 \mathrm{H}-3^{\prime}, 5^{\prime}\right), 5.81\left(4 \mathrm{H}, \mathrm{s}, 2 \mathrm{CH}_{2}\right), 2.34(12 \mathrm{H}, \mathrm{s}$, $\left.4 \mathrm{CH}_{3}\right), 2.25\left(4 \mathrm{H}, \mathrm{t}, 2 \mathrm{CH}_{2} \mathrm{CO}\right), 1.56\left(4 \mathrm{H}, \mathrm{t}, 2 \mathrm{CH}_{2}\right) .{ }^{13} \mathrm{C}-\mathrm{NMR}$ $\left(\mathrm{DMSO}-d_{6}\right) \delta: 171.1(2 \mathrm{CO}), 144.6(2 \mathrm{C}), 139.0$ (2C), $137.3(2 \mathrm{C})$, $133.4(2 \mathrm{C}), 131.6(2 \mathrm{C}), 130.3(2 \mathrm{C}), 128.1(4 \mathrm{CH}), 119.2(4 \mathrm{CH})$, $118.1(2 \mathrm{CH}), 109.7(2 \mathrm{CH}), 50.5\left(2 \mathrm{CH}_{2}\right), 36.2\left(2 \mathrm{CH}_{2}\right), 28.6$ $\left(2 \mathrm{CH}_{2}\right), 20.3\left(2 \mathrm{CH}_{3}\right), 19.8\left(2 \mathrm{CH}_{3}\right) . \mathrm{C}_{36} \mathrm{H}_{38} \mathrm{~N}_{8} \mathrm{O}_{2} ; \mathrm{MW} 614.74 ;$ Elem. Anal.: Calcd C 70.34, H 6.23, N 18.23 Found C 70.14, H 6.28, N 18.23. LC/MS: $m / z 615[\mathrm{M}+\mathrm{H}]^{+}$.

\section{6-((4-)(5,6-Dimethyl-1H-Benzo[d][1,2,3] Triazol-1-yl)methyl)phenyl) amino)-6-Oxohexanoic Acid (11c)}

Compound 11c was obtained in 30\% total yield; m.p. $203-204{ }^{\circ} \mathrm{C}$; TLC (chloroform/methanol 9.5/0.5); $\mathrm{R}_{f}=0.20 ;{ }^{1} \mathrm{H}-\mathrm{NMR}$ $\left(200 \mathrm{MHz}, \mathrm{DMSO}-d_{6}\right) \delta: 9.91(1 \mathrm{H}, \mathrm{s}, \mathrm{NH}), 7.78(1 \mathrm{H}, \mathrm{s}, \mathrm{H}-4)$, $7.69(1 \mathrm{H}, \mathrm{s} \mathrm{H}-7), 7.55\left(2 \mathrm{H}, \mathrm{d}, J=8.2, \mathrm{H}-2^{\prime}, 6^{\prime}\right), 7.23(2 \mathrm{H}, \mathrm{d}, J=8.2$, $\left.\mathrm{H}-3^{\prime}, 5^{\prime}\right), 5.81\left(2 \mathrm{H}, \mathrm{s}, \mathrm{CH}_{2}\right), 2.27\left(6 \mathrm{H}, \mathrm{s}, 2 \mathrm{CH}_{3}\right), 2.24(4 \mathrm{H}, \mathrm{m}$, $2 \mathrm{CH}_{2} \mathrm{CO}$ ), $1.52\left(4 \mathrm{H}, \mathrm{m}, \mathrm{CH}_{2} \mathrm{CH}_{2}\right) .{ }^{13} \mathrm{C}-\mathrm{NMR}$ (DMSO- $\left.d_{6}\right) \delta$ : 174.8 (CO), 171.5 (CO), 145.0 (C), 139.5 (C), 137.8 (C), 133.9 (C), $132.1(\mathrm{C}), 130.8(\mathrm{C}), 128.6(2 \mathrm{CH}), 119.7(2 \mathrm{CH}), 118.6(\mathrm{CH})$, $110.2(\mathrm{CH}), 50.9\left(\mathrm{CH}_{2}\right), 36.5\left(\mathrm{CH}_{2}\right), 33.8\left(\mathrm{CH}_{2}\right), 25.0\left(\mathrm{CH}_{2}\right), 24.6$ $\left(\mathrm{CH}_{2}\right), 20.8\left(\mathrm{CH}_{3}\right), 20.3\left(\mathrm{CH}_{3}\right) . \mathrm{C}_{21} \mathrm{H}_{24} \mathrm{~N}_{4} \mathrm{O}_{3} ; \mathrm{MW}$ 380.44; Elem. Anal.: Calcd C 66.30, H 6.36, N 14.73 Found C 66.30, H 6.46, N 15.00. LC/MS: $m / z 381[\mathrm{M}+\mathrm{H}]^{+}$.

\section{$N^{1}, N^{4}$-Bis(4-((5,6-Dimethyl-1H-Benzo[d] $[1,2,3]$ Triazol-1-yl)methyl)phenyl) Fumaramide (8d)}

Compound 8d was obtained in $10 \%$ total yield; m.p. $117-119^{\circ} \mathrm{C}$; TLC (chloroform/methanol 9.8/0.2) $\quad \mathrm{R}_{f}=0.35 ;{ }^{1} \mathrm{H}-\mathrm{NMR}$ $\left(200 \mathrm{MHz}, \mathrm{DMSO}-d_{6}\right) \delta: 10.30(1 \mathrm{H}, \mathrm{s}, \mathrm{NH}), 7.78(2 \mathrm{H}, \mathrm{s}, 2 \mathrm{H}-$ 4), $7.68(2 \mathrm{H}, \mathrm{s}, 2 \mathrm{H}-7), 7.62\left(4 \mathrm{H}, \mathrm{d}, J=8.6,2 \mathrm{H}-2^{\prime}, 6^{\prime}\right), 7.25(4 \mathrm{H}, \mathrm{d}$, $\left.J=8.6,2 \mathrm{H}-3^{\prime}, 5^{\prime}\right), 6.64(2 \mathrm{H}, \mathrm{s}, \mathrm{CH}=\mathrm{CH}), 5.80\left(4 \mathrm{H}, \mathrm{s}, 2 \mathrm{CH}_{2}\right), 2.34$ $\left(12 \mathrm{H}, \mathrm{s}, 4 \mathrm{CH}_{3}\right) .{ }^{13} \mathrm{C}-\mathrm{NMR}$ (DMSO- $\left.d_{6}\right) \delta: 162.0$ (2CO), 144.6 (2C), $138.4(2 \mathrm{C}), 137.4(2 \mathrm{C}), 134.0(2 \mathrm{CH}), 133.5(2 \mathrm{C}), 131.6(2 \mathrm{C})$, $131.5(2 \mathrm{C}), 128.3(4 \mathrm{CH}), 119.4(4 \mathrm{CH}), 118.1(2 \mathrm{CH}), 109.7(2 \mathrm{CH})$, $50.4\left(2 \mathrm{CH}_{2}\right), 20.4\left(2 \mathrm{CH}_{3}\right), 19.8\left(2 \mathrm{CH}_{3}\right) . \mathrm{C}_{34} \mathrm{H}_{32} \mathrm{~N}_{8} \mathrm{O}_{2} ; \mathrm{MW}$ 584.67; Elem. Anal.: Calcd C 69.85, H 5.52, N 19.17 Found C 69.85, H 5.52, N 19.17. LC/MS: $m / z 585[\mathrm{M}+\mathrm{H}]^{+}$.

\section{$(E)-4-((4-)(5,6-D i m e t h y l-1 H-B e n z o[d][1,2,3]$}

\section{Triazol-1-yl)methyl)phenyl)}

\section{amino)-4-Oxobut-2-Enoic Acid (11d)}

Compound $11 \mathrm{~d}$ was obtained in $20 \%$ total yield; m.p. $256-258^{\circ} \mathrm{C}$; TLC (chloroform/methanol 8.5/1.5); $\quad \mathrm{R}_{f}=0.24 ;{ }^{1} \mathrm{H}-\mathrm{NMR}$ $\left(200 \mathrm{MHz}, \mathrm{DMSO}-d_{6}\right) \delta: 10.29(1 \mathrm{H}, \mathrm{s}, \mathrm{NH}), 7.78(1 \mathrm{H}, \mathrm{s}, \mathrm{H}-4)$,
$7.65(1 \mathrm{H}, \mathrm{s}, \mathrm{H}-7), 7.60\left(2 \mathrm{H}, \mathrm{d}, J=8.6, \mathrm{H}-2^{\prime}, 6^{\prime}\right), 7.25(2 \mathrm{H}, \mathrm{d}, J=8.6$, $\left.\mathrm{H}-3^{\prime}, 5^{\prime}\right), 6.65(2 \mathrm{H}, \mathrm{s}, \mathrm{CH}=\mathrm{CH}), 5.82\left(2 \mathrm{H}, \mathrm{s}, \mathrm{CH}_{2}\right), 2.34(6 \mathrm{H}, \mathrm{s}$, $2 \mathrm{CH}_{3}$ ). ${ }^{13} \mathrm{C}-\mathrm{NMR}$ (DMSO- $\left.d_{6}\right) \delta: 169.2(\mathrm{CO}), 164.1(\mathrm{CO}), 144.6$ (C), $139.1(\mathrm{C}), 137.3(\mathrm{C}), 133.4(\mathrm{CH}), 131.6(\mathrm{C}), 130.6(\mathrm{C}), 128.3$ $(\mathrm{CH}), 128.2(\mathrm{CH}), 119.4(2 \mathrm{CH}), 118.1(2 \mathrm{CH}), 109.7(2 \mathrm{CH}), 50.5$ $\left(\mathrm{CH}_{2}\right), 20.3\left(\mathrm{CH}_{3}\right), 19.8\left(\mathrm{CH}_{3}\right) . \mathrm{C}_{19} \mathrm{H}_{18} \mathrm{~N}_{4} \mathrm{O}_{3}$; MW 350,37; Elem. Anal.: Calcd C 65.13, H 5.18, N 15.99 Found C 65.18, H 5.25, N 15.78. LC/MS: $m / z 351[\mathrm{M}+\mathrm{H}]^{+}$.

\section{$N^{1}, N^{4}$-Bis(4-((5,6-Dimethyl-1H-Benzo[d] [1,2,3]Triazol-1-yl)methyl)phenyl) Trephthalamide (8e)}

Compound 8e was obtained in $10 \%$ total yield; m.p. $250-252{ }^{\circ} \mathrm{C}$; TLC (chloroform/methanol 9.8/0.2); $\mathrm{R}_{f}=0.35 ;{ }^{1} \mathrm{H}-\mathrm{NMR}(200 \mathrm{MHz}$, DMSO- $\left.d_{6}\right) \delta: 10.35(2 \mathrm{H}, \mathrm{s}, 2 \mathrm{NH}), 7.96\left(2 \mathrm{H}, \mathrm{d}, J=7.8, \mathrm{H}-2^{\prime \prime}, 6^{\prime \prime}\right) 7.79$ $(2 \mathrm{H}, \mathrm{s}, 2 \mathrm{H}-4), 7.73\left(4 \mathrm{H}, \mathrm{d}, J=8.2,2 \mathrm{H}-2^{\prime}, 6^{\prime}\right), 7.60(2 \mathrm{H}, \mathrm{s}, 2 \mathrm{H}-7), 7.57$ $\left(2 \mathrm{H}, \mathrm{d}, J=7.8, \mathrm{H}-3^{\prime \prime}, 5^{\prime \prime}\right), 7.30\left(4 \mathrm{H}, \mathrm{d}, J=8.2,2 \mathrm{H}-3^{\prime}, 5^{\prime}\right), 5.86(4 \mathrm{H}, \mathrm{s}$, $\left.2 \mathrm{CH}_{2}\right), 2.35\left(12 \mathrm{H}, \mathrm{s}, 4 \mathrm{CH}_{3}\right) .{ }^{13} \mathrm{C}-\mathrm{NMR}$ (DMSO- $\left.d_{6}\right) \delta: 169.3$ (2CO), 144.6 (2C), 139.4 (2C), 138.3 (2C), 136.5 (2C), 135.3 (2C), 131.6 (2C), $131.3(\mathrm{C}), 131.2(\mathrm{C}), 128.1(4 \mathrm{CH}), 127.8(2 \mathrm{CH}), 127.7(2 \mathrm{CH})$, $120.6(4 \mathrm{CH}), 119.3(2 \mathrm{CH}), 109.7(2 \mathrm{CH}), 50.5\left(2 \mathrm{CH}_{2}\right), 19.8\left(2 \mathrm{CH}_{3}\right)$, $18.6\left(2 \mathrm{CH}_{3}\right) . \mathrm{C}_{38} \mathrm{H}_{34} \mathrm{~N}_{8} \mathrm{O}_{2}$; MW 634.73; Elem. Anal.: Calcd C 71.91, H 5.40, N 17.65 Found C 71.75, H 5.62, N 17.56. LC/MS: $m / z 635$ [M $+\mathrm{H}]^{+}$.

\section{4-((4-((5,6-Dimethyl-1H-Benzo[d][1,2,3] Triazol-1-yl)methyl)phenyl)carbamoyl) Benzoic Acid (11e)}

Compound 11e was obtained in $20 \%$ total yield; m.p. $>300^{\circ} \mathrm{C}$; TLC (chloroform/methanol 8.5/1.5); $\mathrm{R}_{f}=0.37 ;{ }^{1} \mathrm{H}-\mathrm{NMR}$ $\left(200 \mathrm{MHz}, \mathrm{DMSO}-d_{6}\right) \delta: 10.43(1 \mathrm{H}, \mathrm{s}, \mathrm{NH}), 8.00(4 \mathrm{H}, \mathrm{s}, \mathrm{H}-$ $\left.2^{\prime \prime}, 3^{\prime \prime}, 5^{\prime \prime}, 6^{\prime \prime}\right) 7.79(1 \mathrm{H}, \mathrm{s}, \mathrm{H}-4), 7.74\left(2 \mathrm{H}, \mathrm{d}, J=8.4, \mathrm{H}-2^{\prime}, 6^{\prime}\right), 7.61$ (1H, s H-7), $7.31\left(2 \mathrm{H}, \mathrm{d}, J=8.4, \mathrm{H}-3^{\prime}, 5^{\prime}\right), 5.86\left(2 \mathrm{H}, \mathrm{s}, \mathrm{CH}_{2}\right), 2.36$ $\left(6 \mathrm{H}, \mathrm{s}, 2 \mathrm{CH}_{3}\right) .{ }^{13} \mathrm{C}-\mathrm{NMR}$ (DMSO- $\left.d_{6}\right) \delta: 168.3(\mathrm{CO}), 165.6(\mathrm{CO})$, 145.1 (C), 139.3 (C), 137.8 (C), 137.7 (C), 133.9 (2C), 132.1 (C), $131.7(\mathrm{C}), 129.6(2 \mathrm{CH}), 128.5(2 \mathrm{CH}), 128.0(2 \mathrm{CH}), 121.1(2 \mathrm{CH})$, $118.6(\mathrm{CH}), 110.2(\mathrm{CH}), 51.0\left(2 \mathrm{CH}_{2}\right), 20.8\left(\mathrm{CH}_{3}\right), 20.3\left(\mathrm{CH}_{3}\right)$. $\mathrm{C}_{23} \mathrm{H}_{20} \mathrm{~N}_{4} \mathrm{O}_{3}$; MW 400.43; Elem. Anal.: Calcd C 68.99, H 5.03, N 13.99 Found C 68.99, H 5.03, N 13.99. LC/MS: $m / z 401[\mathrm{M}+\mathrm{H}]^{+}$.

\section{$N^{2}, N^{6}$-Bis(4-((5,6-Dimethyl-1H-Benzo[d] $[1,2,3]$ Triazol-1-yl)methyl)phenyl) Pyridine-2,6-Dicarboxamide (8f)}

Compound 8 f was obtained in $34 \%$ total yield; m.p. $186-188^{\circ} \mathrm{C}$; TLC (chloroform/methanol 9.8/0.2); $\mathrm{R}_{f}=0.50 ;{ }^{1} \mathrm{H}-\mathrm{NMR}$ $\left(200 \mathrm{MHz}, \mathrm{DMSO}-d_{6}\right) \delta: 11.08(2 \mathrm{H}, \mathrm{s}, 2 \mathrm{NH}), 8.46-8.43(3 \mathrm{H}$, $\left.\mathrm{m}, \mathrm{H}-3^{\prime \prime}, 4^{\prime \prime}, 5^{\prime \prime}\right), 7.93\left(4 \mathrm{H}, \mathrm{d}, J=8.6,2 \mathrm{H}-2^{\prime}, 6^{\prime}\right), 7.88(2 \mathrm{H}, \mathrm{s}, 2 \mathrm{H}-4)$, $7.69(2 \mathrm{H}, \mathrm{s} 2 \mathrm{H}-7), 7.45\left(4 \mathrm{H}, \mathrm{d}, J=8.6,2 \mathrm{H}-3^{\prime}, 5^{\prime}\right), 5.98(4 \mathrm{H}, \mathrm{s}$, $\left.2 \mathrm{CH}_{2}\right), 2.44\left(12 \mathrm{H}, \mathrm{s}, 4 \mathrm{CH}_{3}\right) .{ }^{13} \mathrm{C}-\mathrm{NMR}$ (DMSO- $\left.d_{6}\right) \delta: 162.0$ (2CO), $148.6(2 \mathrm{C}), 145.7$ (2C), 144.9 (2C), 140.9 (2C), 138.9 (2C), $132.0(2 \mathrm{C}), 131.6(2 \mathrm{C}), 128.6(2 \mathrm{CH}), 123.6(4 \mathrm{CH}), 121.9$ $(4 \mathrm{CH}), 121.2(1 \mathrm{CH}), 120.9(2 \mathrm{CH}), 120.6(2 \mathrm{CH}), 50.9\left(2 \mathrm{CH}_{2}\right)$. $\mathrm{C}_{37} \mathrm{H}_{33} \mathrm{~N}_{9} \mathrm{O}_{2}$; MW 635.72; Elem. Anal.: Calcd C 69.90, H 5.23, N 19.83 Found C 69.98, H 5.36, N 19.83. LC/MS: $m / z 636[\mathrm{M}+\mathrm{H}]^{+}$. 


\section{6-((4-)((5,6-Dimethyl-1H-Benzo[d] $[1,2,3]$} Triazol-1-yl)methyl)phenyl)carbamoyl) Picolinic Acid (11f)

Compound 11 was obtained in $27 \%$ total yield; m.p. $214-216{ }^{\circ} \mathrm{C}$; TLC (chloroform/methanol 8.5/1.5); $\quad \mathrm{R}_{f}=0.23 ;{ }^{1} \mathrm{H}-\mathrm{NMR}$ $\left(200 \mathrm{MHz}, \mathrm{DMSO}-d_{6}\right) \delta: 11.41(1 \mathrm{H}, \mathrm{s}, \mathrm{NH}), 8.22-8.01(3 \mathrm{H}, \mathrm{m}$, $\left.\mathrm{H}-3^{\prime \prime}, 4^{\prime \prime}, 5^{\prime \prime}\right), 7.87\left(2 \mathrm{H}, \mathrm{d}, J=8.6, \mathrm{H}-2^{\prime}, 6^{\prime}\right), 7.79$ (1H, s, H-4), 7.62 (1H, s H-7), $7.32\left(2 \mathrm{H}, \mathrm{d}, J=8.6, \mathrm{H}-3^{\prime}, 5^{\prime}\right), 5.87\left(2 \mathrm{H}, \mathrm{s}, \mathrm{CH}_{2}\right), 2.34$ $\left(6 \mathrm{H}, \mathrm{s}, 2 \mathrm{CH}_{3}\right) .{ }^{13} \mathrm{C}-\mathrm{NMR}\left(\mathrm{DMSO}-d_{6}\right) \delta: 164.7(\mathrm{CO}), 161.6(\mathrm{CO})$, $150.0(2 \mathrm{C}), 148.2(\mathrm{C}), 144.3(\mathrm{C}), 140.1(\mathrm{CH}), 138.0(\mathrm{C}), 132.0(\mathrm{C})$, $131.2(\mathrm{C}), 130.8(\mathrm{C}), 128.6(\mathrm{CH}), 128.5(\mathrm{CH}), 127.0(\mathrm{CH}), 125.8$ $(\mathrm{CH}), 121.3(\mathrm{CH}), 120.9(\mathrm{CH}), 120.6(\mathrm{CH}), 112.5(\mathrm{CH}), 50.8$ $\left(\mathrm{CH}_{2}\right) . \mathrm{C}_{22} \mathrm{H}_{19} \mathrm{~N}_{5} \mathrm{O}_{3}$; MW 401.42; Elem. Anal.: Calcd C 65.83, $\mathrm{H}$ 4.77, N 17.45 Found C 66.10, H 4.80, N 17.55. LC/MS: $m / z 402$ $[\mathrm{M}+\mathrm{H}]^{+}$.

\section{$N^{2}, N^{5}$-Bis(4-((5,6-Dimethyl-1H-Benzo[d] $[1,2,3]$ Triazol-1-yl)methyl)phenyl) Thiophene-2,5-Dicarboxamide (8g)}

Compound $8 \mathrm{~g}$ was obtained in $10 \%$ total yield; m.p. $225-227^{\circ} \mathrm{C}$; TLC (chloroform/methanol 9.8/0.2); $\mathrm{R}_{f}=0.47 ;{ }^{1} \mathrm{H}-\mathrm{NMR}$ $\left(200 \mathrm{MHz}, \mathrm{DMSO}-d_{6}\right) \delta: 10.52(2 \mathrm{H}, \mathrm{s}, 2 \mathrm{NH}), 8.02(2 \mathrm{H}, \mathrm{s}, \mathrm{H}-$ $\left.3^{\prime \prime}, 4^{\prime \prime}\right), 7.79(2 \mathrm{H}, \mathrm{s}, 2 \mathrm{H}-4), 7.49\left(4 \mathrm{H}, \mathrm{d}, J=7.8,2 \mathrm{H}-2^{\prime}, 6^{\prime}\right), 7.61(2 \mathrm{H}$, s, $2 \mathrm{H}-7), 7.31\left(4 \mathrm{H}, \mathrm{d}, J=7.8,2 \mathrm{H}-3^{\prime}, 5^{\prime}\right), 5.87\left(4 \mathrm{H}, \mathrm{s}, 2 \mathrm{CH}_{2}\right), 2.35$ $\left(12 \mathrm{H}, \mathrm{s}, 4 \mathrm{CH}_{3}\right) .{ }^{13} \mathrm{C}-\mathrm{NMR}$ (DMSO- $\left.d_{6}\right) \delta: 161.5$ (2CO), 145.7 (2C), 144.6 (2C), 143.8 (2C), 137.9 (2C), 137.3 (2C), 136.3 (2C), $133.9(2 \mathrm{CH}), 131.7(2 \mathrm{C}), 131.5(2 \mathrm{C}), 128.5(2 \mathrm{CH}), 128.4(2 \mathrm{CH})$, $120.7(2 \mathrm{CH}), 120.6(2 \mathrm{CH}), 119.3(2 \mathrm{CH}), 118.1(2 \mathrm{CH}), 109.7$ $(2 \mathrm{CH}), 52.6\left(2 \mathrm{CH}_{2}\right), 20.4\left(2 \mathrm{CH}_{3}\right), 20.3\left(2 \mathrm{CH}_{3}\right) . \mathrm{C}_{36} \mathrm{H}_{32} \mathrm{~N}_{8} \mathrm{O}_{2} \mathrm{~S}$; MW 640.76; Elem. Anal.: Calcd C 67.48, H 5.03, N 17.49 Found C 69.98, H 5.40, N 20.13. LC/MS: $m / z 641[\mathrm{M}+\mathrm{H}]^{+}$.

\section{5-((4-((5,6-Dimethyl-1H-Benzo[d][1,2,3] Triazol-1-yl)methyl)phenyl)carbamoyl) thiophene-2-carboxylic Acid (11g)}

Compound $11 \mathrm{~g}$ was obtained in $40 \%$ total yield; m.p. $>300{ }^{\circ} \mathrm{C}$; TLC (chloroform/methanol 8.5/1.5); $\mathrm{R}_{f}=0.21 ;{ }^{1} \mathrm{H}-\mathrm{NMR}$ $\left(200 \mathrm{MHz}, \mathrm{DMSO}-d_{6}\right) \delta: 10.22(1 \mathrm{H}, \mathrm{s}, \mathrm{NH}), 7.79(2 \mathrm{H}, \mathrm{d}$, $\left.J=3.8, \mathrm{H}-3^{\prime \prime}, 4^{\prime \prime}\right), 7.79(1 \mathrm{H}, \mathrm{s}, \mathrm{H}-4), 7.68(2 \mathrm{H}, \mathrm{d}, J=8.0, \mathrm{H}-$ $\left.2^{\prime}, 6^{\prime}\right), 7.60(1 \mathrm{H}, \mathrm{s} \mathrm{H}-7), 7.29\left(2 \mathrm{H}, \mathrm{d}, J=8.0, \mathrm{H}-3^{\prime}, 5^{\prime}\right), 5.86(2 \mathrm{H}, \mathrm{s}$, $\left.\mathrm{CH}_{2}\right), 2.34\left(6 \mathrm{H}, \mathrm{s}, 2 \mathrm{CH}_{3}\right) .{ }^{13} \mathrm{C}-\mathrm{NMR}$ (DMSO- $\left.d_{6}\right) \delta: 165.2(\mathrm{CO})$, 160.2 (CO), 144.6 (C), 138.5 (C), 137.4 (2C), 133.5 (2C), 131.6 (C), $131.1(\mathrm{C}), 128.1(2 \mathrm{CH}), 120.5(2 \mathrm{CH}), 118.1(2 \mathrm{CH}), 109.7$ (2CH), $50.4\left(\mathrm{CH}_{2}\right), 20.4\left(\mathrm{CH}_{3}\right), 19.8\left(\mathrm{CH}_{3}\right) \cdot \mathrm{C}_{21} \mathrm{H}_{18} \mathrm{~N}_{4} \mathrm{O} 3 \mathrm{~S} ; \mathrm{MW}$ 406.46; Elem. Anal.: Calcd C 62.05, H 4.46, N 13.78 Found 62.04, $\mathrm{H}$ 4.46, N 14.05. LC/MS: $m / z 407[\mathrm{M}+\mathrm{H}]^{+}$.

\section{$N^{1}, N^{4}$-Bis(4-((5,6-Dichloro-1H-Benzo[d] $[1,2,3]$ Triazol-1-yl)methyl)phenyl) Succinamide (9a)}

Compound 9a was obtained in $10 \%$ total yield; m.p. $>300^{\circ} \mathrm{C}$; TLC (chloroform/methanol 9.5/0.5); $\mathrm{R}_{f}=0.70 ;{ }^{1} \mathrm{H}-\mathrm{NMR}(400 \mathrm{MHz}$,
DMSO- $\left.d_{6}\right) \delta: 10.03(2 \mathrm{H}, \mathrm{s}, \mathrm{NH}), 8.48(2 \mathrm{H}, \mathrm{s}, \mathrm{H}-4), 8.36(2 \mathrm{H}, \mathrm{s}$, $\mathrm{H}-7), 7.55\left(4 \mathrm{H}, \mathrm{d}, J=8.4, \mathrm{H}-3^{\prime}, 5^{\prime}\right), 7.31\left(4 \mathrm{H}, \mathrm{d}, J=8.4, \mathrm{H}-2^{\prime}, 6^{\prime}\right), 5.90$ $\left(4 \mathrm{H}, \mathrm{s}, \mathrm{CH}_{2}-\mathrm{N}\right), 2.51\left(4 \mathrm{H}, \mathrm{s}, \mathrm{CH}_{2}-\mathrm{CH}_{2}\right) .{ }^{13} \mathrm{C}-\mathrm{NMR}$ (DMSO- $\left.d_{6}\right) \delta$ : 170.4 (2CO), 144.3 (2C), 139.2 (2C), 131.9 (2C), 130.7 (2C), 129.6 (2C), $128.5(4 \mathrm{CH}), 127.2(2 \mathrm{C}), 120.6(2 \mathrm{CH}), 119.1(2 \mathrm{CH}), 112.5$ $(4 \mathrm{CH}), 51.4\left(2 \mathrm{CH}_{2}-\mathrm{N}\right), 29.0\left(2 \mathrm{CH}_{2}\right) . \mathrm{C}_{30} \mathrm{H}_{22} \mathrm{Cl}_{4} \mathrm{~N}_{8} \mathrm{O}_{2} ; \mathrm{MW} \mathrm{668.36;}$ Elem. Anal.: Calcd C 53.91, H 3.32, N 16.77 Found C 53.65, H 3.46, N 16.80 LC/MS: $m / z 669[\mathrm{M}+\mathrm{H}]^{+}, 671[\mathrm{M}+\mathrm{H}]^{+}, 667[\mathrm{M}+\mathrm{H}]^{+}$.

\section{4-((4-((5,6-Dichloro-1H-Benzo[d][1,2,3] Triazol-1-yl)methyl)phenyl) amino)-4-Oxobutanoic Acid (12a)}

Compound 12a was obtained in $18 \%$ total yield; m.p. $214-216^{\circ} \mathrm{C}$; TLC (chloroform/methanol 9.5/0.5); $\mathrm{R}_{f}=0.38 ;{ }^{1} \mathrm{H}-\mathrm{NMR}$ $\left(400 \mathrm{MHz}, \mathrm{DMSO}-d_{6}\right) \delta: 10.29(1 \mathrm{H}, \mathrm{s}, \mathrm{NH}), 8.48(1 \mathrm{H}, \mathrm{s}, \mathrm{H}-4)$, $8.37(1 \mathrm{H}, \mathrm{s}, \mathrm{H}-7), 7.55\left(2 \mathrm{H}, \mathrm{d}, J=8.0, \mathrm{H}-3^{\prime}, 5^{\prime}\right), 7.31(2 \mathrm{H}, \mathrm{d}, J=8.0$, $\left.\mathrm{H}-2^{\prime}, 6^{\prime}\right), 5.90\left(2 \mathrm{H}, \mathrm{s}, \mathrm{CH}_{2}-\mathrm{N}\right), 2.51\left(4 \mathrm{H}, \mathrm{s}, \mathrm{CH}_{2} \mathrm{CH}_{2}\right){ }^{13} \mathrm{C}-\mathrm{NMR}$ $\left(\right.$ DMSO- $\left.d_{6}\right) \delta: 176.9(\mathrm{COOH}), 171.6(\mathrm{CONH}), 144.2(\mathrm{C}), 139.5$ (C), $131.8(\mathrm{C}), 130.7$ (C), $129.3(\mathrm{C}), 128.5(2 \mathrm{CH}), 127.2(\mathrm{C}), 120.5$ $(\mathrm{CH}), 119.1(2 \mathrm{CH}), 112.5(\mathrm{CH}), 50.9\left(\mathrm{CH}_{2}-\mathrm{N}\right), 33.0\left(\mathrm{CH}_{2}\right), 32.0$ $\left(\mathrm{CH}_{2}\right) . \mathrm{C}_{17} \mathrm{H}_{14} \mathrm{Cl}_{2} \mathrm{~N}_{4} \mathrm{O}_{3}$; MW 393.22; Elem. Anal.: Calcd C 51.93, H 3.59, N 14.25 Found C 51.73, H 3.60, N 14.25 LC/MS: $m / z 417$ $[\mathrm{M}+\mathrm{Na}]^{+}, 415[\mathrm{M}+\mathrm{Na}]^{+}, 393[\mathrm{M}+\mathrm{H}]^{+}$.

\section{$N^{1}, N^{5}$-Bis(4-((5,6-Dichloro-1H-Benzo[d] $[1,2,3]$ Triazol-1-yl)methyl)phenyl) Glutaramide (9b)}

Compound $9 \mathbf{b}$ was obtained in $10 \%$ total yield; m.p. $204-206^{\circ} \mathrm{C}$; TLC (chloroform/methanol 9.5/0.5); $\mathrm{R}_{f}=0.70 ;{ }^{1} \mathrm{H}-\mathrm{NMR}$ $\left(400 \mathrm{MHz}, \mathrm{DMSO}-d_{6}\right) \delta: 9.94(2 \mathrm{H}, \mathrm{s}, \mathrm{NH}), 8.48(2 \mathrm{H}, \mathrm{s}, \mathrm{H}-4)$, $8.37(2 \mathrm{H}, \mathrm{s}, \mathrm{H}-7), 7.56\left(4 \mathrm{H}, \mathrm{d}, J=8.0, \mathrm{H}-3^{\prime}, 5^{\prime}\right), 7.31(4 \mathrm{H}, \mathrm{d}, J=8.0$, $\left.\mathrm{H}-2^{\prime}, 6^{\prime}\right), 5.90\left(4 \mathrm{H}, \mathrm{s}, \mathrm{CH}_{2}-\mathrm{N}\right), 2.33\left(4 \mathrm{H}, \mathrm{t}, \mathrm{CH}_{2} \mathrm{CO}\right), 1.87-1.85$ $\left(2 \mathrm{H}, \mathrm{m},-\mathrm{CH}_{2}-\right) .{ }^{13} \mathrm{C}-\mathrm{NMR}$ (DMSO- $\left.d_{6}\right) \delta: 170.8(2 \mathrm{CO}), 144.3$ (2C), $139.2(2 \mathrm{C}), 131.9(2 \mathrm{C}), 130.7(2 \mathrm{C}), 129.7(2 \mathrm{C}), 128.5(4 \mathrm{CH})$, 127.2 (2C), $120.6(2 \mathrm{CH}), 119.3(4 \mathrm{CH}), 112.5(2 \mathrm{CH}), 50.9\left(2 \mathrm{CH}_{2}-\right.$ $\mathrm{N}), 35.4\left(2 \mathrm{CH}_{2}\right), 20.8\left(\mathrm{CH}_{2}\right) . \mathrm{C}_{31} \mathrm{H}_{24} \mathrm{Cl}_{4} \mathrm{~N}_{8} \mathrm{O}_{2}$; MW 682.39; Elem. Anal.: Calcd C 54.56, H 3.54, N 16.42 Found C 54.46, H 3.60, N 16.26. LC/MS: $m / z 685[\mathrm{M}+\mathrm{H}]^{+}, 681[\mathrm{M}+\mathrm{H}]^{+}$.

\section{5-((4-((5,6-Dichloro-1H-Benzo[d] [1,2,3] Triazol-1-yl)methyl)phenyl) amino)-5-Oxopentanoic Acid (12b)}

Compound $12 \mathbf{b}$ was obtained in $15 \%$ total yield; m.p. $173-175^{\circ} \mathrm{C}$; TLC (chloroform/methanol 9.5/0.05); $\mathrm{R}_{f}=0.35 ;{ }^{1} \mathrm{H}-\mathrm{NMR}$ $\left(400 \mathrm{MHz}, \mathrm{DMSO}-d_{6}\right) \delta: 10.31(1 \mathrm{H}, \mathrm{s}, \mathrm{NH}), 8.47(1 \mathrm{H}, \mathrm{s}, \mathrm{H}-4)$, $8.36(1 \mathrm{H}, \mathrm{s}, \mathrm{H}-7), 7.57\left(2 \mathrm{H}, \mathrm{d}, J=8.0, \mathrm{H}-3^{\prime}, 5^{\prime}\right), 7.30(2 \mathrm{H}, \mathrm{d}, J=8.0$, $\left.\mathrm{H}-2^{\prime}, 6^{\prime}\right), 5.89\left(2 \mathrm{H}, \mathrm{s}, \mathrm{CH}_{2}-\mathrm{N}\right), 2.29\left(2 \mathrm{H}, \mathrm{t}, \mathrm{CH}_{2}-\mathrm{CO}-\mathrm{N}\right), 2.05-2.01$ $\left(2 \mathrm{H}, \mathrm{m}, \mathrm{CH}_{2}-\mathrm{COOH}\right), 1.74\left(2 \mathrm{H}, \mathrm{t},-\mathrm{CH}_{2}-\right) .{ }^{13} \mathrm{C}-\mathrm{NMR}$ (DMSO- $\left.d_{6}\right)$ $\delta: 171.4$ (2CO), 144.3 (C), 139.4 (C), 131.9 (C), 130.7 (C), 129.5 (C), $128.5(2 \mathrm{CH}), 127.2(\mathrm{C}), 120.5(\mathrm{CH}), 119.2(2 \mathrm{CH}), 112.5$ $(\mathrm{CH}), 50.9\left(\mathrm{CH}_{2}-\mathrm{N}\right), 36.0\left(\mathrm{CH}_{2}\right), 35.5\left(\mathrm{CH}_{2}\right), 21.5\left(\mathrm{CH}_{2}\right)$. $\mathrm{C}_{18} \mathrm{H}_{16} \mathrm{Cl}_{2} \mathrm{~N}_{4} \mathrm{O}_{3}$; MW 407.25; Elem. Anal.: Calcd C 53.09, $\mathrm{H}$ 3.96, N 13.76 Found C 52.86, H 4.16, N 14.14. LC/MS: $m / z$ $447[\mathrm{M}+\mathrm{K}]^{+}, 445[\mathrm{M}+\mathrm{K}]^{+}$. 
$N^{1}, N^{6}$-bis(4-((5,6-Dichloro-1H-Benzo[d]

$[1,2,3]$ Triazol-1-yl)methyl)phenyl)

\section{Adipamide (9c)}

Compound 9c was obtained in $15 \%$ total yield; m.p. $>300^{\circ} \mathrm{C}$; TLC (chloroform/methanol 9.5/0.5); $\mathrm{R}_{f}=0.63 ;{ }^{1} \mathrm{H}-\mathrm{NMR}(400 \mathrm{MHz}$, DMSO- $\left.d_{6}\right) \delta: 9.92(2 \mathrm{H}, \mathrm{s}, \mathrm{NH}), 8.48(2 \mathrm{H}, \mathrm{s}, \mathrm{H}-4), 8.36(2 \mathrm{H}, \mathrm{s}, \mathrm{H}-$ 7), $7.55\left(4 \mathrm{H}, \mathrm{d}, J=8.0, \mathrm{H}-3^{\prime}, 5^{\prime}\right), 7.31\left(4 \mathrm{H}, \mathrm{d}, J=8.0, \mathrm{H}-2^{\prime}, 6^{\prime}\right), 5.90$ $\left(4 \mathrm{H}, \mathrm{s}, \mathrm{CH}_{2}-\mathrm{N}\right), 2.29\left(4 \mathrm{H}, \mathrm{s}, 2 \mathrm{CH}_{2} \mathrm{CO}\right), 1.58\left(4 \mathrm{H}, \mathrm{s}, \mathrm{CH}_{2}-\mathrm{CH}_{2}\right)$. ${ }^{13} \mathrm{C}-\mathrm{NMR}$ (DMSO- $d_{6}$ ) $\delta: 171.1$ (2C), 144.3 (2C), 139.3 (2C), 131.9 (2C), 130.7 (2C), $129.6(2 \mathrm{C}), 128.5(4 \mathrm{CH}), 127.2(2 \mathrm{C}), 120.6$ $(2 \mathrm{CH}), 119.2(4 \mathrm{CH}), 112.5(2 \mathrm{CH}), 50.9\left(2 \mathrm{CH}_{2}-\mathrm{N}\right), 36.2\left(2 \mathrm{CH}_{2}\right)$, $24.7\left(2 \mathrm{CH}_{2}\right) . \mathrm{C}_{32} \mathrm{H}_{26} \mathrm{Cl}_{4} \mathrm{~N}_{8} \mathrm{O}_{2} ; \mathrm{MW}$ 696.41; Elem. Anal.: Calcd C 55.19, H 3.76, N 16.09 Found C 55.10, H 3.80, N 15.89. LC/MS: $m$ / $z 697[\mathrm{M}+\mathrm{H}]^{+}, 695[\mathrm{M}+\mathrm{H}]^{+}$.

\section{6-((4-)((5,6-Dichloro-1H-Benzo[d][1,2,3] \\ Triazol-1-yl)methyl)phenyl) amino)-6-Oxohexanoic Acid (12c)}

Compound $12 \mathrm{c}$ was obtained in $13 \%$ total yield; m.p. $228-230^{\circ} \mathrm{C}$; TLC (chloroform/methanol 9.5/0.5); $\mathrm{R}_{f}=0.38 ;{ }^{1} \mathrm{H}-\mathrm{NMR}$ $\left(400 \mathrm{MHz}, \mathrm{DMSO}-d_{6}\right) \delta: 10.05(1 \mathrm{H}, \mathrm{s}, \mathrm{NH}), 8.48(1 \mathrm{H}, \mathrm{s}, \mathrm{H}-4)$, $8.37(1 \mathrm{H}, \mathrm{s}, \mathrm{H}-7), 7.57\left(2 \mathrm{H}, \mathrm{d}, J=8.0, \mathrm{H}-3^{\prime}, 5^{\prime}\right), 7.31(2 \mathrm{H}, \mathrm{d}, J=8.0$, $\left.\mathrm{H}-2^{\prime}, 6^{\prime}\right), 5.90\left(2 \mathrm{H}, \mathrm{s}, \mathrm{CH}_{2}-\mathrm{N}\right), 2.27\left(2 \mathrm{H}, \mathrm{t}, \mathrm{CH}_{2}-\mathrm{CO}\right), 2.12(2 \mathrm{H}, \mathrm{t}$, $\mathrm{CH}_{2}-\mathrm{CO}$ ), $1.58-1.49$ (4H, m, $\mathrm{CH}_{2}-\mathrm{CH}_{2}$ ). ${ }^{13} \mathrm{C}-\mathrm{NMR}$ (DMSO- $d_{6}$ ) $\delta$ : 171.3 (2CO), 144.3 (C), 139.3 (C), 131.9 (C), 130.7 (C), 129.6 (C), $128.5(2 \mathrm{CH}), 127.2(\mathrm{C}), 120.6(\mathrm{CH}), 119.2(2 \mathrm{CH}), 112.5$ $(\mathrm{CH}), 50.9\left(\mathrm{CH}_{2}-\mathrm{N}\right), 36.1\left(2 \mathrm{CH}_{2}\right), 24.9\left(\mathrm{CH}_{2}\right), 24.6\left(\mathrm{CH}_{2}\right)$. $\mathrm{C}_{19} \mathrm{H}_{18} \mathrm{Cl}_{2} \mathrm{~N}_{4} \mathrm{O}_{3}$; MW 421.28; Elem. Anal.: Calcd C 54.17, $\mathrm{H}$ 4.31, N 13.30 Found C 53.85, H 4.30, N 13.62. LC/MS: $m / z$ $445[\mathrm{M}+\mathrm{Na}]^{+}, 443[\mathrm{M}+\mathrm{Na}]^{+}$.

\section{$N^{1}, N^{4}$-Bis(4-((5,6-Dichloro-1H-Benzo[d] $[1,2,3]$ Triazol-1-yl)methyl)phenyl) Fumaramide (9d)}

Compound 9d was obtained in $10 \%$ total yield; m.p. $>300^{\circ} \mathrm{C}$; TLC (chloroform/methanol 9.5/0.5); $\mathrm{R}_{f}=0.85 ;{ }^{1} \mathrm{H}-\mathrm{NMR}(400 \mathrm{MHz}$, DMSO- $\left.d_{6}\right) \delta: 10.32(2 \mathrm{H}, \mathrm{s}, \mathrm{NH}), 8.48(2 \mathrm{H}, \mathrm{s}, \mathrm{H}-4), 8.38(2 \mathrm{H}, \mathrm{s}, \mathrm{H}-$ 7), $7.66\left(4 \mathrm{H}, \mathrm{d}, J=8.0, \mathrm{H}-3^{\prime}, 5^{\prime}\right), 7.33\left(4 \mathrm{H}, \mathrm{d}, J=8.0, \mathrm{H}-2^{\prime}, 6^{\prime}\right), 6.66$ $(2 \mathrm{H}, \mathrm{s}, \mathrm{CH}=\mathrm{CH}), 5.92\left(4 \mathrm{H}, \mathrm{s}, \mathrm{CH}_{2}\right) .{ }^{13} \mathrm{C}-\mathrm{NMR}\left(\mathrm{DMSO}-d_{6}\right) \delta$ : 164.4 (2CO), 144.3 (2C), 139.4 (2C), 131.9 (2C), 130.7 (2C), 129.9 (2C), $128.9(6 \mathrm{CH}), 127.2(2 \mathrm{C}), 120.8(2 \mathrm{CH}), 119.5(4 \mathrm{CH}), 112.7$ (2CH), $50.9\left(2 \mathrm{CH}_{2}\right) \cdot \mathrm{C}_{30} \mathrm{H}_{20} \mathrm{Cl}_{4} \mathrm{~N}_{8} \mathrm{O}_{2}$; MW 666.34; Elem. Anal.: Calcd C 54.07, H 3.03, N 16.82 Found C 54.36, H 3.33, N 16.90. LC/MS: $m / z 687[\mathrm{M}+\mathrm{Na}]^{+}, 667[\mathrm{M}+\mathrm{H}]^{+}, 665[\mathrm{M}+\mathrm{H}]^{+}$.

\section{(E)-4-((4-((5,6-Dichloro-1H-Benzo[d] $[1,2,3]$} Triazol-1-yl)methyl)phenyl) mmino)-4-Oxobut-2-Enoic Acid (12d)

Compound 12d was obtained in $10 \%$ total yield; m.p. $272-273^{\circ} \mathrm{C}$; TLC (chloroform/methanol 9.5/0.5) $\quad \mathrm{R}_{f}=0.29 ;{ }^{1} \mathrm{H}-\mathrm{NMR}$ $\left(400 \mathrm{MHz}, \mathrm{DMSO}-d_{6}\right) \delta: 10.32(1 \mathrm{H}, \mathrm{s}, \mathrm{NH}), 8.48(1 \mathrm{H}, \mathrm{s}, \mathrm{H}-4)$, $8.38(1 \mathrm{H}, \mathrm{s}, \mathrm{H}-7), 7.66\left(2 \mathrm{H}, \mathrm{d}, J=8.4 \mathrm{~Hz}, \mathrm{H}-3^{\prime}, 5^{\prime}\right), 7.33(2 \mathrm{H}, \mathrm{d}, J=$ $\left.8.4 \mathrm{~Hz}, \mathrm{H}-2^{\prime}, 6^{\prime}\right), 6.66(2 \mathrm{H}, \mathrm{s}, \mathrm{CH}=\mathrm{CH}), 5.92\left(2 \mathrm{H}, \mathrm{s}, \mathrm{CH}_{2}\right)$.
${ }^{13} \mathrm{C}-\mathrm{NMR}$ (DMSO- $\left.d_{6}\right) \quad \delta: 164.5(\mathrm{CONH}), 163.9(\mathrm{COOH})$, 145.2(C), $136.4 \quad(\mathrm{HNCO}-\underline{\mathrm{CH}}=), \quad 134.6 \quad(\mathrm{C}), \quad 134.2$ (=ㄷH-COOH), $133.5(2 \mathrm{C}), 132.8(\mathrm{C}), 131.8(\mathrm{C}), 130.3(2 \mathrm{CH})$, $126.9(2 \mathrm{CH}), 121.5(2 \mathrm{CH}), 52.2\left(\mathrm{CH}_{2}\right) . \mathrm{C}_{17} \mathrm{H}_{12} \mathrm{Cl}_{2} \mathrm{~N}_{4} \mathrm{O}_{3} ; \mathrm{MW}$ 391.21; Elem. Anal.: Calcd C 52.19, H 3.09, N 14.32 Found C 51.99, H 3.29, N 14.55. LC/MS: $m / z 429[\mathrm{M}+\mathrm{K}]^{+}, 393[\mathrm{M}+\mathrm{H}]^{+}$.

\section{$N^{1}, N^{4}-B s(4-((5,6-D i c h l o r o-1 H-B e n z o[d]$ [1,2,3]Triazol-1-yl)methyl)phenyl) \\ Terephthalamide (9e)}

Compound 9e was obtained in $19 \%$ total yield; m.p. $>300^{\circ} \mathrm{C}$; TLC (chloroform/methanol 9/1); $\quad \mathrm{R}_{f}=0.54 ;{ }^{1} \mathrm{H}-\mathrm{NMR}$ $\left(400 \mathrm{MHz}, \mathrm{DMSO}-d_{6}\right) \delta: 10.43(2 \mathrm{H}, \mathrm{s}, \mathrm{NH}), 8.48(2 \mathrm{H}, \mathrm{s}$, $2 \mathrm{H}-4), 8.39$ (2H, s, $2 \mathrm{H}-7), 8.05$ (6H, s, H-3 $\left.3^{\prime}, 5^{\prime}, 2^{\prime \prime}, 3^{\prime \prime}, 5^{\prime \prime}, 6^{\prime \prime}\right)$, $7.78\left(2 \mathrm{H}, \mathrm{s}, \mathrm{H}-3^{\prime}, 5^{\prime}\right), 7.39\left(4 \mathrm{H}, \mathrm{s}, 2 \mathrm{H}-2^{\prime}, 2 \mathrm{H}-6^{\prime}\right), 5.95(4 \mathrm{H}, \mathrm{s}$, $2 \mathrm{CH}_{2}$ ). ${ }^{13} \mathrm{C}-\mathrm{NMR}$ (DMSO- $\left.d_{6}\right) \delta: 166.7$ (2CO), $164.9(2 \mathrm{C})$, 144.3 (2C), 138.9 (2C), 138.4 (2C), 131.9 (2C), 130.7 (2C), $130.7(2 \mathrm{C}), 129.4(2 \mathrm{CH}), 129.2(4 \mathrm{CH}), 127.9(4 \mathrm{CH}), 127.2$ (2C), $120.6(4 \mathrm{CH}), 112.5(2 \mathrm{CH}), 50.9\left(2 \mathrm{CH}_{2}\right) . \mathrm{C}_{34} \mathrm{H}_{22} \mathrm{Cl}_{4} \mathrm{~N}_{8} \mathrm{O}_{2}$; MW 716.40; Elem. Anal.: Calcd C 57.00, H 3.10, N 15.64 Found C 57.24, H 3.36, N 15.32. LC/MS: $m / z 717[\mathrm{M}+\mathrm{K}]^{+}, 715[\mathrm{M}$ $+\mathrm{H}]^{+}$.

\section{$N^{2}, N^{6}$-Bis(4-((5,6-Dichloro-1H-Benzo[d] $[1,2,3]$ Triazol-1-yl)methyl)phenyl) Pyridine-2,6-Dicarboxamide (9f)}

Compound 9 f was obtained in $13 \%$ total yield; m.p. $>300^{\circ} \mathrm{C}$; TLC (chloroform/methanol 9/1); $\mathrm{R}_{f}=0.84 ;{ }^{1} \mathrm{H}-\mathrm{NMR}(400 \mathrm{MHz}$, DMSO- $\left.d_{6}\right) \delta: 10.91(2 \mathrm{H}, \mathrm{s}, \mathrm{NH}), 8.50(2 \mathrm{H}, \mathrm{s}, 2 \mathrm{H}-4), 8.43(2 \mathrm{H}$, s, $2 \mathrm{H}-7), 8.40-8.36\left(1 \mathrm{H}, \mathrm{m}, \mathrm{H}-4^{\prime \prime}\right), 8.32-8.25\left(2 \mathrm{H}, \mathrm{m}, \mathrm{H}-3^{\prime \prime}, 5^{\prime \prime}\right)$, $7.82\left(4 \mathrm{H}, \mathrm{d}, J=8.4,2 \mathrm{H}-3^{\prime}, 5^{\prime}\right), 7.45\left(4 \mathrm{H}, \mathrm{d}, J=8.4,2 \mathrm{H}-2^{\prime}, 6^{\prime}\right), 5.99$ $\left(4 \mathrm{H}, \mathrm{s}, 2 \mathrm{CH}_{2}\right) .{ }^{13} \mathrm{C}-\mathrm{NMR}$ (DMSO- $\left.d_{6}\right) \delta: 162.0(2 \mathrm{CO}), 148.6(2 \mathrm{C})$, 144.7 (2C), 143.4 (2C), 139.9 (2C), 138.9 (2C), 132.0 (2C), 131.6 $(2 \mathrm{C}), 128.6(2 \mathrm{CH}), 123.6(4 \mathrm{CH}), 121.9(4 \mathrm{CH}), 121.2(1 \mathrm{CH}), 120.9$ (2CH), $120.6(2 \mathrm{CH}), 50.9\left(2 \mathrm{CH}_{2}\right) . \mathrm{C}_{33} \mathrm{H}_{21} \mathrm{Cl}_{4} \mathrm{~N}_{9} \mathrm{O}_{2}$; MW 717.39; Elem. Anal.: Calcd C 55.25, H 2.95, N 17.57 Found C 55.00, H 3.10, N 17.78. LC/MS: $m / z 756[\mathrm{M}+\mathrm{K}]^{+}, 718[\mathrm{M}+\mathrm{H}]^{+}$.

\section{6-((4-)((5,6-Dichloro-1H-Benzo[d][1,2,3]}

\section{Triazol-1-yl)methyl)phenyl)carbamoyl)}

\section{Picolinic Acid (12f)}

Compound 12f was obtained in $40 \%$ total yield; m.p. $175-177^{\circ} \mathrm{C}$; TLC (chloroform/methanol 9/1); $\mathrm{R}_{f}=0.16$; ${ }^{1} \mathrm{H}-\mathrm{NMR}\left(400 \mathrm{MHz}, \mathrm{DMSO}-d_{6}\right) \delta: 11.06(1 \mathrm{H}, \mathrm{s}, \mathrm{OH}), 10.96$ $(1 \mathrm{H}, \mathrm{s}, \mathrm{NH}), 8.52(1 \mathrm{H}, \mathrm{s}, \mathrm{H}-4), 8.45-8.41(3 \mathrm{H}, \mathrm{t}, J=8.4, \mathrm{H}-7, \mathrm{H}-$ $\left.3^{\prime}, 5^{\prime}\right), 8.36-8.31\left(1 \mathrm{H}, \mathrm{m}, \mathrm{H}-4^{\prime \prime}\right), 7.94\left(1 \mathrm{H}, \mathrm{d}, J=8.4, \mathrm{H}-3^{\prime \prime}\right), 7.85$ $\left(1 \mathrm{H}, \mathrm{d}, J=8.4, \mathrm{H}-5^{\prime \prime}\right), 7.50\left(2 \mathrm{H}, \mathrm{d}, J=8.4, \mathrm{H}-2^{\prime}, 6^{\prime}\right), 6.03(2 \mathrm{H}, \mathrm{s}$, $\left.\mathrm{CH}_{2}\right) .{ }^{13} \mathrm{C}-\mathrm{NMR}$ (DMSO- $d_{6}$ ) $\delta: 164.7$ (CO), 161.6 (CO), 149.0 (2C), $146.2(\mathrm{C}), 144.3(\mathrm{C}), 140.1(\mathrm{CH}), 138.0(\mathrm{C}), 132.0(\mathrm{C})$, $131.2(\mathrm{C}), 130.8(\mathrm{C}), 128.6(\mathrm{CH}), 128.5(\mathrm{CH}), 127.0(\mathrm{CH})$, $125.8(\mathrm{CH}), 121.3(\mathrm{CH}), 120.9(\mathrm{CH}), 120.6(\mathrm{CH}), 112.5(\mathrm{CH})$, $50.8\left(\mathrm{CH}_{2}\right) . \mathrm{C}_{20} \mathrm{H}_{13} \mathrm{Cl}_{2} \mathrm{~N}_{5} \mathrm{O}_{3}$; MW 442.25; Elem. Anal.: Calcd C 54.32, H 2.96, N 15.84 Found C 54.32, H 3.06, N 15.74. LC/MS: $m / z 443[\mathrm{M}+\mathrm{H}]^{+}, 441[\mathrm{M}+\mathrm{H}]^{+}$. 


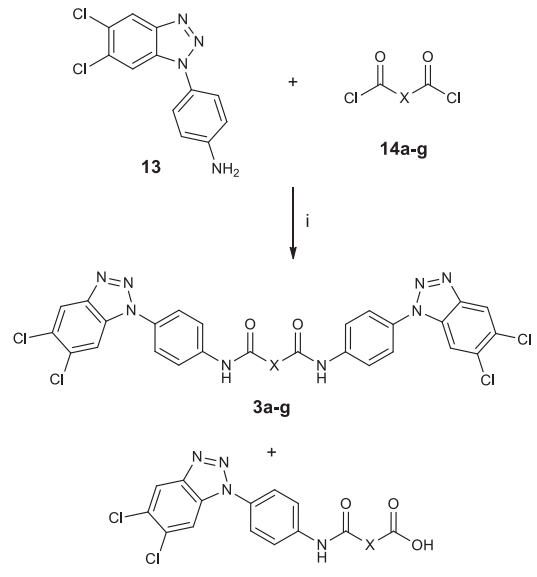

$4 a-d, f$<smiles>Nc1ccc(-n2nc3cc(Cl)c(Cl)cc3n2)cc1</smiles>

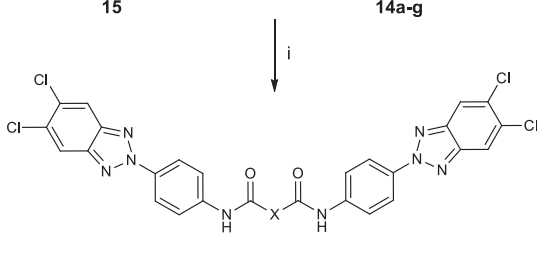<smiles>O=[Y](Nc1ccc(-n2nc3cc(Cl)c(Cl)cc3n2)cc1)C(=O)O</smiles>

$6 f$

X a $\left(\mathrm{CH}_{2}\right)_{2} \quad$ b $\quad\left(\mathrm{CH}_{2}\right)_{3} \quad$ c $\quad\left(\mathrm{CH}_{2}\right)_{4}$ d $\quad \mathrm{CH}=\mathrm{CH}$

e 4 尔

SCHEME 1 | Synthesis of $N, N^{\prime}$-bis [4-(1H(2H)-benzo [d] [1,2,3]triazol-1(2)yl)phenyl] alkyl(aryl) dicarboxamides (3a-g; 5e-g) and 4-((4-(5,6-dichloro-1H(2H)-benzo[d] $[1,2,3]$ triazol-1(2)-yl)phenyl)amino)-4-oxoalkyl(aryl)oic acids (4a-d,f; 6f). 1) DMF, TEA, r.t., 3-72 h.

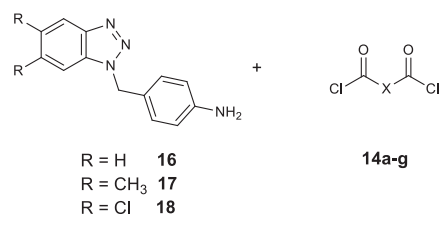

X a $\left(\mathrm{CH}_{2}\right)_{2} \quad$ b $\left(\mathrm{CH}_{2}\right)_{3} \quad$ c $\left(\mathrm{CH}_{2}\right)_{4}$ d $\mathrm{CH}=\mathrm{CH}$

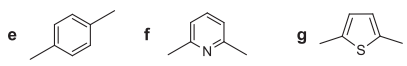

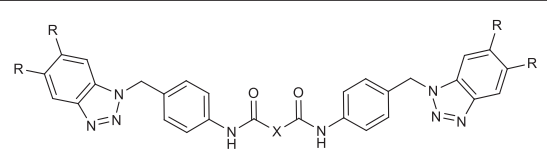

$\mathrm{R}=\mathrm{CH}_{3}=8 \quad 8 \mathrm{a}-\mathrm{g}$

$\mathrm{R}=\mathrm{Cl}=9$ 9a-g

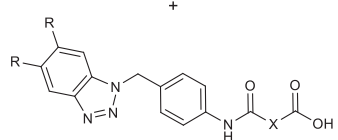

$\mathrm{R}=\mathrm{H} \quad=10 \quad 10 \mathrm{a}-\mathrm{g}$

$\begin{array}{lll}\mathrm{R}=\mathrm{CH}_{3}=11 & 11 \mathrm{a}-\mathrm{g} \\ \mathrm{R}=\mathrm{Cl} & =12 & 12 \mathrm{a}-\mathrm{d}\end{array}$

SCHEME 2 | Synthesis of $N, N^{\prime}$-bis[4-((5,6-R-1H-benzo[d][1,2,3]triazol-1-yl)methyl)phenyl]alkyl(aryl) dicarboxamides (7a-g; 8a-g; 9a-g) and 4-((4-((5,6-R1H-benzo [d][1,2,3]triazol-1-yl)methyl)phenyl)amino)-4-oxoalkyl (aryl)oic acids (10a-g, 11a-g; 12a-d,f). 1) DMF, TEA, r.t., 3-72 h.

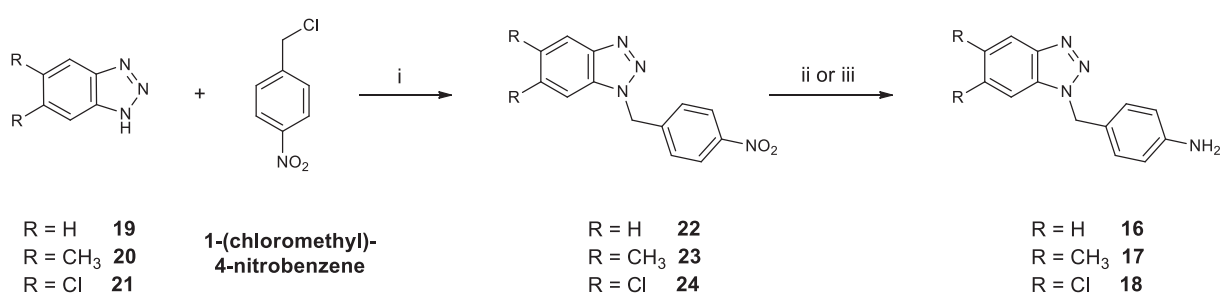

SCHEME 3 | Synthesis of 4-((5,6-R-1H-benzo [d][1,2,3]triazol-1-yl)methyl)aniline (16-18). 1) $\mathrm{Cs}_{2} \mathrm{CO}_{3}, \mathrm{DMF}^{\circ}, 60^{\circ} \mathrm{C}$ for $\left.48 \mathrm{~h} ; 2\right) \mathrm{NH} \mathrm{NH}_{2}(1: 20), \mathrm{Pd} \mathrm{C}(10 \% \mathrm{w} / \mathrm{W})$, $\mathrm{EtOH}, 80^{\circ} \mathrm{C}$ for $2 \mathrm{~h}$ (to afford compounds $\mathbf{1 6}$ and 17); 3) $\mathrm{CH}_{3} \mathrm{NHNH}_{2}$ (1:10), EtOH, $100^{\circ} \mathrm{C}$ for $48 \mathrm{~h}$ in autoclave (to afford compound 18). 
<smiles>[Y]C(=O)Nc1ccc(-n2nnc3cc(Cl)c(Cl)cc32)cc1</smiles>

$3 a-9$<smiles>O=C(Nc1ccc(-n2nc3cc(Cl)c(Cl)cc3n2)cc1)Nc1ccc(-n2nc3cc(Cl)c(Cl)cc3n2)cc1</smiles>

$5 e-g$<smiles>[R]c1cc2nnn(Cc3ccc(NC(=O)Nc4ccc(Cn5nnc6cc([R])c([R])cc65)cc4)cc3)c2cc1[R]</smiles>

$\mathrm{R}=\mathrm{H} \quad=7 \quad 7 \mathrm{a}-\mathrm{g}$

$\mathrm{R}=\mathrm{CH}_{3}=8 \quad 8 \mathrm{a}-\mathrm{g}$

$\mathrm{R}=\mathrm{Cl}=9$ 9a-g<smiles>O=C(O)C(=O)Nc1ccc(-n2nnc3cc(Cl)c(Cl)cc32)cc1</smiles>

4a-d,f<smiles>O=C(O)[X]C(=O)Nc1ccc(-n2nc3cc(Cl)c(Cl)cc3n2)cc1</smiles>

$6 f$<smiles>[R]c1cc2nnn(Cc3ccc(NC(=O)[Y](=O)O)cc3)c2cc1[R]</smiles>

$\mathrm{R}=\mathrm{H} \quad=10 \quad 10 \mathrm{a}-\mathrm{g}$

$\mathrm{R}=\mathrm{CH}_{3}=11 \quad 11 \mathrm{a}-\mathrm{g}$

$\mathrm{R}=\mathrm{Cl}=12 \quad 12 \mathrm{a}-\mathrm{d}, \mathrm{f}$

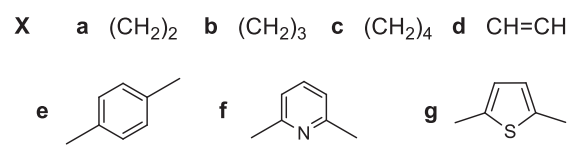

FIGURE 3 | Synthesized derivatives, $N, N^{\prime}$-bis [4-1H(2H)-benzo[d][1,2,3]triazol-1 (2)-yl)phenyl] alkyl (aryl)dicarboxamides (series $\mathbf{3}$ and $\mathbf{5}$ ) and $N, N^{\prime}$-bis [4-1H-benzo [d][1,2,3]triazol-1-yl) (methyl)phenyl]alkyl (aryl)dicarboxamides (series 7-9). 4- (4-(5,6-dichloro-1H-benzo[d][1,2,3]triazol-1 (2)-yl)phenyl)amino)-4-oxoalkyl (aryl)oic acids (series 4 and 6), 4- (4-((5,6-R-1H-benzo[d][1,2,3]triazol-1-yl)methyl)phenyl)amino)-4-oxoalkyl (aryl)oic acids (series 10-12).

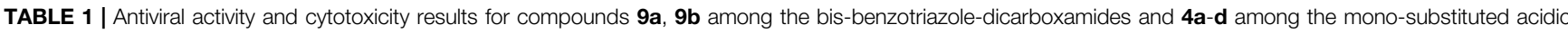
derivatives.

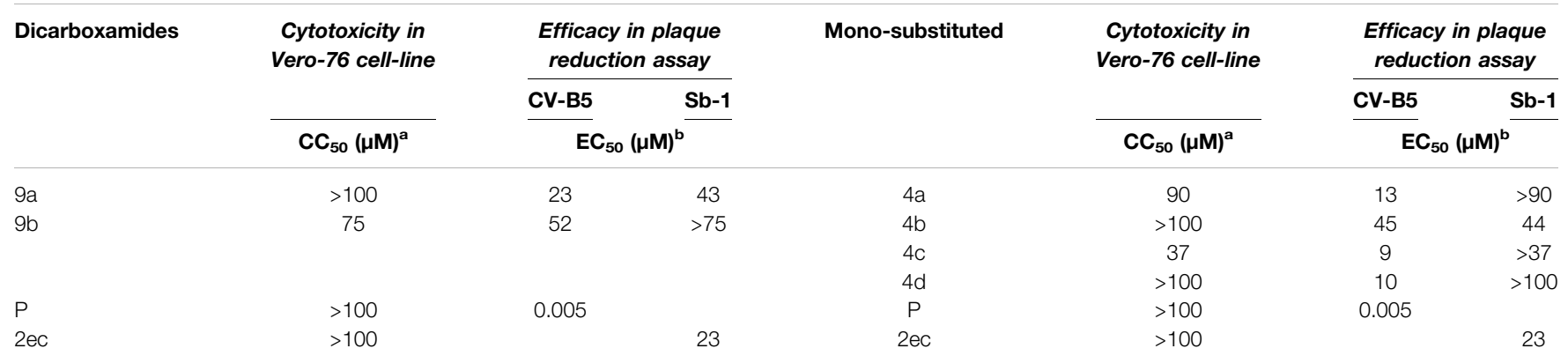

Pleconaril (P) and 2'-C-ethynyl-cytidine (2ec) were used as control. Data represent mean values for three independent determinations. Variation among duplicate samples was less than $15 \%$.

${ }^{a}$ Compound concentration $(\mu M)$ required to reduce the viability of mock-infected Vero-76 cells by 50\%, as determined by the MTT method.

${ }^{b}$ Compound concentration $(\mu M)$ required to reduce the plaque number of CV-B5 or Sb-1 by $50 \%$ in Vero-76 monolayers. 
TABLE 2 | Anti-proliferative activity for compounds $\mathbf{3 b}, \mathbf{3 d}, \mathbf{4 d}$, and $\mathbf{9 b}$ against human leukemia-lymphoma-derived cell lines and solid tumor-derived cell-lines.

\begin{tabular}{|c|c|c|c|c|c|c|c|c|}
\hline \multirow[t]{2}{*}{ Compounds } & \multicolumn{8}{|c|}{$\mathrm{CC}_{50}(\mu \mathrm{M})^{\mathrm{a}}$} \\
\hline & CCRF-CEM ${ }^{\mathrm{b}}$ & $W I L-2 N S^{c}$ & $C C R F-S B^{d}$ & $S K-M E L 28^{e}$ & $S K-M E S 1^{f}$ & $D U 145^{g}$ & $H e L a^{h}$ & $C R L 7065^{\mathrm{i}}$ \\
\hline $3 b$ & $0.5 \pm 0.1$ & $>100$ & $0.35 \pm 0.07$ & $6.2 \pm 1.3$ & $6.8 \pm 3.5$ & $5.1 \pm 0$ & $7.1 \pm 2.7$ & $0.75 \pm 0.05$ \\
\hline $3 d$ & $0.07 \pm 0.02$ & $>100$ & $7.9 \pm 0.9$ & $>100$ & $>100$ & $>100$ & $>100$ & $0.37 \pm 0.04$ \\
\hline $4 d$ & $3.3 \pm 1.7$ & $64 \pm 10$ & $0.51 \pm 0.13$ & $>100$ & $>100$ & $>100$ & $>100$ & $1.7 \pm 0.1$ \\
\hline $9 b$ & $5.5 \pm 1.8$ & $23 \pm 7$ & $8.5 \pm 3.2$ & $2.6 \pm 0.7$ & $9.9 \pm 3.1$ & $5.2 \pm 0.4$ & $5.4 \pm 0.7$ & $6.7 \pm 2.4$ \\
\hline Vincristine & $0.003 \pm 0.001$ & $0.006 \pm 0.002$ & $0.003 \pm 0.001$ & $>4$ & $0.01 \pm 0.02$ & $0.02 \pm 0.01$ & $0.05 \pm 0.02$ & $>4$ \\
\hline Doxorubicin & $0.02 \pm 0.01$ & $0.06 \pm 0.01$ & $0.03 \pm 0.02$ & $1.1 \pm 0.2$ & $0.65 \pm 0.05$ & $0.3 \pm 0.1$ & $1.8 \pm 0.2$ & $2.0 \pm 0.2$ \\
\hline
\end{tabular}

Control is represented by CRL 7065 cell line. Vincristine and Doxorubicin were used as positive controls.

${ }^{a}$ Compound concentration required to reduce cell proliferation by $50 \%$, as determined by the MTT method, under conditions allowing untreated controls to undergo at least three consecutive rounds of multiplication. Data represent mean values $( \pm S D)$ for three independent determinations.

${ }^{b} \mathrm{CD} 4^{+}$human acute T-lymphoblastic leukemia.

${ }^{c}$ Human splenic B-lymphoblastoid cells.

dHuman acute B-lymphoblastic.

eHuman skin melanoma.

tHuman lung squamous carcinoma.

${ }^{g}$ Human prostate carcinoma.

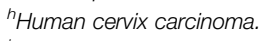

iHuman foreskin fibroblasts.

\section{$N^{2}, N^{5}$-Bis(4-((5,6-Dichloro-1H-Benzo[d] $[1,2,3]$ Triazol-1-yl)methyl)phenyl) Thiophene-2,5-Dicarboxamide (9g)}

Compound $9 \mathrm{~g}$ was obtained in $11 \%$ total yield; m.p. $>300^{\circ} \mathrm{C}$; TLC (chloroform/methanol 9/1); $\mathrm{R}_{f}=0.82 ;{ }^{1} \mathrm{H}-\mathrm{NMR}(400 \mathrm{MHz}$, DMSO- $\left.d_{6}\right) \delta: 10.43(2 \mathrm{H}, \mathrm{s}, \mathrm{NH}), 8.49(2 \mathrm{H}, \mathrm{s}, 2 \mathrm{H}-4), 8.40(2 \mathrm{H}, \mathrm{s}$, $2 \mathrm{H}-7), 8.01\left(2 \mathrm{H}, \mathrm{s}, \mathrm{H}-3^{\prime \prime}, 4^{\prime \prime}\right), 7.71\left(4 \mathrm{H}, \mathrm{d}, J=8.4,2 \mathrm{H}-3^{\prime}, 5^{\prime}\right), 7.39$ $\left(4 \mathrm{H}, \mathrm{d}, J=8.4,2 \mathrm{H}-2^{\prime}, 6^{\prime}\right), 5.96\left(4 \mathrm{H}, \mathrm{s}, 2 \mathrm{CH}_{2}\right) .{ }^{13} \mathrm{C}-\mathrm{NMR}$ (DMSO$\left.d_{6}\right) \delta: 159.3$ (2CO), $144.3(2 \mathrm{C}), 143.9(2 \mathrm{C}), 138.4(2 \mathrm{C}), 134.1$ (2C), 132.0 (2C), 130.9 (2C), $130.8(2 \mathrm{CH}), 129.4(4 \mathrm{CH}), 128.5$ $(2 \mathrm{CH}), 127.2(2 \mathrm{C}), 120.7(4 \mathrm{CH}), 112.5(2 \mathrm{CH}), 50.8\left(2 \mathrm{CH}_{2}\right)$. $\mathrm{C}_{32} \mathrm{H}_{20} \mathrm{Cl}_{4} \mathrm{~N}_{8} \mathrm{O}_{2} \mathrm{~S}$; MW 722.43; Elem. Anal.: Calcd C 53.20, $\mathrm{H}$ 2.79, N 15.51 Found C 52.88, H 3.00, N 15.67. LC/MS: $m / z 761$ $[\mathrm{M}+\mathrm{K}]^{+}, 721[\mathrm{M}+\mathrm{H}]^{+}$.

\section{RESULTS AND DISCUSSION}

\section{Chemistry}

Synthetic pathways constructed to obtain the desired products are illustrated in Scheme 1 and Scheme 2, while Scheme 3 shows the synthetic route used to synthesize the benzylintermediates. 4- (5,6-dichloro-1(2)H-benzo [d][1,2,3]triazol-1yl)aniline intermediates (13 and 15) were synthesized according to the previously described procedure (Carta et al., 2007). Diacyldichloride (14a-g) and 1-(chloromethyl)-4-nitrobenzene reagents were commercially purchased (Sigma-Aldrich). All the designed bis-benzotriazole-dicarboxamide derivatives were prepared by condensation of the corresponding benzotriazoleanilines (13,15 and 16-18) with the suitable diacyl dichloride (14a-g) in $N, N$-dimethylformamide (DMF) in the presence of triethylamine (TEA). These synthetic routes afforded the desired compounds bis-benzotriazole-dicarboxamides (3a-g, 5e-g, 7a-g, 8a-g, 9a-g) and the corresponding mono-substituted acidic derivatives (4a-d,f, 6f, 10a-g, 11a-g, 12a-d,f) as secondary products, that also were separated, purified and biologically evaluated. The bis-benzotriazole-dicarboxamides and the mono-substituted acidic derivatives were generally obtained in variable ratios. Intermediates $\mathbf{1 6 - 1 8}$ were obtained as depicted in Scheme 3, by a first substitution of the properly substituted benzotriazole (19-21) with 1-(chloromethyl)-4-nitrobenzene in basic conditions for triethylamine (TEA). The two isomers were separated from the 5,6-(R)-1 (2)-(4-nitrobenzyl)-1H (2H)-benzo $[d][1,2,3]$ triazole mixture and the 5,6-(R)-1-(4-nitrobenzyl)$1 H$-benzo $[d][1,2,3]$ triazoles $(\mathbf{2 2 - 2 4 )}$ were subjected to reduction by two different synthetic pathways. Intermediates 16 and 17 were obtained by reduction of 22 and 23 respectively, with hydrazine and Palladium on carbon in ethanol, while compound $\mathbf{1 8}$ was gained by reduction of $\mathbf{2 4}$ solved in ethanol with methylhydrazine in the autoclave for $48 \mathrm{~h}$.

\section{Antiviral activity}

All the 56 synthesized compounds, depicted in Figure 3, were tested in a plaque-reduction assay for antiviral activity and in a cell-based assay for cytotoxicity. Viruses selected for the assay were Coxsackievirus B5 (CV-B5), a well-known human pathogen and the Poliovirus strain Sb-1, both belonging to the family of Picornaviridae. Compounds cytotoxicity was evaluated against three cell lines (Vero-76, MDBK, BHK-21). Table 1 shows the antiviral activity results and the corresponding cytotoxicity against the cell-line that supports viral replication, Vero-76. Results for the only active compounds are reported: derivatives 9a, 9b among the bis-benzotriazole-dicarboxamides and $\mathbf{4 a - d}$ among the mono-substituted acidic derivatives. The remaining derivatives results are not reported in the table since they turned out not considerably active $\left(\mathrm{EC}_{50}\right.$ values exceeded $\left.100 \mu \mathrm{M}\right) .9 \mathrm{a}$ is the sole compound amidst the designed ones which turned out quite active against both the tested Picornaviruses $\left(\mathrm{EC}_{50}\right.$ values of 23 and $43 \mu \mathrm{M}$, respectively). Surprisingly, the mono-substituted derivatives obtained as secondary products were found more active than the corresponding dicarboxamides. Compound $\mathbf{4 c}$ was the most active against CV-B5, along with $\mathbf{4 a}$ and $\mathbf{4 d}$ with $\mathrm{EC}_{50}$ values ranging from 9 to $13 \mu \mathrm{M}$. The latter two are also 

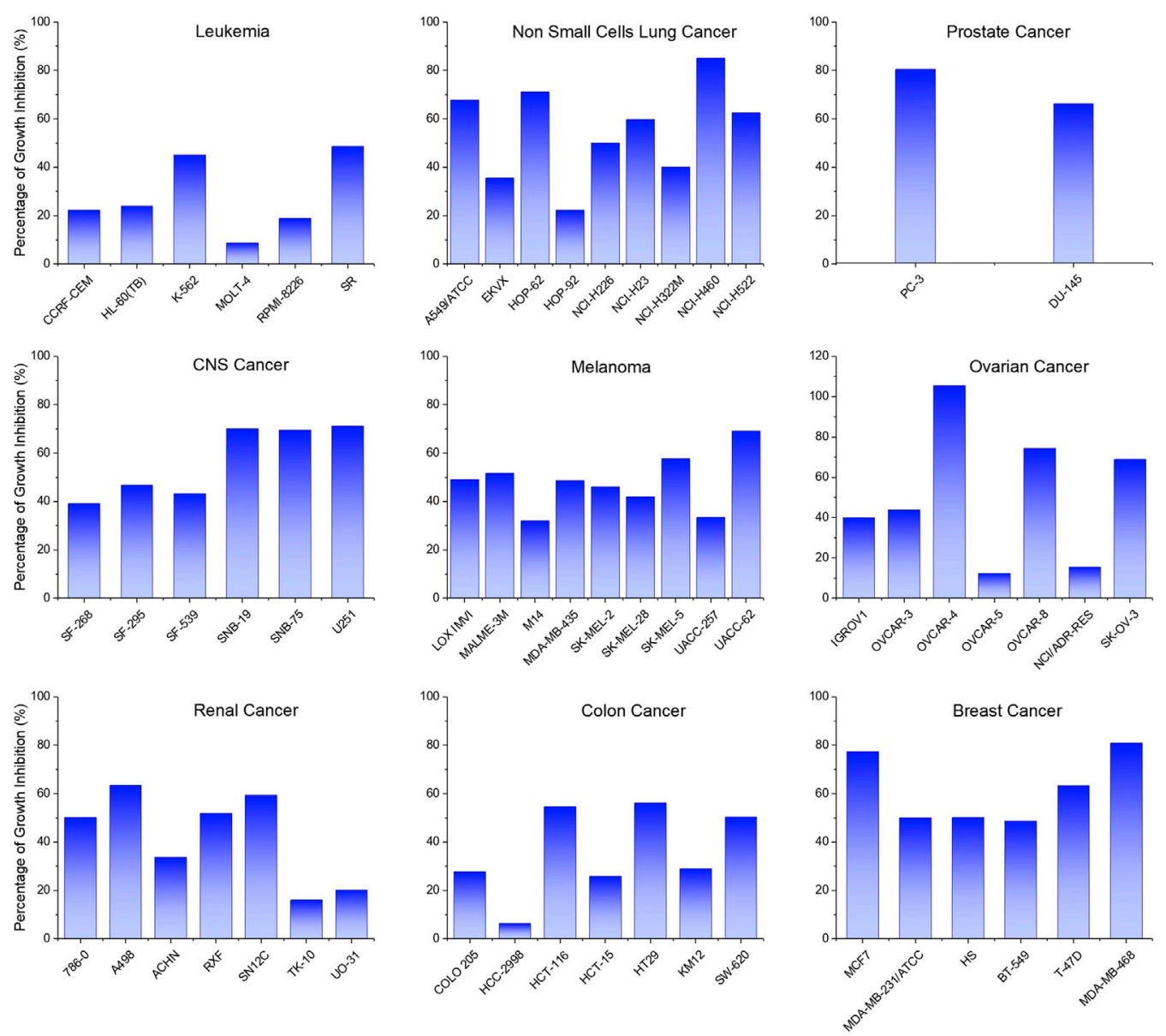

FIGURE 4 | Antiproliferative screening assay: Percentage of Growth Inhibition (\%) recorded on a panel of sixty cell lines treated with compound $\mathbf{3 b}$ at $10 \mu \mathrm{M}$ concentration.

endowed with poor or no cytotoxicity against Vero-76 cell line ( $\mathrm{CC}_{50} 90 \mu \mathrm{M}$ and $>100 \mu \mathrm{M}$ respectively).

\section{Antitumor activity}

All synthesized compounds was also tested for antitumor activity against 7 cancer cell lines. For this purpose, human leukemialymphoma-derived cell lines CCRF-CEM, WIL-2NS, CCRF-SB and solid tumor-derived cell lines SK-MEL28, SK-MES 1, DU145, HeLa were selected. Fibroblast CRL 7065 cell line was used as control. Table 2 shows the results of the most promising compounds, derivatives $\mathbf{3 b}, \mathbf{3 d}$ among bis-benzotriazoledicarboxamides and $\mathbf{4 d}, \mathbf{9 b}$ among mono-substituted acidic derivatives. In general terms, compound $\mathbf{3} \mathbf{b}$ showed the widest range of activity reducing cell proliferation of six out of seven cell lines with $\mathrm{CC}_{50}$ ranging in the low micromolar values. Derivative 3d had the lowest $\mathrm{CC}_{50}$ value against CCRF-CEM cell line $(70 \mathrm{nM})$, while resulted inactive against most of the other tested cell lines. Among the mono-substituted acidic derivatives, 4d was proved active when tested on human leukemia-lymphoma-derived cell lines while completely inactive against solid tumors proving an interesting selectivity of action. Compound $\mathbf{9 b}$ is the one that turned out active against all the tested cancer cell lines, proving a wide range of action, showing, however, very low $\mathrm{CC}_{50}$ values. Dicarboxamides turned out slightly more cytotoxic when tested on CRL 7065 control cell line than the tested mono-substituted derivatives. To determine the cytotoxic selectivity of tested compounds, the selectivity index (SI) was calculated as a ratio of $\mathrm{CC}_{50}$ of non-tumor cells and $\mathrm{CC}_{50}$ of tumor cells. Since the non-specific mechanism of action of designed compounds SI values turned out very low, except for compound 3d. The latter possessed $\mathrm{CC}_{50}$ values of $70 \mathrm{nM}$ against tumor CCRF-CEM cell line and $370 \mathrm{nM}$ against non-tumor CRL 7065 cell line, with a resulting SI of 5.3.

The above-mentioned four promising compounds (3b, 3d, 4d, and 9b) were then subjected to the NCI60 Human Tumor Cell Lines Screen (full tables of results in Supplementary Material). This screening was performed by the National Cancer Institute (NCI, Bethesda, United States), and evaluated our compounds in the anticancer assay at $10 \mu \mathrm{M}$ concentration against a panel of 60 human tumor cell lines. The panel comprises a series of different cancer lines comprising hematological (leukemia) tumors and solid ones (non-small cell lung - NSCL, colon, central nervous system - CNS, renal, ovarian, breast and prostate cancers and melanoma). Among the tested 

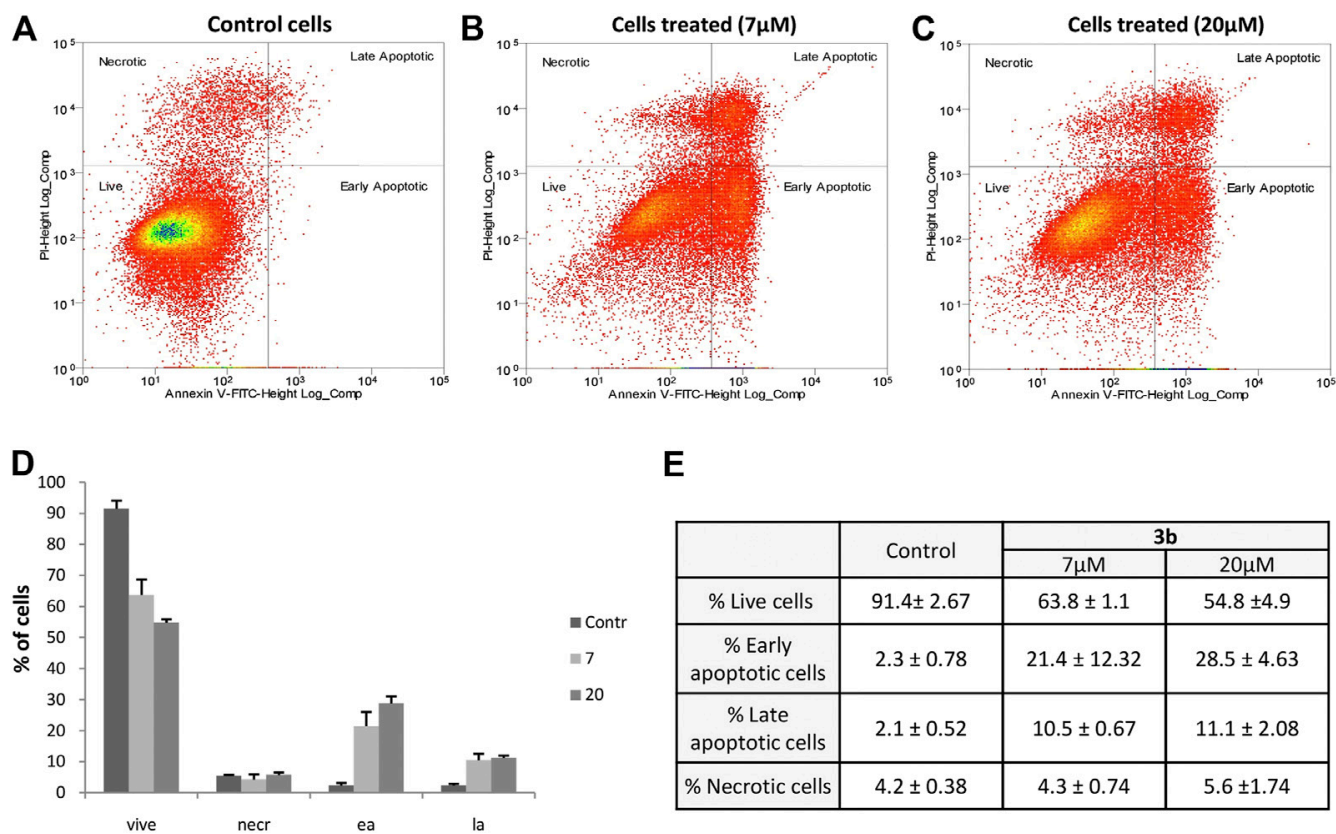

$\mathbf{E}$

\begin{tabular}{l|c|c|c|c|}
\hline & \multirow{2}{*}{ Control } & \multicolumn{2}{|c|}{ 3b } \\
\cline { 3 - 5 }$=$ Contr & $7 \mu \mathrm{M}$ & $20 \mu \mathrm{M}$ \\
\cline { 2 - 5 }$=20$ & \% Live cells & $91.4 \pm 2.67$ & $63.8 \pm 1.1$ & $54.8 \pm 4.9$ \\
\cline { 2 - 5 } & $\begin{array}{c}\text { \% Early } \\
\text { apoptotic cells }\end{array}$ & $2.3 \pm 0.78$ & $21.4 \pm 12.32$ & $28.5 \pm 4.63$ \\
\cline { 2 - 5 } $\begin{array}{c}\text { \% Late } \\
\text { apoptotic cells }\end{array}$ & $2.1 \pm 0.52$ & $10.5 \pm 0.67$ & $11.1 \pm 2.08$ \\
\hline \% Necrotic cells & $4.2 \pm 0.38$ & $4.3 \pm 0.74$ & $5.6 \pm 1.74$ \\
\hline \multicolumn{2}{|c|}{} \\
\hline
\end{tabular}

FIGURE $5 \mid N^{1}, N^{5}$-Bis(4-(5,6-dichloro-1H-benzo [d][1,2,3]triazol-1-yl)phenyl)glutaramide (3b) induced apoptosis in human lung carcinoma SK-MES 1 cells. The percentage of live, apoptotic, and necrotic cells were measured by flow cytometry using the PI-annexin $\mathrm{V}$ assay. Dot plots show cell death in SK-MES1 cells: control (A), treated cells with $20 \mu \mathrm{M}(\mathbf{B})$, treated cells with $7 \mu \mathrm{M}$ (C). Percentage of live, apoptotic, and necrotic cells (D,E). Each value represents the mean \pm SD of independent experiments $(n=3)$

compounds, $\mathbf{3} \mathbf{b}$ turned out as the most active with the widest range of action. Results from the assays are reported as Percentage of Growth Inhibition (PGI) and are graphed in bar charts depicted in Figure 4. Cell lines are grouped per type of cancer. Our lead compound $\mathbf{3 b}$ showed PGI values higher than $50 \%$ for 29 of the 60 cell lines, proving a wide antiproliferative activity. Best scores were recorded for breast cancer since most of the PGI values ranged from 48 up to $81 \%$, and for prostate cancer ( 80 and $66 \%$ values of PGI against the two cell lines). Compound $\mathbf{3 b}$ can be considered as an interesting antiproliferative agent against ovarian (OVCAR-8, SK-OV-3), CNS (SF-295, SNB19, SNB75, U251) and NSCL (A549/ATCC, HOP-62, NCI-H226, NCI$\mathrm{H} 23$, NCI-H460, NCI-H522) cancers, while the growth of leukemia, melanoma, renal and colon cancer cells was less affected by the administration of derivative $\mathbf{3 b}$. The latter was also proved cytotoxic more than antiproliferative, against one ovarian cancer cell line (OVCAR-4) showing a PGI of $105.56 \%$.

\section{Apoptosis Assay}

Aiming to investigate the mechanism wherewith the cells die after lead compound administration, an apoptosis assay was performed. Data plots were produced by employing normalized fluorescent expression of Annexin $\mathrm{V}$ and PI (Figures 5A-C). Based on intensities distribution the percentage of living, early apoptotic, late apoptotic, and necrotic cells in untreated and treated conditions were analyzed. In the untreated cells (control) the majority
(91.4\%) of the cells were viable, the remaining cells died in the apoptotic and necrotic way (4.4 and $4.2 \%$, respectively) (Figure 5A). Compound 3b induced apoptosis after $96 \mathrm{~h}$ in a dose-dependent manner with $40 \%$ of apoptotic cells in $20 \mu \mathrm{m}$ treated and $32 \%$ in $7 \mu \mathrm{m}$ treated cells (Figures $\mathbf{5 B}, \mathbf{C}$, respectively). Particularly, Figures 5D,E clearly showed that most dead cells are characterized by early apoptotic features.

\section{CONCLUSION}

We have designed and synthesized 56 new compounds, 31 bis-benzotriazole dicarboxamides (3a-g, 5e-g, 7a-g, 8ag, 9a-g) and 25 corresponding mono-substituted acidic compounds (4a-d,f, 6f, 10a-g, 11a-g, 12a-d,f) as potential antiviral and/or antitumor agents, acting as false substrates. They were purified, characterized and tested for antiviral and antitumor activity in properly selected assays. Only a few of the synthesized compounds turned out as active against Coxsackievirus B5. Compounds 4a, 4c, and 4d showed $\mathrm{EC}_{50}$ values ranging from 9 to $13 \mu \mathrm{M}$ against $\mathrm{CV}$-B5, while derivative $9 \mathbf{a}$ is the sole compound among the bisbenzotriazole dicarboxamides that turned out quite active against both the tested Picornaviruses with $\mathrm{EC}_{50}$ values of 23 and $43 \mu \mathrm{M}$, against CV-B5 and Sb-1, respectively. From a selection of representatives that were subjected to an antitumor in vitro assay, four of them $(\mathbf{3 b}, \mathbf{3 d}, \mathbf{4 d}$ and $\mathbf{9 b})$ resulted as the most interesting for their $\mathrm{CC}_{50}$ values that 
mostly turned out to be in the micromolar range. The same derivatives were tested by the National Cancer Institute on a panel of 60 human tumor cell lines. All the newly synthesized compounds that showed antiviral or anticancer activity bear two chlorine atoms on the BT scaffold (series 3, 4 and 9). Concerning the linker, the medium-length $\left(-\left(\mathrm{CH}_{2}\right)_{3^{-}}\right)$and the unsaturated $(-\mathrm{CH}=\mathrm{CH}-)$ ones showed the best antitumor results (3b, 3d, $\mathbf{4 d}$, and $\mathbf{9 b}$ ), while the aromatic linkers entail a complete loss of activity. $1 \mathrm{H}$-BT moiety turned out to be the scaffold endowed with both biological activities (series 3, 4, and 9). For the wide range of activity and the potency proved by the two screening assays, compound $\mathbf{3 b}$ was selected as lead compound. When derivative $\mathbf{3 b}$ was evaluated in apoptosis assay, results showed that the compound induced cell death by apoptosis in human lung tumor SK-MES 1. These findings will grant further studies involving this promising antiproliferative candidate. The latter will be used as a starting point for the next generation of compounds that will be the result of a proper structure modification process in order to increase the antiproliferative activity and potency. Alongside, compound $\mathbf{4 c}$ will be used as a base to design new mono-substituted acidic compounds endowed with selective anti-Coxsackievirus activity.

\section{DATA AVAILABILITY STATEMENT}

The original contributions presented in the study are included in the article/Supplementary Material, further inquiries can be directed to the corresponding authors.

\section{AUTHOR CONTRIBUTIONS}

SP and AC conceived and designed the experiments. RI, SP, PC, and FR synthesized the compounds. RL, ID, GC, GS, PC

\section{REFERENCES}

Agudo, R, Arias, A., and Domingo, E. (2009). 5-fluorouracil in Lethal Mutagenesis of FootAnd-Mouth Disease Virus. Future Med. Chem. 1, 529-539. doi:10.4155/fmc.09.26

Al-Soud, Y. A., Al-Masoudi, N. A., and Ferwanah, A. E.-R. S. (2003). Synthesis and Properties of New Substituted 1,2,4-triazoles: Potential Antitumor Agents. Bioorg. Med. Chem. 11, 1701-1708. doi:10.1016/S0968-0896(03)00043-9

Bergman, A. M., Pinedo, H. M., and Peters, G. J. (2002). Determinants of Resistance to $2^{\prime}, 2^{\prime}$-difluorodeoxycytidine (Gemcitabine). Drug Resist. Updates 5, 19-33. doi:10.1016/S1368-7646(02)00002-X

Borowski, P., Deinert, J., Schalinski, S., Bretner, M., Ginalski, K., Kulikowski, T., et al. (2003). Halogenated Benzimidazoles and Benzotriazoles as Inhibitors of the NTPase/helicase Activities of Hepatitis C and Related Viruses. Eur. J. Biochem. 270, 1645-1653. doi:10.1046/j.1432-1033.2003.03540.x

Briguglio, I., Piras, S., Corona, P., Gavini, E., Nieddu, M., Boatto, G., et al. (2015). Benzotriazole: An Overview on its Versatile Biological Behavior. Eur. J. Med. Chem. 97, 612-648. doi:10.1016/j.ejmech.2014.09.089

Brüning, A., Burger, P., Gingelmaier, A., and Mylonas, I. (2012). The HIV Reverse Transcriptase Inhibitor Tenofovir Induces Cell Cycle Arrest in Human Cancer Cells. Invest. New Drugs 30, 1389-1395. doi:10.1007/s10637-011-9704-7

Carta, A., Loriga, M., Piras, S., Paglietti, G., Ferrone, M., Fermeglia, M., et al. (2007). Synthesis and Anti-picornaviridae In Vitro Activity of a New Class of and TC performed antiviral, antiproliferative and apoptosis experiments. All authors analyzed the data. SP and RI wrote the paper. All authors reviewed and approved the manuscript.

\section{FUNDING}

This research was supported by the "University of Sassari, Italy" with "Fondo di Ateneo per la ricerca 2020", grant number FAR2020PIRAS; and by "Regione Autonoma della Sardegna” (Sardinia, Italy), with "Legge Regionale 7 agosto 2007:CRP1_574, 22/41 del 2017”, grant number RASSR01499.

\section{ACKNOWLEDGMENTS}

The authors acknowledge the University of Sassari and "Regione Autonoma della Sardegna" for funding this work. They also acknowledge the National Cancer Institute (NCI), Developmental Therapeutics Program, NCI (Bethesda, MD, United States; https://dtp.cancer.gov) for the data from in vitro anti-cancer screening and Maria Orecchioni (Department of Chemistry and Pharmacy, University of Sassari, Italy) for NMR analysis. We acknowledge the CeSAR (Centro Servizi Ricerca d'Ateneo) core facility of the University of Cagliari and Rita Pillai for assistance with the generation of the flow cytometry data.

\section{SUPPLEMENTARY MATERIAL}

The Supplementary Material for this article can be found online at: https://www.frontiersin.org/articles/10.3389/fchem.2021.660424/ full\#supplementary-material

Helicase Inhibitors the N,N-bis[4-(1H(2H)-benzotriazol-1(2)-yl)phenyl] Alkyldicarboxamides. Mc 3, 520-532. doi:10.2174/157340607782360308

Carta, A., Palomba, M., Briguglio, I., Corona, P., Piras, S., Jabes, D., et al. (2011). Synthesis and Anti-mycobacterial Activities of Triazoloquinolones. Eur. J. Med. Chem. 46, 320-326. doi:10.1016/j. ejmech.2010.11.020

Cooper, P. D. (1964). The Mutation of Poliovirus by 5-fluorouracil. Virology 22, 186-192. doi:10.1016/0042-6822(64)90003-0

De Clercq, E. (2004). Antiviral Drugs in Current Clinical Use. J. Clin. Virol. 30, 115-133. doi:10.1016/j.jcv.2004.02.009

De Clercq, E. (2013). The Nucleoside Reverse Transcriptase Inhibitors, Nonnucleoside Reverse Transcriptase Inhibitors, and Protease Inhibitors in the Treatment of HIV Infections (AIDS). Adv. Pharmacol. 67, 317-358. doi:10. 1016/B978-0-12-405880-4.00009-3

Dragún, M., Rada, B., Novotný, L., and Beránek, J. (1990). Antiviral Activities of Pyrimidine Nucleoside Analogues: Some Structure-Aactivity Relationships. Acta Virol. 34, 321-329.

Furuta, Y., Komeno, T., and Nakamura, T. (2017). Favipiravir (T-705), a Broad Spectrum Inhibitor of Viral RNA Polymerase. Proc. Jpn. Acad. Ser. B: Phys. Biol. Sci. 93, 449-463. doi:10.2183/pjab.93.027

Ibba, R., Carta, A., Madeddu, S., Caria, P., Serreli, G., Piras, S., et al. (2021). Inhibition of Enterovirus A71 by a Novel 2-Phenyl-Benzimidazole Derivative. Viruses 13, 58. doi:10.3390/v13010058 
Ibba, R., Corona, P., Carta, A., Giunchedi, P., Loddo, R., Sanna, G., et al. (2018). Antiviral Activities of 5-chlorobenzotriazole Derivatives. Monatsh Chem. 149, 1247-1256. doi:10.1007/s00706-018-2234-7

Kaufman, H. E. (1980). Antimetabolite Drug Therapy in Herpes Simplex. Ophthalmology 87, 135-139. doi:10.1016/S0161-6420(80)35273-1

Kneller, D. W., Agniswamy, J., Ghosh, A. K., and Weber, I. T. (2019). Potent Antiviral HIV-1 Protease Inhibitor Combats Highly Drug Resistant Mutant PR20. Biochem. Biophysical Res. Commun. 519, 61-66. doi:10.1016/j.bbrc.2019.08.126

Matsuda, A., Fukushima, M., Wataya, Y., and Sasaki, T. (1999). A New Antitumor Nucleoside, 1- (3-C-Ethynyl- $\beta$-D-Ribo-Pentofuranosyl)-Cytosine (ECyd), Is a Potent Inhibitor of RNA Synthesis. Nucleosides and Nucleotides 18, 811-814. doi:10.1080/15257779908041568

Ochal, Z., Bretner, M., Wolinowska, R., and Tyski, S. (2013). Synthesis and In Vitro Antibacterial Activity of 5-Halogenomethylsulfonyl- Benzimidazole and Benzotriazole Derivatives. Mc 9, 1129-1136. doi:10.2174/1573406411309080015

Pariente, N., Airaksinen, A., and Domingo, E. (2003). Mutagenesis versus Inhibition in the Efficiency of Extinction of Foot-And-Mouth Disease Virus. Jvi 77, 7131-7138. doi:10.1128/jvi.77.12.7131-7138.2003

Patel, P. D., Patel, M. R., Kocsis, B., Kocsis, E., Graham, S. M., Warren, A. R., et al. (2010). Design, Synthesis and Determination of Antifungal Activity of 5(6)substituted Benzotriazoles. Eur. J. Med. Chem. 45, 2214-2222. doi:10.1016/j. ejmech.2010.01.062

Pauwels, R., Balzarini, J., Baba, M., Snoeck, R., Schols, D., Herdewijn, P., et al. (1988). Rapid and Automated Tetrazolium-Based Colorimetric Assay for the Detection of Anti-HIV Compounds. J. Virol. Methods 20, 309-321. doi:10. 1016/0166-0934(88)90134-6

Piras, S., Corona, P., Ibba, R., Riu, F., Murineddu, G., Sanna, G., et al. (2020a). Preliminary Anti-Coxsackie Activity of Novel 1-[4-(5,6-Dimethyl(H)$1 \mathrm{H}(2 \mathrm{H})$-Benzotriazol-1(2)-Yl)phenyl]-3-Alkyl(aryl)ureas. Mc 16, 677-688. doi:10.2174/1573406416666191226142744
Piras, S., Sanna, G., Carta, A., Corona, P., Ibba, R., Loddo, R., et al. (2019b) Dichloro-Phenyl-Benzotriazoles: A New Selective Class of Human Respiratory Syncytial Virus Entry Inhibitors. Front. Chem. 7, 247. doi:10.3389/fchem.2019. 00247

Ramachandran, R., Rani, M., Senthan, S., Jeong, Y. T., and Kabilan, S. (2011). Synthesis, Spectral, Crystal Structure and In Vitro Antimicrobial Evaluation of Imidazole/benzotriazole Substituted Piperidin-4-One Derivatives. Eur. J. Med. Chem. 46, 1926-1934. doi:10.1016/j.ejmech.2011.02.036

Sanna, G., Farci, P., Busonera, B., Murgia, G., La Colla, P., and Giliberti, G. (2015). Antiviral Properties from Plants of the Mediterranean Flora. Nat. Product. Res. 29, 2065-2070. doi:10.1080/14786419.2014.1003187

Sanna, G., Piras, S., Madeddu, S., Busonera, B., Klempa, B., Corona, P., et al. (2020). 5,6-Dichloro-2-Phenyl-Benzotriazoles: New Potent Inhibitors of Orthohantavirus. Viruses 12, 122. doi:10.3390/v12010122

Sanna, P., Carta, A., Paglietti, G., Zanetti, S., and Fadda, G. (1992). 1,2,3-triazolo [4,5-h]quinolines. III. Preparation and Antimicrobial Evaluation of 4-Ethyl-4,7Dihydro-1(2)-R-1(2)H Triazolo[4,5-H]quinolin-7-One-6-Carboxylic Acids as Antiinfectives of the Urinary Tract. Farmaco 47, 1001-1019.

Conflict of Interest: The authors declare that the research was conducted in the absence of any commercial or financial relationships that could be construed as a potential conflict of interest.

Copyright (c) 2021 Ibba, Piras, Corona, Riu, Loddo, Delogu, Collu, Sanna, Caria, Dettori and Carta. This is an open-access article distributed under the terms of the Creative Commons Attribution License (CC BY). The use, distribution or reproduction in other forums is permitted, provided the original author(s) and the copyright owner(s) are credited and that the original publication in this journal is cited, in accordance with accepted academic practice. No use, distribution or reproduction is permitted which does not comply with these terms. 